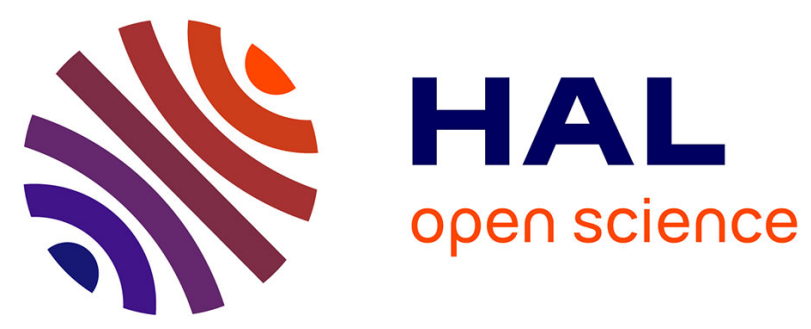

\title{
Une petite ville romaine de moyenne montagne, Javols/Anderitum (Lozère), chef-lieu de cité des Gabales : état des connaissances (1996-2007)
}

Alain Ferdière, Emmanuel Marot, Alain Trintignac, Michel Amandry, Caroline Bideau, Anne-Lise Cohen, Julien Courtois, Jane de Rose-Evans, Francesca Di Napoli, Mélanie Fondrillon, et al.

\section{To cite this version:}

Alain Ferdière, Emmanuel Marot, Alain Trintignac, Michel Amandry, Caroline Bideau, et al.. Une petite ville romaine de moyenne montagne, Javols/Anderitum (Lozère), chef-lieu de cité des Gabales: état des connaissances (1996-2007). Gallia - Archéologie de la France antique, 2009, 66 (2), pp.171-225. 10.3406/galia.2009.3370 . hal-01899066

\section{HAL Id: hal-01899066 https://hal.science/hal-01899066}

Submitted on 19 Dec 2019

HAL is a multi-disciplinary open access archive for the deposit and dissemination of scientific research documents, whether they are published or not. The documents may come from teaching and research institutions in France or abroad, or from public or private research centers.
L'archive ouverte pluridisciplinaire HAL, est destinée au dépôt et à la diffusion de documents scientifiques de niveau recherche, publiés ou non, émanant des établissements d'enseignement et de recherche français ou étrangers, des laboratoires publics ou privés.

\section{(ㅇ)(1) $\$$}

Distributed under a Creative Commons Attribution - NonCommercial - NoDerivatives 44.0 


\section{UNE PETITE VILLE ROMAINE DE MOYENNE MONTAGNE, JAVOLS/ANDERITUM (LOZÈRE), CHEF-LIEU DE CITÉ DES GABALES}

\section{État des connaissances (1996-2007)}

\section{Sous la direction d'Alain FERDIÈRE, Emmanuel MAROT et Alain TRINTIGNAC**}

avec la collaboration de Michel AMANDRY, Caroline BIDEAU, Anne-Lise COHEN, Julien Courtois, Jane DE Rose-Evans, Francesca Di NAPOLI, Mélanie FONDRILLON, Benoît GIRAUD, Thomas GuIllemard, Romana HARFOUCHE-POUPET, Aurélien LEFEuvre, Benoît Ode, Mathilde NoËL, Raffaela PIEROBOn-BEnoÎT, Grégory POITEVIN, Pierre POUPET

\footnotetext{
Mots-clés. La Tène finale, époque romaine, haut Moyen Âge, urbanisme, ville antique, évaluation, extension, rétraction, monuments publics, voirie.

Résumé. En 1996, un programme d'évaluation a été entrepris sur le site de Javols/Anderitum (Lozère), chef-lieu de cité des Gabales, dans la province d'Aquitaine.

À l'issue de douze années de travaux sur les recherches anciennes et surtout de sondages multiples, un bilan peut être tiré concernant cette modeste capitale et son territoire. Son contrôle sur le territoire peut aussi être mieux appréhendé.

Seule la partie centrale du site avait fait l'objet de quelques fouilles à partir du début du XIXe s.

Est en effet aujourd'hui mieux perçue l'histoire du site, de ses origines à La Tène finale jusqu'au village actuel, et surtout à la période romaine : extension de l'agglomération antique, mise en place de son urbanisme, de sa voirie, de son équipement monumental, aspects les plus communs de la vie quotidienne, dans la période d'extension maximale au II s. apr. J.-C., puis de sa rétraction à partir de la fin de ce siècle jusqu'à sa défection comme capitale de cité.
}

Key-words. Late La Tène, Roman period, early Middle Age, urbanism, antique town, evaluation, expansion, retraction, public buildings, street system.

Abstract. An evaluation programme was undertaken in 1996 on the site of Javols/Anderitum (Lozère), capital of the Gabali civitas, in Aquitania.

After 12 years work including recordings of prior research and especially numerous limited excavations, an appraisal on this small chief town and its territory can be drawn. Now also its control on the territory can be observed.

Since the beginning of the $19^{\text {th }}$ century a short series of excavations have only been organized in the central quarter.

\footnotetext{
* Les adresses des auteurs se trouvent p. 216.
} 
The history of the site is better understood, from its origin in the late La Tene until the actual village, and of course along the Roman period: development of the antique town, urban setting, street system equipment, the most common features in everyday life during its maximal expansion in the $2^{\text {nd }}$ century A.D., its retraction towards the end of that century until its failure as a civitas capital and beyond.

Translation: Isabelle FAUDUET

Schlüsselwörter. Spätlatènezeit, römische Zeit, Frühmittelalter, Urbanismus, antike Stadt, Bewertung, Ausdehnung, Niedergang, Straßennetz, öffentliche Gebäude.

Zusammenfassung. 1996 wurde in Javols/Anderitum (Departement Lozère), dem Hauptort der Gabali, in der Provinz Aquitanien, ein Programm zur Auswertung der archäologischen Interventionen in Angriff genommen.

12 Jahre lang wurden die Altgrabungen neu aufgerollt und vor allem zahlreiche Sondierungen vorgenommen, was es nun ermöglicht eine Schlussbilanz bezüglich dieses bescheidenen Hauptortes und dessen Territoriums zu ziehen. Auch die Kontrolle, die er über die von ihm anhängigen Gebiete ausgeübt hatte, wird nun besser erfasst.

Nur die Ortsmitte war seit dem Beginn des 19. Jahrhunderts mehrfach Gegenstand von Ausgrabungen gewesen.

Heute ist die Geschichte der Ortschaft, von ihren Anfängen in der Spätlatènezeit bis zum heutigen Dorf, und vor allem die römische Zeit besser greifbar: Ausdehnung der antiken Siedlung, Gestaltung ihres Urbanismus, ihres Verkehrsnetzes, ihrer großen öffentlichen Gebäude, die gewöhnlichsten Aspekte des Alltagslebens zur Zeit ihrer größten Ausdehnung im 2. Jh. n. Chr., und schließlich ihr Niedergang, der am Ende desselben Jahrhunderts beginnt und mit dem Verlust ihres Status als Civitas-Hauptort endet.

Übersetzung: Isa ODENHARDT-DONVEZ

Un programme de recherche a été engagé en 1996 sur le site archéologique de Javols/Anderitum, à la sollicitation du Service régional de l'archéologie de Languedoc-Roussillon, sous la forme d'un programme collectif de recherche $(\mathrm{PCR})^{1}$ : c'est le bilan de douze ans de sondages et de recherches sur cette modeste capitale de cité d'Aquitaine qui est présenté ici.

\section{UN CHEF-LIEU ET SA CITÉ : BILAN DES RECHERCHES}

\section{JAVOLS/ANDERITUM ET LES GABALES}

\section{LA CIVITAS}

Il est sans conteste aujourd'hui admis que Javols est l'antique Anderitum, capitale gallo-romaine de la civitas des Gabales ${ }^{2}$ (fig. 1), peuple qui entre dans l'Histoire en 52 av. J.-C. comme étant sous la domination de ses voisins

1. Sous la responsabilité de A. Ferdière, financé à parts égales par l'État, la région Languedoc-Roussillon et le département de la Lozère, et avec le soutien de l'université et du Laboratoire archéologie et territoires de Tours. Sauf indication contraire, les figures (au trait ou photos) sont de la documentation du PCR Javols ; l'essentiel de l'infographie (plans et coupes) a été assuré par B. Ode, de 1996 à 2002, puis par J. Courtois, avec A. Trintignac.

2. Ce territoire est relativement méconnu au plan archéologique : voir notamment la $C A G$ de la Lozère (Fabrié, 1989), malheureusement très lacunaire et erronée, et auparavant Balmelle, 1937. du nord, les Arvernes (César, B. G., VII, 7-8 et 75, 2) ${ }^{3}$. La cité est intégrée, après la Conquête, dans la nouvelle grande province augustéenne d'Aquitaine, aux confins de la Narbonnaise (Ferdière, 2003b). La cité est en Aquitaine Première au Bas-Empire, puis disputée entre les Francs et les Wisigoths au haut Moyen Âge (Darnas, Duthu, 2002, p. 98). La civitas romaine, puis le diocèse du haut Moyen Âge, correspondent à peu près au département de la Lozère (à quelques communes près au sud-est et au sud-ouest), auquel il faut ajouter le canton de Saugues (Haute-Loire), au nord-est ${ }^{4}$.

La création d'une civitas spécifique pour les Gabales, comme d'ailleurs pour les Vellaves dont le territoire est encore plus exigu, peut avoir eu pour motivation, de la part d'Auguste, de ne pas accorder un territoire trop vaste et donc une hégémonie trop importante aux puissants Arvernes, au nord, et ce aux confins septentrionaux de la Narbonnaise.

Cette position - notamment par rapport d'une part à la Narbonnaise occidentale, de l'autre à la moyenne vallée du Rhône (cités des Helviens et des Volques Arécomiques de Nîmes) - peut avoir été l'un des atouts, notamment économique, pour le maintien et le développement de cette modeste cité (Trintignac, 2001a ; Ferdière, 2003b).

3. D’une manière générale, sur les sources textuelles et épigraphiques concernant Javols et les Gabales, voir Ferdière et al., dir., à paraître, ann. 6 . 4. Sur ces limites au nord, voir par exemple dernièrement : Trément et al., 2007. 


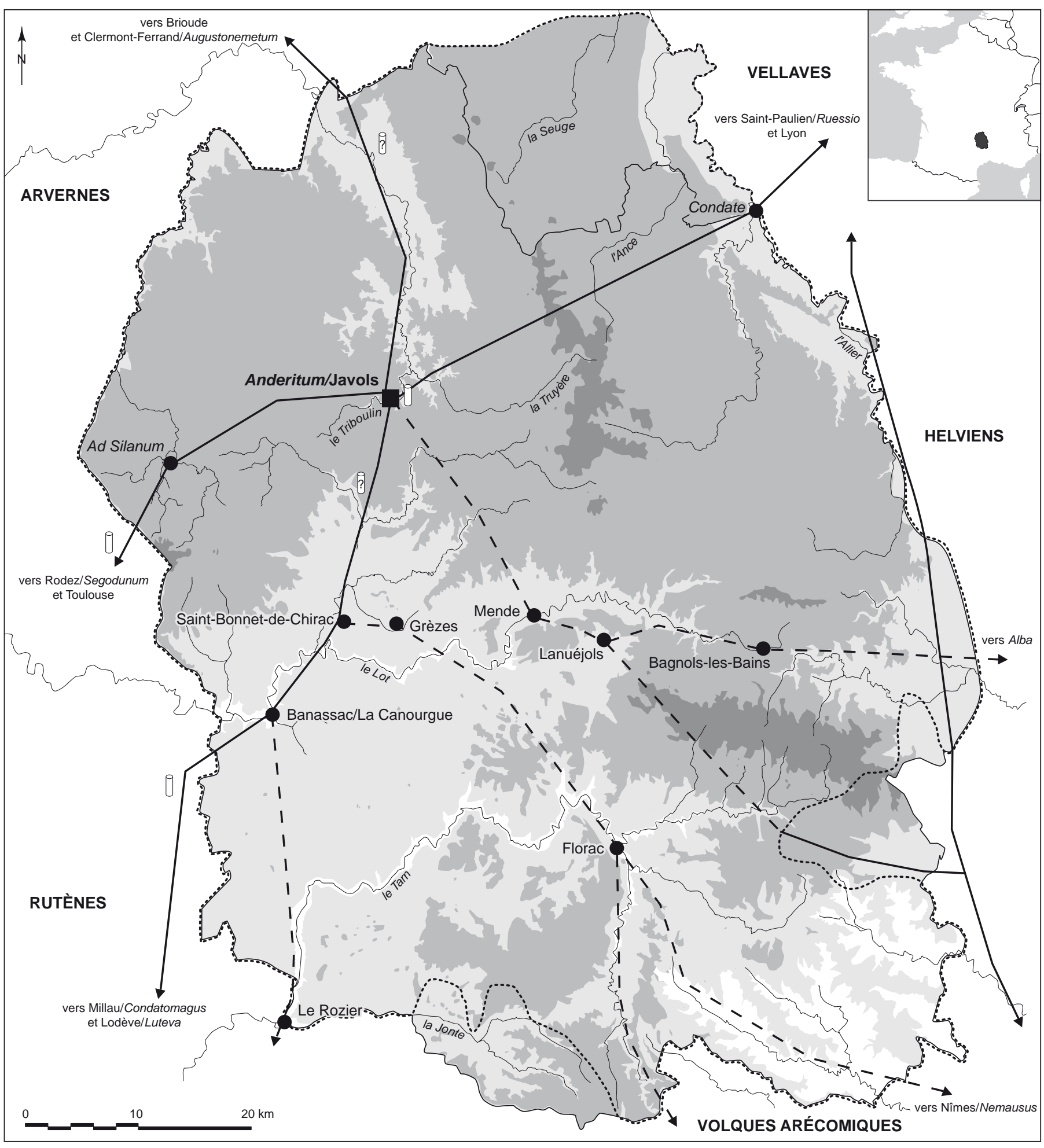

chef-lieu de cité

agglomération secondaire

$\left.\begin{array}{ll}\text { ….. limite supposée de la cité } & - \text { attestée } \\ \text { _ limite du département de la Lozère } \quad-\quad \text { supposée }\end{array}\right\}$ voie antique

$\left.\begin{array}{l}\text { Qttestée } \\ \text { ? supposée }\end{array}\right\}$ borne milliaire

altitudes
$0 \mathrm{~m}$
$600 \mathrm{~m}$
$1000 \mathrm{~m}$
$1400 \mathrm{~m}$

Fig. 1 - La cité des Gabales, son réseau routier et ses agglomérations (DAO : B. Ode et A. Trintignac, PCR Javols/Anderitum). 
Le Gévaudan antique est ainsi entouré de puissantes cités, parmi lesquelles seule celle des Vellaves au nord-est est encore plus modeste.

Ce territoire est accidenté : le département de la Lozère est le plus « haut » de France, en moyenne, et est entrecoupé de nombreuses vallées, à la naissance des bassins versants de la Loire (par l'Allier) et de la Dordogne-Garonne (par le Lot et le Tarn). Il est malgré tout drainé - outre ces voies fluviales - par un réseau routier non négligeable, bien qu'en grande partie méconnu, dont l'axe principal est la voie de Lyon à l'Aquitaine méridionale (dont Toulouse, puis éventuellement Bordeaux), doublant la "voie d'Agrippa » Lyon-Saintes par Clermont-Ferrand et Limoges, et qui est qualifiée de " rocade sud du Massif central ", par Feurs/ Forum Segusiavorum, Saint-Paulien/Ruessio, Javols/Anderitum, Rodez/Segodunum et Albi (Ignon, 1840-1841, p. 133 sqq. ; Étiévant, 1869 ; Portal, 1890, p. 14-16 ; Alla, 1972-1973 ; Michou, Dufort, 1974 ; Fabrié, 1989, p. 27-30 ; Sillières, 1992 ; Provost, 2006). La Table de Peutinger indique que le chef-lieu de cité des Gabales est encadré de deux stations, l'une à l'est (Condate/ "Chapeauroux » à Saint-Bonnet-de-Montauroux), l'autre à l'ouest (ad Silanum/Puech Crémat-Bas à Nasbinals) (Weber, 1976, seg. I, 3-4) : cet axe, selon les milliaires connus surtout plus au nord, aurait été établi définitivement sous Claude. Il coupe à Javols une autre voie importante, d'axe nord-sud, mettant en communication les Arvernes avec la Méditerranée, par Clermont-Ferrand/Augustonemetum, Brioude ${ }^{5}$, Javols, Banassac, Millau/Condatomagus ${ }^{6}$ (Soutou, 1988), puis le Languedoc. Cet axe est doublé plus à l'est par la «voie Régordane ", ne passant pas par le chef-lieu et mettant en relation les Arvernes avec le Bas Languedoc (Trintignac, 2001a, p. 67-68). Enfin, une voie vers l'est, dite «de Coudoulous " ${ }^{7}$, mettait en relation la région de Mende et les mines de plomb argentifère du mont Lozère avec les Volques Arécomiques et Nîmes.

L'occupation du sol dans les campagnes gabales est encore assez méconnue, du fait des conditions paysagères peu propices aux découvertes et aux prospections. Un nombre non négligeable d'établissements ruraux, villae, etc. est cependant connu (Chambrun, 1981 ; Roger, 1993 ; Trintignac, 2001a). Il faut compléter ce survol de l'équipement de la cité gabale par la mention d'un nombre assez

5. Milliaire de Postume à Saint-Léger-du-Malzieu, Lozère (CIL, XIII, 8882).

6. Milliaire de Philippe l'Arabe à la frontière des Rutènes (Labrousse, 1980).

7. Graffiti romains sur la paroi d'un passage montagneux au Collet-deDèze (Pauc, 1987). important d'agglomérations secondaires, placées généralement sur les axes routiers évoqués plus haut : Condate/SaintBonnet-de-Montauroux (Ferdière, 2002d) et ad Silanum et Mons Helarius/Nasbinals et Marchastel (Chardonnet, Ferdière, 2002) déjà mentionnés, ainsi que Bagnols-les-Bains (Valaison, 2002), Banassac et La Canourgue (Chardonnet, Fages, 2002), Grèzes (Ferdière, 2002a), sans doute Lanuéjols et ses mausolées, et bien sûr Mende, qui deviendra capitale des Gabales au haut Moyen Âge, sans oublier Saint-Bonnetde-Chirac, où une occupation gallo-romaine succède à un oppidum celtique et qui est proposé comme chef-lieu du peuple gabale avant la Conquête (Vernhet, 1967 ; Ferdière, 2002b).

$\mathrm{Au}$ plan économique, les productions gabales sont sans doute peu diversifiées mais permettent à l'évidence à la cité, par leur développement, de tenir son rang au sein de la Gaule romanisée (sur l'artisanat chez les Gabales, voir Trintignac, 2001b). Ses spécificités géographiques lui permettent notamment de développer l'exploitation des ressources forestières : ceci concerne le bois, comme combustible, dans les Causses, pour les grands ateliers de sigillée de Gaule du Sud (la Graufesenque en tête, voir Vernhet, 1981), ou comme matière première pour la production de tonneaux destinés à la viticulture extensive de la moyenne vallée du Rhône (Ferdière, 2003b), ou encore de ses dérivés, charbon de bois pour la sidérurgie et surtout poix pour les dolia des chais vinicoles de cette même Narbonnaise, le calfat des bateaux ou d'autres usages (Trintignac, 2003, 2005a et à paraître). En outre, les plombs argentifères du mont Lozère ont certainement formé un atout important quant à son intégration dans le monde romain, l'argent étant particulièrement recherché pour la rémunération des armées (Ferdière, 2003b) : il est d'ailleurs possible que ces mines aient été à l'origine de la fortune de la famille de L. Pomponius Bassulus et Balbinus qui a fait ériger le mausolée de Lanuéjols (CIL, XIII, 1567 ; Joulia, 1974).

La cité gabale a su par ailleurs s'insérer dans les secteurs lucratifs de la production et du commerce de la céramique, et notamment de la sigillée, en profitant du formidable moteur qu'a constitué l'essor des centres de production de la Graufesenque et de ses satellites au ${ }^{\text {er }}$ s. apr. J.-C. (Trintignac, 2001a ; Ferdière, 2003b) : ainsi apparaissent les ateliers du Rozier aux confins des Rutènes (Thuault, Vernhet, 1986), puis celui de Banassac (Hofmann, 1986 et 1988), sans compter les ateliers de céramique commune connus à Florac, ou encore de terres cuites architecturales à Saint-Maurice-de-Ventalon (Dardaine, Waton, 1986) et Serverette, ce dernier aux portes de Javols. Enfin, sans que 
la question de la place de l'élevage soit encore suffisamment documentée, notamment par des études archéozoologiques, on est en droit de penser que cette région de moyenne montagne a été particulièrement propice au développement d'une économie rurale de caractère prioritairement pastorale : la production de fromages renommés, attestée par deux textes, l'un du $\mathrm{I}^{\mathrm{er}}$ s. apr. J.-C. (Pline l'Ancien, H. N., XI, 240), l'autre du VI ${ }^{\mathrm{e}}$ s. (Grégoire de Tours, G. C., II), en est une confirmation (Reisser, 1901 ; Ferdière, 2003b, p. 220).

$\mathrm{Au}$ plan religieux enfin, nos connaissances sont faibles pour la civitas (Fabrié, 1985) :

- quelques sanctuaires sont attestés, souvent dans des agglomérations proches de Javols : «Vidalès » aux Laubies (Marnhac, Chambrun, 1970), « le Baou " à Fontans (Fabrié, 1989, p. 105), ainsi que plus loin "Cadoule » à La Canourgue (Peyre, 1968), "Rouffiac » à SaintBauzile (Peyre, 1970c), " le Truc » à Saint-Bonnet-deChirac (Vernhet, 1967 ; Ferdière, 2002b), « Saint-Andéol » à Marchastel (Chardonnet, Ferdière, 2002) et " Mont Buisson » à Saint-Pierre-des-Tripiers (Boude, 1984).

- quelques inscriptions mentionnent Jupiter à Lanuéjols (CIL, XIII, 1564 et 1565), ou Mars à Barjac et, sans doute, à Saint-Laurent-de-Trèves (CIL, XIII, 1561 ; Fabrié, 1989, p. 59 et p. 123) ;

- on y ajoutera des figurations divines qui montrent notamment un engouement pour le dieu au Maillet, sans doute patron des tonneliers : outre la fameuse statue de Javols (voir infra, p. 200), on mentionnera celles du Born et de Canilhac (Chassaing, 1962 et 1986, p. 75-83).

\section{LE CHEF-LIEU}

La capitale de cité, Javols/Anderitum, n'est quant à elle mentionnée qu'au II ${ }^{\mathrm{e}}$ s. apr. J.-C. par Ptolémée (Géographie, II, 7, 11), puis sur la Table de Peutinger (Desjardins, 1884, seg. I ; Weber, 1976, seg. I, 3-4). Comme la plupart des chefs-lieux de cité, vers la fin du III $^{\mathrm{e}}$ s., la ville perd cette dénomination d'origine celtique ( le grand gué » ou "près du gué », voir Ferdière, 2001a) pour devenir génériquement la ville d'ad Gabalos (ou -es), vocable qui, par différents intermédiaires attestés au Moyen Âge, donnera aujourd'hui Javols (Longnon, 1887, p. 18 ; Jullian, 1920-1926, vol. I, p. 838 ; Grimaud, Balmelle, 1925, p. 69 ; Rouche, 1969 ; Ferdière, 2000b et 2001a, p. 18 ; Ferdière, Ode, 2004). Ce changement de toponyme est en tout cas la preuve que cette ville était donc et reste, du moins durant une partie du $\mathrm{IV}^{\mathrm{e}}$ s., la capitale de la civitas des Gabales, qui ne sera trans- férée à Mende que plus tard, au haut Moyen Âge (Ferdière, 2000b ; Ferdière, Ode, 2004).

On est ici en Haut Gévaudan, dans la partie septentrionale de la cité des Gabales, en Terre de Peyre, entre les plateaux de Margeride, à l'est et au nord, et d'Aubrac, à l'ouest. Le substrat géologique est exclusivement granitique. Le site profite d'un relatif élargissement de la vallée d'un modeste affluent (rive gauche) de la Truyère qui coule plus au nord et est tributaire du Lot : le Triboulin prend ici, à Javols, un cours plus sud-nord, après avoir reçu, au sud-sud-est du site, le ru d'Arbouroux, et l'on note aussi, au niveau du site, trois autres vallons convergeant, $d u$ "Cros » au nord-ouest, de « l'Oustal Neuf » au sud-est et du " Mas Astruc » au nord-est. Son altitude (pour l'aire occupée pendant l'Antiquité) varie de $972 \mathrm{~m}$ au fond du vallon en aval à $995 \mathrm{~m}$ pour sa limite orientale sur la colline qui le domine, et $1015 \mathrm{~m}$ sur le plateau occidental.

Cette situation, dans une région de moyenne montagne à la topographie relativement accidentée, confère au site des conditions de fouilles assez particulières (Ferdière, Poupet, 2005) : les apports colluviaux y sont parfois importants en bas de pente, protégeant ainsi les vestiges, mais au détriment des hauteurs environnantes, très fortement attaquées par l'érosion ; dans la partie basse du vallon, l'eau est partout présente à faible profondeur et nécessite des pompages pour permettre la fouille des niveaux ennoyés ; enfin, le terrain est très acide, occasionnant des détériorations importantes aux vestiges calciques (pierre, céramiques à pâte calcaire, ossements, etc.) et donc d'importantes pertes d'informations ; et ceci sans parler des dégâts occasionnés par les fouilles anciennes. La contrepartie en est une assez bonne accessibilité aux niveaux archéologiques, pour cette ville aujourd'hui «à la campagne », qui a grandement facilité notre programme de sondages systématiques d'évaluation. Ces terrains interdisent toutefois les prospections à vue, en partie celles aériennes et géophysiques, ainsi que, pour l'essentiel, les carottages.

\section{HISTORIQUE DES REGHERCHES}

\section{LES RECHERCHES ANCIENNES}

En ce qui concerne les fouilles et travaux menés avant les années 1990, le site est connu au moins depuis le XVII ${ }^{\mathrm{e}} \mathrm{s}$. par la présence de «quais » en grand appareil le long des berges du Triboulin (L'Ouvreleul, 1724-1726, p. 22-23 ; Notice..., 1865, p. 472 ; Cayx, 1826 ; Fabrié, 1989). Mais les véritables recherches archéologiques ne furent entreprises 


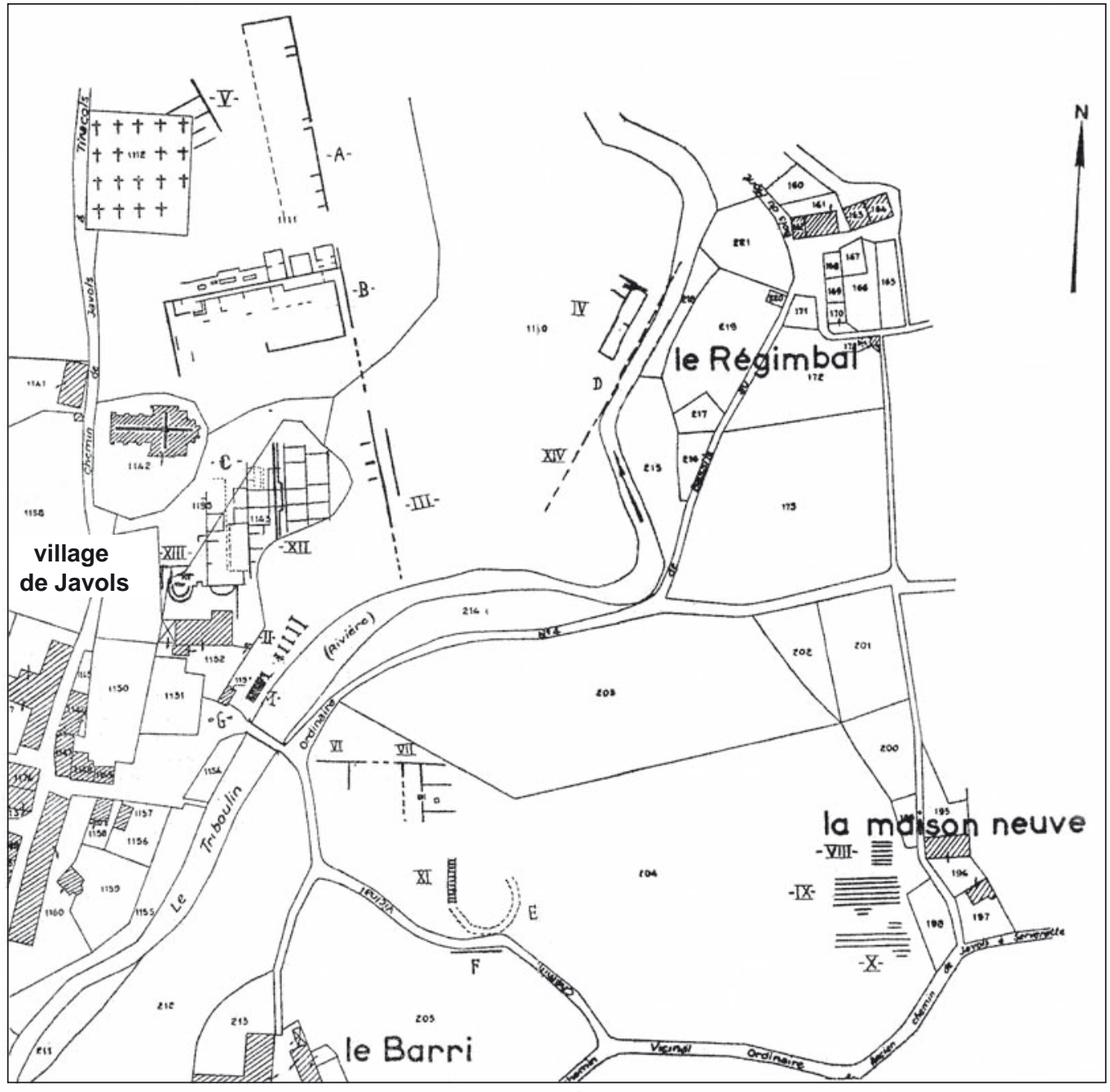

Fig. 2 - Plan d'ensemble du site, dit "plan Morel », de 1962 (d'après Peyre, 1969b, plan h. t.).

qu'à partir des années 1820 par J. J.-M. Ignon (1840-1841) et É. de Moré (1856a et b, 1858a et b et 1859), à la suite de la découverte du milliaire de Postume. Au XX ${ }^{\mathrm{e}}$ s., parmi les principaux fouilleurs du site, il faut retenir les noms de P. de Brun, J. Lyonnais, du $\mathrm{D}^{\mathrm{r}} \mathrm{Ch}$. Morel et de l'abbé Vassal, avant et après la Seconde Guerre mondiale, en 1937-1939 et 1950 (Morel, 1962), puis, surtout, de 1969 à 1978, les travaux de l'abbé P. Peyre ${ }^{8}$ (1969b, 1970b, 1971a), et enfin, de 1987 à 1994 puis de 1996 à 1999, ceux de R. Pierobon-Benoît ${ }^{9}$ (1992) ; à ceci ne s'ajoutent que quelques interventions

8. Les archives de fouille et les rapports annuels de P. Peyre sont au SRA de Languedoc-Roussillon (Montpellier), avec copies au dépôt de fouilles de Javols.

9. Travaux intégrés dans notre programme pour ces dernières années ; rapports antérieurs consultables au SRA et au dépôt de fouilles de Javols. d'archéologie préventive, dans les années précédant immédiatement notre programme ${ }^{10}$. À quelques très rares exceptions près, la totalité de ces travaux antérieurs ont porté, de manière souvent redondante, sur le seul secteur central et surtout monumental de la ville antique, dans la partie basse du vallon et en rive gauche de la rivière (fig. 2).

\section{LE PROGRAMME DE RECHERCHES À PARTIR DE 1996}

Il s'agissait dès l'origine d'un programme intégré d'évaluation globale du site et de son environnement, présentant des objectifs à la fois scientifiques (connaissance historique du site) et patrimoniaux (valorisation, protection, etc.).

10. Dans le bourg en 1991, au terrain de sport en 1992, à la nouvelle École forestière (G. Fages) et au Régimbal (Ch. Chardonnet) en 1995, voir rapports au SRA et au dépôt de fouilles de Javols. 
Ce projet comportait donc la réalisation d'un bilan des connaissances sur le site, pour les acquis antérieurs à nos recherches, et surtout un programme de sondages systématiques pour son évaluation archéologique. Ce programme a été suivi, à partir de 2004, par un second, sous la responsabilité d'Alain Trintignac : engagement d'une importante fouille programmée pluriannuelle et poursuite des opérations de sondages pour compléter l'évaluation ${ }^{11}$. Il s'est en effet avéré que, presque depuis leur origine, les fouilles et découvertes s'étaient cantonnées ici à une faible surface, limitée à la partie plane du vallon du Triboulin (environ 9 ha) : ces données étaient ainsi redondantes, du moins en matière d'évaluation globale du site, et ne permettaient pas de juger de son étendue et de son importance réelles.

De 1996 à 2007 inclus, ce sont donc des sondages multiples - ainsi qu'une fouille programmée en 2005-2007, poursuivie en 2008 - qui ont été réalisés, pour un total d'environ 9350 journées/hommes de terrain. Ils concernent 42 secteurs différents (codes de chantier ${ }^{12}$ ) : ce sont au total près de 300 sondages qui ont été pratiqués, variant de moins de $1 \mathrm{~m}^{2}$ à plus de $200 \mathrm{~m}^{2}$ pour certains - et plus de $350 \mathrm{~m}^{2}$ pour la fouille programmée de JPN.05/06. Seules les possibilités d'obtenir les autorisations des propriétaires des terrains concernés ont limité, pour quelques secteurs, l'extension de ces sondages d'évaluation. Leur implantation a été dictée par les questions concernant les limites, la chronologie, l'urbanisme, l'équipement monumental et le réseau viaire du site, objectifs parfois associés à des impératifs d'évaluation en archéologie préventive. C'est ainsi une surface cumulée (fouille programmée 2005-2007 incluse) de plus de 0,5 ha (environ $5375 \mathrm{~m}^{2}$ ) qui a été sondée. Compte tenu de la surface présumée du site dans son extension maximale (voir infra, p. 182), soit près de $40 \mathrm{ha}$, on peut donc retenir que cette évaluation concerne moins de $1,5 \%$ du site. On peut toutefois considérer cet échantillon comme non négligeable et sans doute assez représentatif ${ }^{13}$.

11. Les données prises en compte ici courent jusqu'en 2007 inclus.

12. Ces points de sondage sont indiqués ici par leur code de chantier : 3 lettres (la première, " J » pour Javols, les deux autres pour le nom du chantier, en général le lieu-dit) et 2 chiffres (pour l'année).

13. On peut se référer, pour plus de détails sur ces fouilles, aux rapports annuels fournis au SRA (Ferdière et al., 1996 ; Ferdière, 1997 ; Ferdière dir., 1997, 1998, 1999, 2003 ; Ferdière, Ode dir., 2000, 2001, 2002 ; Ode dir., 2004 ; Trintignac dir., 2005, 2006, 2007 ; voir Trintignac, 2007a), soit aux notices (rapports préliminaires) publiées annuellement dans la Revue du Gévaudan (Ferdière et al., 1997, 1998, 1999, 2000 ; Ferdière, Ode, 2001a, 2002, 2003 ; Trintignac, 2005b, 2006c ; Trintignac et al., $2005)$; voir encore Ferdière, Ode, 1999 ; Ferdière, 2002c ; Trintignac, 2007 b ; De Rose Evans et al., 2009 ; Ferdière et al., dir., à paraître).

\section{JAVOLS/ANDERITUM, UNE VILLE CAPITALE DE LA CIVITAS GABALORUM}

Les recherches menées ces dernières années, et notamment l'importante série de sondages réalisés à l'occasion de ce programme, comme le récolement de la documentation antérieure, autorisent donc aujourd'hui une vision globale de cette agglomération antique, dans son extension topographique comme dans son évolution : c'est sur ce double bilan que repose la synthèse présentée ici.

\section{L'EXTENSION URBAINE}

On se situe d'emblée ici dans la période de splendeur de ce chef-lieu de cité, au II ${ }^{\mathrm{e}}$ s. apr. J.-C. (voir infra, p. 184-185). La question des limites urbaines est, un peu paradoxalement, relativement épineuse, celles-ci étant établies essentiellement en négatif, entre ce qui est reconnu comme urbain et le reste, rural, extra-urbain ou périurbain (voir par ex. Esmonde Cleary, 1987 ; Bedon dir., 1998 ; Goodman, 2006). Ainsi, en fonction des résultats de nos investigations comme des connaissances antérieures, les limites urbaines d'Anderitum seront définies par rapport à l'emplacement des carrières de pierre de construction antiques, des nécropoles (ce dernier aspect étant examiné pour lui-même infra, p. 209-210) ; aucune zone de rejets de dépotoirs extra-urbains ni secteur artisanal périphérique n'étant par ailleurs reconnus ici. Toujours un peu en négatif, le réseau de voies convergent et l'environnement rural de la capitale de cité contribuent aussi, dans une certaine mesure, à la définition de ces limites.

\section{L'environnement du site : voies et contexte rural}

À partir du réseau viaire antique défini plus haut, les axes concernant Anderitum peuvent être fixés, sans grande précision : l'axe majeur, peut-être à l'origine du choix de l'emplacement du chef-lieu de cité gallo-romain, est la voie Lyon-Toulouse qui, venant de la capitale des Trois Gaules par le chef-lieu des Vellaves, Ruessio/Saint-Paulien, puis la station de Condate, à XXII lieues selon la Table de Peutinger, entre dans Anderitum par l'est, d'une direction nord-est ; elle en ressort par l'ouest, selon une direction plein ouest puis sudouest, vers la station d'ad Silanum, à XVIII lieues, vers Rodez, capitale des Rutènes. C'est en fait la seule voie dont le tracé aux abords de Javols est à peu près reconnu (fig. 3).

L'emplacement des deux nécropoles du Haut-Empire localisées à Javols, ainsi que le constat de la raideur de la 


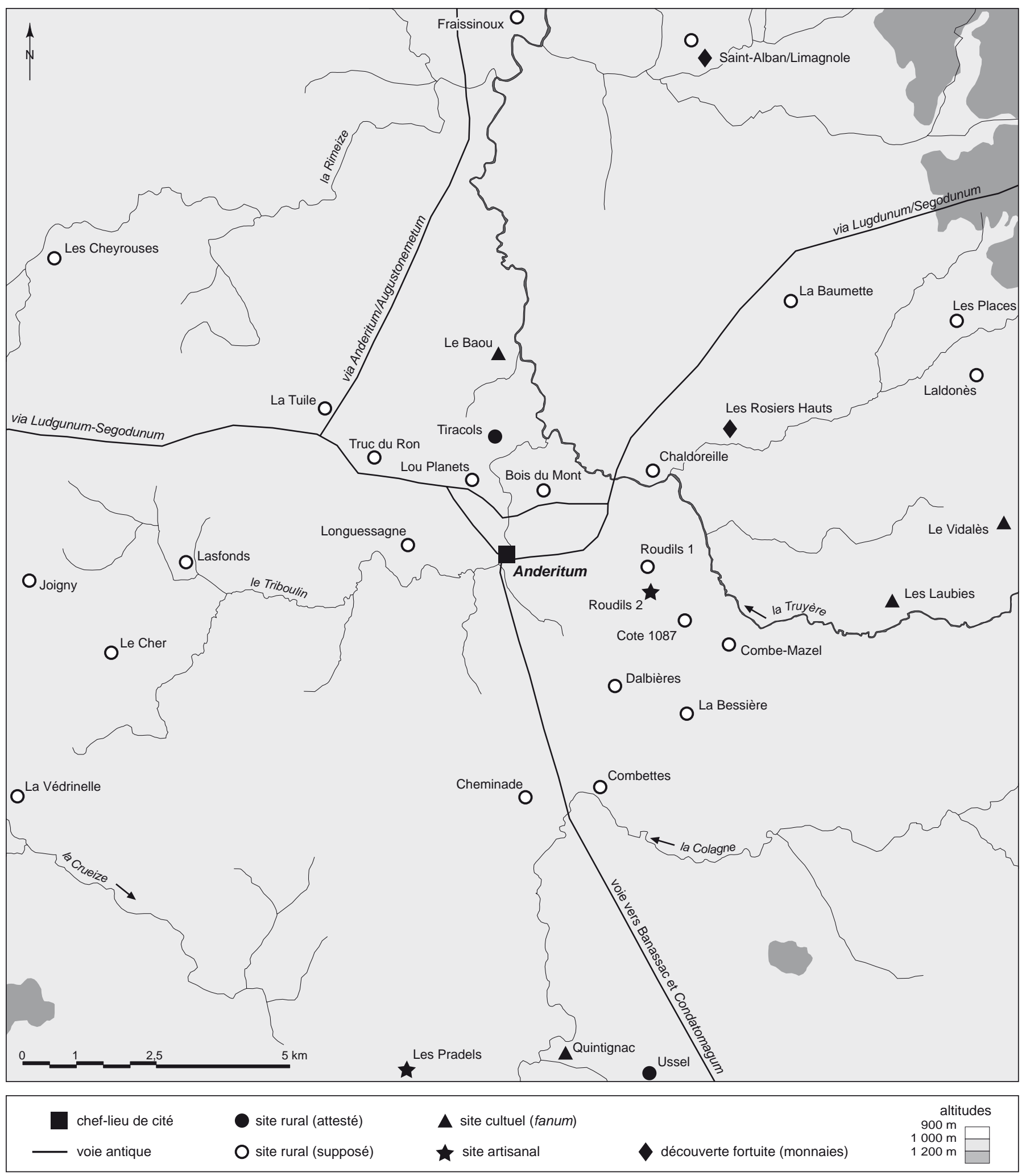

Fig. 3 - Sites et voies antiques aux alentours de Javols/Anderitum (rayon de 10 km) (DAO : A. Trintignac, PCR Javols/Anderitum). 
pente des portions de cette voie sortant de la ville romaine vers l'est et l'ouest, nous ont fait émettre l'hypothèse d'une sorte de « rocade » praticable par les chariots, se détachant à distance de Javols de la voie officielle pour pénétrer en ville à l'est par le vallon du «Mas Astruc » et à l'ouest par celui du «Cros» (fig. 4).

Mais d'autres voies se croisaient à Anderitum et ce n'est pas à cette dernière que semble se rapporter le milliaire « 0 »-sans distance précisée, en fait « milliaire-dédicace » à Postume-découvert ici (CIL, XIII, 8883), du moins si l'on en juge par la présence d'un autre milliaire de Postume à SaintLéger-du-Malzieu (voir supra, p. 174), indiquant V lieues : l'autre axe important est en effet celui de Clermont-Ferrand/ Augustonemetum à la Narbonnaise par Javols et Condatomagus, très vraisemblablement celui emprunté par le "libelle » de Sidoine Apollinaire (Propempticon ad libellum, Carmina, XXIV, 20-47), sans qu'on soit certain que la ville qu'il mentionne soit bien Javols (Ferdière et al., dir., à paraître). $\mathrm{Au}$ sortir d'Anderitum vers Augustonemetum, cette voie emprunte sur une courte distance celle vers Rodez (à l'ouest), puis s'en détache pour se diriger vers le nord. Vers le sud et Banassac, son tracé n'est qu'hypothétique aux abords de la ville (voir Peytavin, 1998, p. 8). Il n'est pas certain que Javols ait été directement relié à la future capitale épiscopale du haut Moyen Âge, Mende/Mimate, alors apparemment modeste agglomération (voir supra, p. 174) : celle-ci pouvait n'être desservie que par un diverticule à partir de la voie vers Banassac puis Millau. Aucune autre voie sortant de Javols n'est donc connue, en l'état des recherches.

En revanche, en ce qui concerne l'environnement rural de la capitale de cité, ce sont aujourd'hui une vingtaine de sites qui sont attestés dans un rayon de $10 \mathrm{~km}^{14}$ (fig. 2), dont une partie enregistrée à l'occasion de notre programme de recherche et parmi lesquels se distinguent au moins deux sites cultuels (dédicace à Liber Pater de Lachamp et fanum des Laubies) et un site artisanal (atelier de tuilier de «Pont de Roudils » à Serverette). Le reste doit correspondre à des établissements ruraux (dont quatre sur la commune même de Javols).

\section{Les limites de la ville}

Ainsi, en examinant cet espace dans le sens des aiguilles d'une montre, depuis le nord, les bornes suivantes peuvent être établies pour l'extension urbaine antique, sous réserve des zones restant encore à sonder (fig. 5) :

14. Soit moins de $2 \mathrm{~h}$ de trajet pour l'époque.
- rive droite de la rivière, au nord-ouest du « Mas Astruc », la limite est relativement nette, entre sondages positifs et négatifs, à partir de la fouille de JLD.00 ${ }^{15}$;

- pour la hauteur surplombant le «Mas Astruc ", la limite reste un peu plus floue, cette colline étant concernée par une carrière du Haut-Empire (JMA.02), mais aussi sans doute par une occupation du Bas-Empire, voire même de La Tène finale, ces dernières étant seulement reconnues dans les colluvions de bas de pente (JLD.00 et JMA.06) ;

- le hameau du «Mas Astruc » lui-même et le vallon qui le jouxte au sud-sud-est sont connus pour des découvertes anciennes ;

- à la hauteur du «Régimbal » (JRE.02), au-delà, vers l'est, d'une installation artisanale à mi-pente (bronzier : seul artisanat éventuellement «périurbain " reconnu à ce jour), on a repéré ce que l'on pense être la nécropole orientale de la ville, sans doute à proximité d'une "rocade » praticable par les chariots, remontant vers le départ de la voie de Lyon, plus à l'est ;

- un peu plus au sud, c'est également à mi-pente que des vestiges d'habitat du $\mathrm{II}^{\mathrm{e}}$ s. ont été décelés (JLV.99);

- sous le hameau de "l'Oustal Neuf », des découvertes sont depuis longtemps signalées, dont certaines datent sans doute de la période gauloise ;

- le vallon profond séparant «l'Oustal Neuf » de la route actuelle vers Serverette a fait l'objet d'observations par l'abbé P. Peyre puis par P. Croiset, mais nécessiterait des sondages complémentaires pour préciser la limite orientale des vestiges ;

- sur le versant opposé (sud) du «promontoire »qui supporte cette route actuelle, des restes d'occupation ont été mis au jour lors des travaux de construction de la nouvelle École forestière, ainsi qu'un peu plus au sud, avec une autre carrière du Haut-Empire (JLM.01) ;

- faute de sondages, la limite précise dans la partie basse du vallon d'Arbouroux reste un peu floue ${ }^{16}$;

- la colline séparant ce vallon de celui du cours supérieur du Triboulin est connue, sur son flanc nord-est, par des découvertes lors de travaux entrepris par l'abbé Peyre (voir aussi JEE.01), sur son flanc ouest par nos sondages

15. Les références aux différents rapports annuels ne sont pas données ici : on se référera aux années indiquées par les deux derniers chiffres des codes de chantiers : voir note 13 .

16. Pour ce secteur et le suivant, notons toutefois qu'un sondage réalisé du côté ouest de ce vallon en 2008 (année dont les données nouvelles ne sont en principe pas prises en compte dans la présente synthèse) a livré une décharge urbaine de la seconde moitié du $\mathrm{II}^{\mathrm{e}}$ s., donnant ainsi une importante précision sur les limites urbaines ici. 


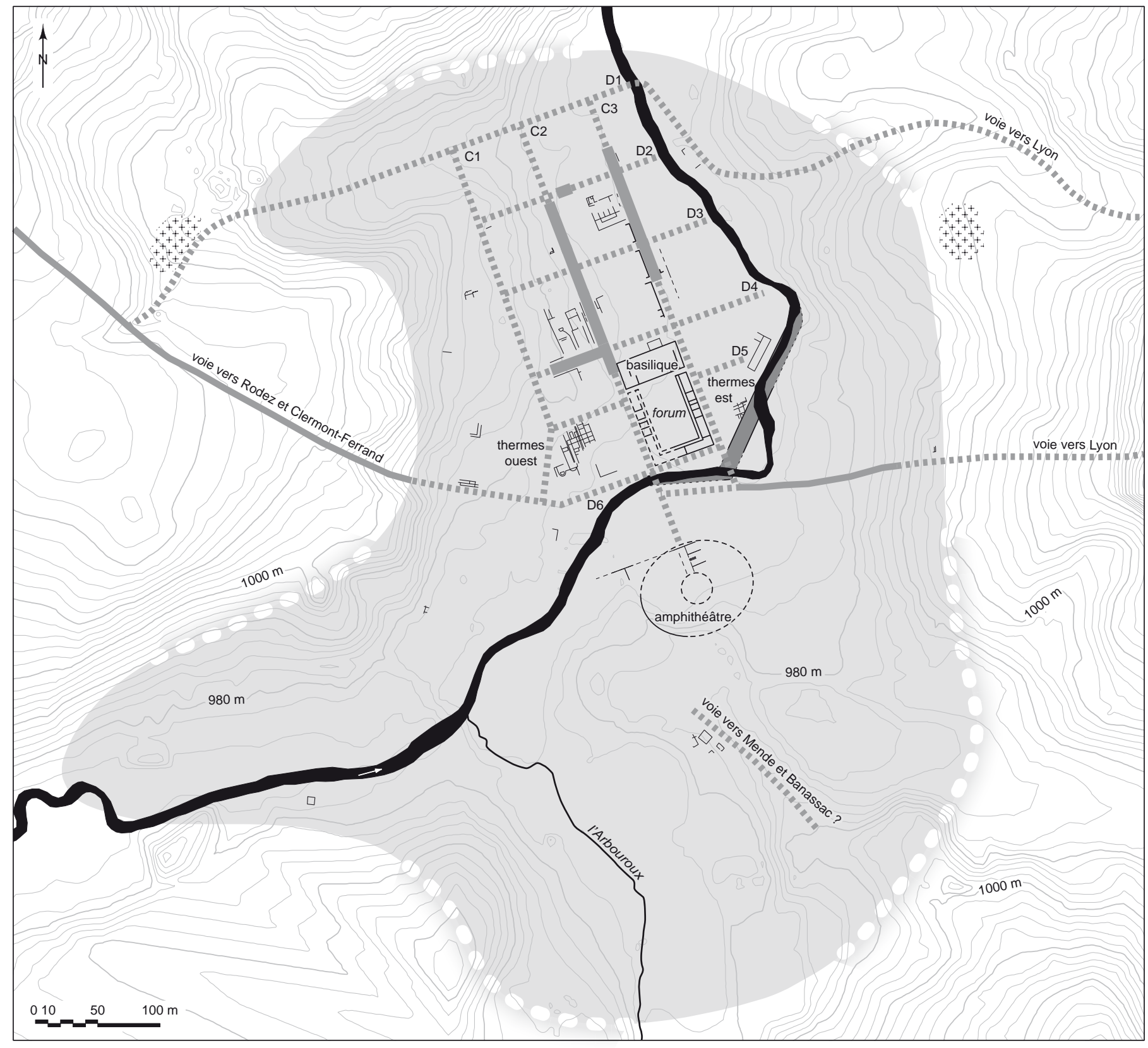

\begin{tabular}{|c|c|c|}
\hline $\left.\begin{array}{l}\text { actuel } \\
\text { supposé }\end{array}\right\}$ cours du Triboulin & 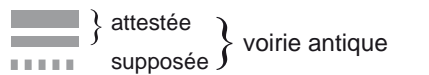 & {$\left[\begin{array}{c}{ }^{+}++^{+}+ \\
t_{1}^{+}++_{+}^{+}\end{array}\right.$nécropole (extension minimale supposée) } \\
\hline 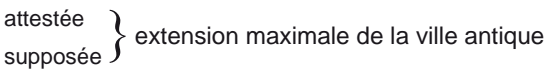 & $\begin{array}{l}\bar{Z} \text { \} attesté } \\
\overline{\Sigma-\Sigma=} \text { \} restitué }\end{array}$ & \\
\hline
\end{tabular}

Fig. 4 - Restitution de la ville antique avec son réseau de rues et les principaux bâtiments reconnus (DAO : J. Courtois, PCR Javols/Anderitum). 


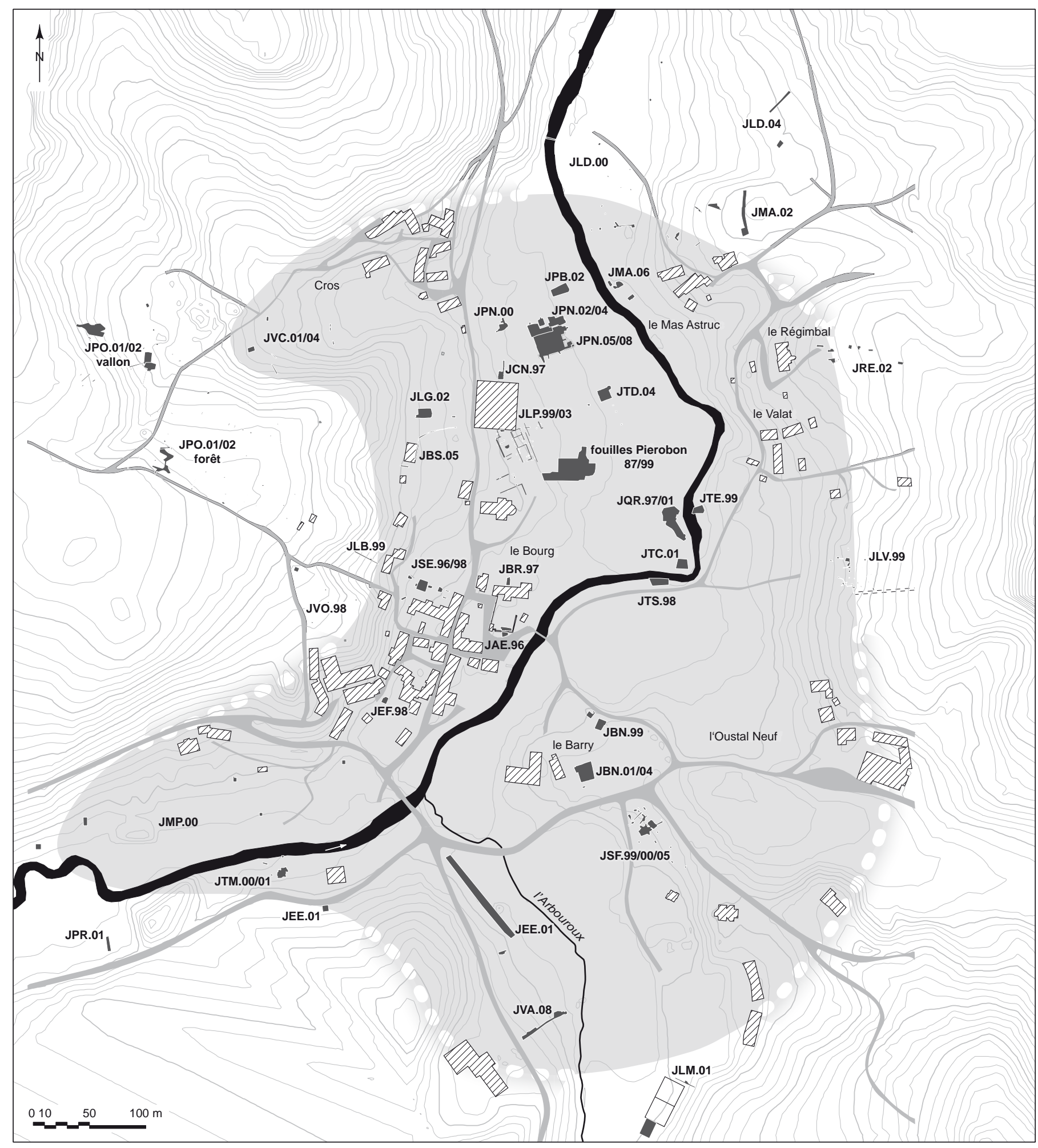

$\left.\begin{array}{l}\text { attestée } \\ \text { supposée }\end{array}\right\}$ extension maximale de la ville antique

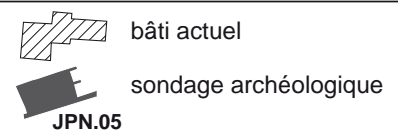

Le Barry lieu-dit

réseau routier actuel

relief (équidistance entre les isolignes : $2 \mathrm{~m}$ )

Fig. 5 - Le site de Javols : extension maximale connue de la ville antique

et points de sondages depuis 1996 (DAO : J. Courtois, PCR Javols/Anderitum). 
JTM.00/01-JEE.01 et JPR.01, ce dernier, négatif, fixant ainsi ici la limite sur la rive droite du Triboulin ;

- sur la rive opposée, vers l'amont de la rivière, la limite a également été bien cernée, un peu plus en amont, par nos sondages JMP.00, tantôt positifs, tantôt négatifs ;

- aux abords de la colline qui surplombe le site à l'ouest et de la route actuelle vers Aumont-Aubrac, les points les plus extrêmes reconnus vers le sud-ouest concernent des observations de G. Fages au pont actuel et notre sondage JEF.98, avec sa nécropole de l'Antiquité tardive, en situation peu élevée ;

- l'occupation de la colline elle-même est dans une certaine mesure une énigme : les sondages multiples pratiqués ici (JPO.01) sont quasi négatifs, mais la nécropole occidentale est tout de même située plus à l'ouest et les colluvions provenant de cette hauteur vers le site, à l'est, contiennent de manière récurrente du mobilier de La Tène finale ou augustéen ;

- sinon, les points positifs les plus extrêmes ici (ouest) concernent un sondage de R. Pierobon et nos fouilles JLB.99 (qui ont mis au jour une carrière), JSE.96/98, JBS.05 et JLG.02;

- à l'arrière du hameau du «Cros », et assez loin dans ce vallon vers le sud-ouest, une nécropole occidentale a été mise en évidence (JPO.01/02) ;

- des traces d'occupation sont anciennement connues plus en aval de ce vallon et sous le hameau même du «Cros » (voir aussi JVC.01 et 04) ;

- enfin, sur la rive gauche du Triboulin, l'occupation ne semble pas dépasser l'étranglement aval du vallon de cette rivière, ni concerner la colline nord-ouest, dont la pente vers le site est assez abrupte (voir entre autres les sondages JPN.00 et JPB.02).

Ainsi, ce sont 35 ha à 40 ha qui sont circonscrits, incluant ou non la colline occidentale (et ce à l'exclusion des nécropoles est et ouest). Cette aire englobe une portion importante du cours du Triboulin, ainsi qu'un petit promontoire venant de l'est et portant aujourd'hui le château du Barri.

\section{L'ÉVOLUTION DU SITE, DES ORIGINES AU MOYEN ÂGE}

Traçons un historique du site urbain, de sa genèse préromaine (?) à son effacement au début du Moyen Âge et au-delà.

\section{Le site préromain}

Pour la Préhistoire, à l'exclusion d'un possible biface paléolithique (en JMP.00), seuls quelques silex taillés erra- tiques, de faciès apparemment néolithique, ont été découverts çà et là dans les sondages. Il faut toutefois signaler une structure de combustion de la fin du Néolithique ou du Chalcolithique mise au jour sur la colline ouest, en JPO.01 (Ferdière et al., 2006 ; Guibert et al., 2006).

Toutefois, ces découvertes antérieures à La Tène finale sont anecdotiques et ne correspondent à l'évidence pas à une occupation importante : ce n'est apparemment qu'au $\mathrm{II}^{\mathrm{e}}$ s. av. J.-C. au plus tôt que le site d'Anderitum semble véritablement prendre naissance. La reconnaissance d'une occupation préromaine sur le site est en effet aujourd'hui clairement avérée (Ferdière, 2000b), mais il reste difficile d'en définir l'ampleur et même la nature : il semble en tout cas exclu d'y voir un oppidum important auquel aurait pu succéder la ville romaine ; et la céramique non tournée reste relativement rare, même dans les couches les plus anciennes du site (Marot, 2007).

Une occupation « de hauteur » est toutefois avérée alors, exclusivement à ce jour il est vrai par le matériel (surtout du I ${ }^{\text {er }}$ s. av. J.-C.) mis au jour dans les colluvions de bas de pente, tant à l'ouest (JAE.96, JSE.98...) qu'à l'est (JMA.06, fouilles Morel en bas du «Mas Astruc »...) et une installation pré-augustéenne, sans doute de caractère cultuel, est en outre attestée au sommet de la colline du Barri (JBN.99 et JBN.01) (fig. 6a). S'y ajoute certainement une occupation « de plaine ", reconnue, assez fugitivement, en plusieurs points de la partie basse du vallon (JPN.00 et JPN.08, JTD.04...). La présence récurrente de matériel préromain (en faible quantité) dans la plupart des sondages et des fouilles dans le vallon confirme cette occupation, et il en est de même de quelques monnaies gauloises ou républicaines éparses (une douzaine au total), même si les premières peuvent avoir circulé jusqu'au milieu du $\mathrm{I}^{\mathrm{er}} \mathrm{s}$. apr. J.-C.

Le nom du site, Anderitum, d'origine celtique (« le grand gué » ou " près du gué ») (Ferdière, 2001a), ne préjuge en rien, en revanche, de son origine préromaine.

\section{La fondation augustéenne}

On s'accorde aujourd'hui à considérer que la plupart des chefs-lieux de cités des Trois Gaules ont été fondés à l'occasion de la réorganisation de ces provinces par Auguste entre 16 et 13 av. J.-C., sans doute en 15 lors de la fondation de l'autel fédéral de Lyon (Ferdière, 2005, p. 137 sqq.).

Les données archéologiques confirment que c'est le cas pour la capitale gabale, mais il est vrai que les traces de cette première urbanisation d'Anderitum restent encore fugaces, en l'état des connaissances : l'une des causes en est que les 
niveaux les plus anciens non seulement ont été largement érodés par les aménagements plus récents (et notamment la grande phase d'urbanisation de la seconde moitié du $\mathrm{I}^{\mathrm{er}}$ s. apr. J.-C.) - comme on a pu le constater à plusieurs reprises -, mais encore sont rendus relativement inaccessibles par le niveau actuel des nappes hydriques.

En quelques points, des couches, voire des structures précoces (autour du tournant de l'ère), ont été mises en évidence dans les sondages : c'est le cas d'une US et de trois fosses sans doute cultuelles sur la butte du Barri (JBN.01/04), d'un niveau de dépotoir et de remblai sousjacent aux aménagements du $\mathrm{I}^{\mathrm{er}}$ s. apr. J.-C. en JTD.04, et sans doute en JCN.97, alors que le premier état de la resserre St.1 de JSF.99/00 semble attribuable au début de ce siècle ; en outre, deux paléosols pourraient aussi être attribuables à cette période précoce, en JSE.98 et JPN.00.

Plus important pour l'urbanisme, les fouilles récentes pratiquées sur les deux rues nord-sud (cardines, voir infra, p. 190-193) ont clairement montré que leur premier état était attribuable aux dernières décennies du $\mathrm{I}^{\mathrm{er}} \mathrm{s}$. av. J.-C. ou au tout début du I ${ }^{\mathrm{er}}$ s. apr. J.-C. (JPB.02 et JTD.04 pour le cardo est, JLP.03 pour le cardo ouest).

De fait, les preuves les plus péremptoires d'une occupation étendue dès la fin du $\mathrm{I}^{\mathrm{er}} \mathrm{s}$. av. J.-C. résident dans l'importante quantité de matériel «augustéen » redéposé dans les couches plus récentes, en position résiduelle : il est notamment souvent mêlé au mobilier de La Tène finale évoqué plus haut, par exemple dans les colluvions de bas de pente, à la base des collines, tant occidentales qu'orientales. Ce matériel précoce est notamment constitué de sigillée italique (ou lyonnaise), déjà notée (bien que rare) dans les fouilles Peyre (Calzone et al., 2001, p. 7-8) ou Pierobon (1991a, p. 12 et 1999, p. 18) ; les monnaies augustéennes sont par ailleurs assez abondantes, tant dans les fouilles plus anciennes (Peyre, 1976a, p. 135-138 ; Richard, Fabrié, 1984, p. 11-12) que dans nos propres sondages, avec une forte représentation des asses de Nîmes ainsi que les frappes à l'autel de Lyon, de même que les monnaies gauloises qui, on le sait, circulent en Gaule presque jusqu'au milieu du I $^{\text {er }}$ s. apr. J.-C. (de même d'ailleurs que les émissions de Nîmes et de Lyon mentionnées).

Mais force est de reconnaître que, si les évidences d'une occupation importante du site existent dès le règne d'Auguste, rien ou presque ne nous est encore parvenu de l'équipement monumental de ce premier urbanisme, car, si l'on propose une fondation augustéenne, il faut alors sans doute restituer un premier forum dès cette époque. Or seuls quelques éléments d'architecture monumentale attribua-

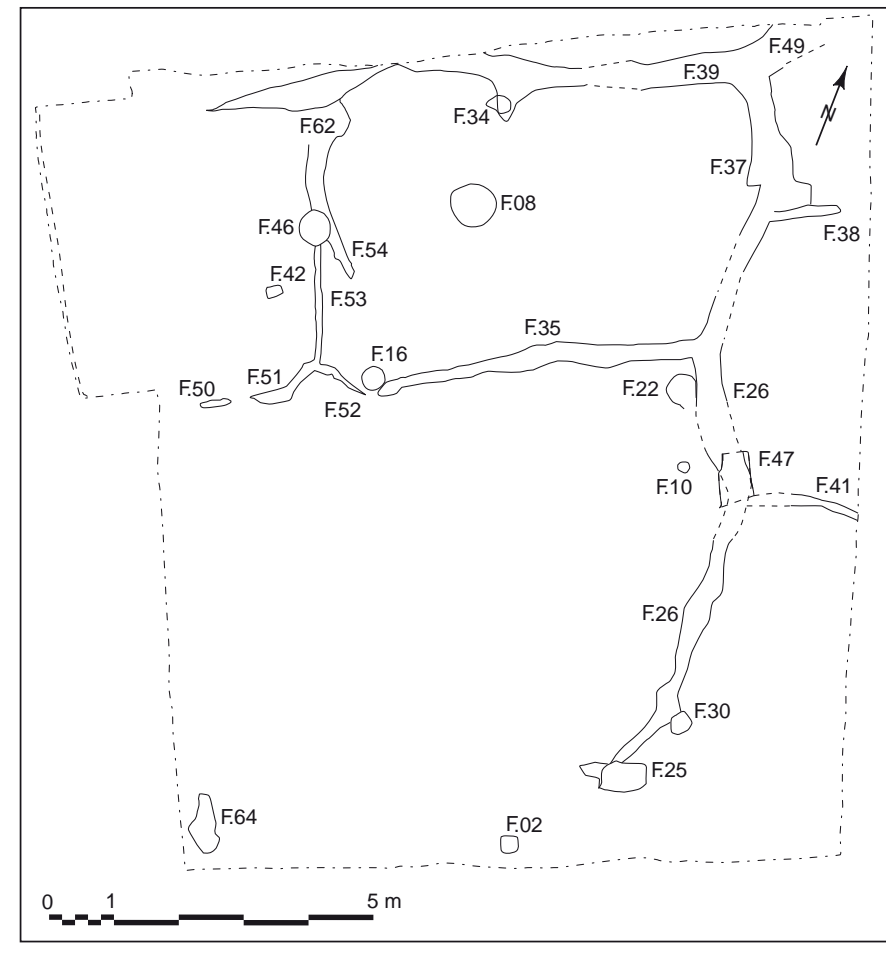

a

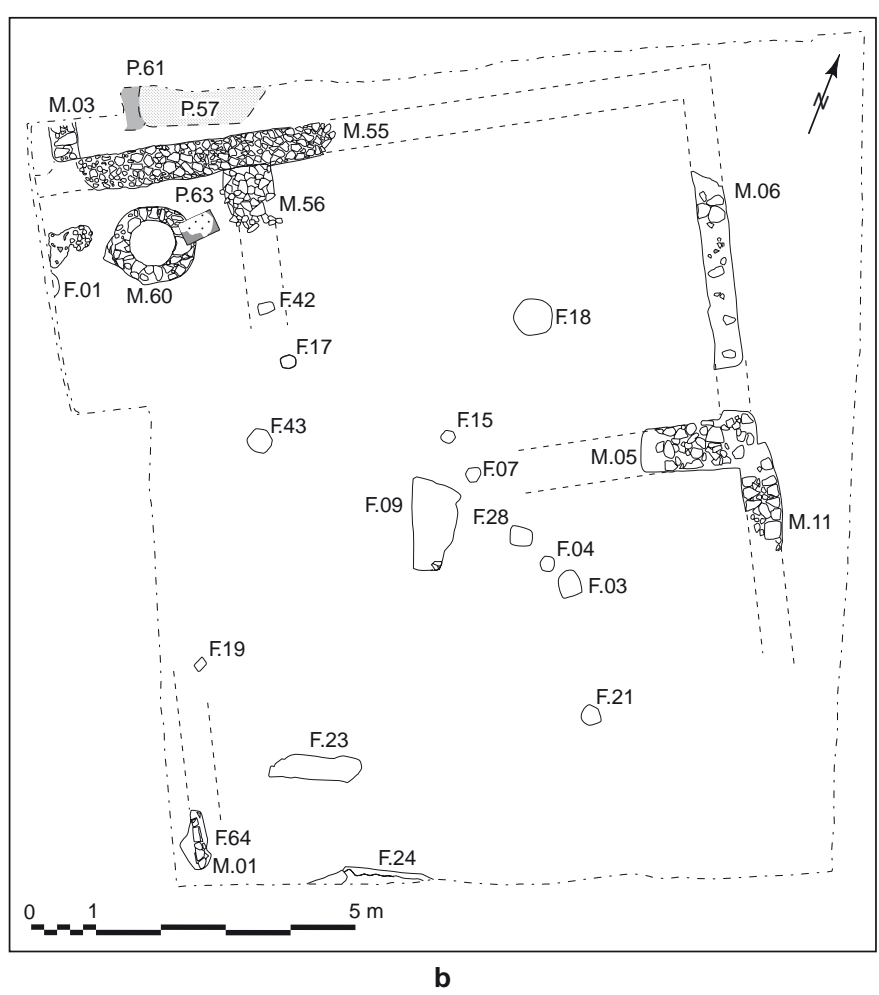

Fig. 6 - Plans de JBN.01/04 à la butte du Barri : a, tranchées de palissade du $I^{e r}$ s. av. J.-C. ; b, structures du Haut-Empire (fosses, fondations, puits et sols) (DAO : PCR Javols/Anderitum). 
bles à cette période sont connus : des fouilles anciennes, un fragment de chapiteau en calcaire à décor végétal (attribution A. Roth Congès, voir Noël, 2002, p. 115 et ann., fiches 98.029 et 98.034), une base de colonne en calcaire de fort diamètre mise au jour en place dans le portique sud du grand bâtiment interprété comme basilique (voir infra, p. 197) (Pierobon-Benoît, 1993b, p. 18 et p. 37, qui attribue ici au début du $I^{\text {er }}$ s. la construction du premier «centre civique ») et peut-être enfin un imposant élément de corniche en granite mis au jour en remploi dans le «quai » de la rive droite du Triboulin (JTE.99), aménagement de berge lui-même sans doute daté au plus tard du milieu du $\mathrm{I}^{\mathrm{er}}$ s. apr. J.-C. (Noël, 2002, p. 115 et ann., fiche 00.224).

Quant à savoir pourquoi ce lieu a été choisi pour l'implantation de la capitale gabale, on ne peut que se perdre en conjectures : dans la partie septentrionale de la cité, granitique, ce vallon est certes l'un des rares espaces de dimension suffisante pour recevoir une telle création, mais pourquoi une localisation aussi décentrée par rapport au territoire de la civitas? La ville a-t-elle été établie ici pour se placer sur une voie importante pour le sud du Massif central, au carrefour avec un autre axe nord-sud également majeur, ou bien au contraire ces voies se croisent-elles ici pour desservir a posteriori le chef-lieu ?

\section{Le développement de la ville au Haut-Empire}

De fait, les principaux aménagements et équipements urbains connus ici ne remontent, pour les plus anciens, qu'au milieu ou à la seconde moitié du $\mathrm{I}^{\mathrm{er}}$ s. apr. J.-C., et sans doute plus particulièrement à la période flavienne (fig. 4 et $5)$ : il faut reconnaître que c'est là encore un topos classique concernant l'urbanisme dans les Trois Gaules et qu'on doit donc veiller à ne pas couler trop facilement Javols, a priori, dans ce moule.

Ainsi, c'est au I ${ }^{\mathrm{er}} \mathrm{s}$. en général qu'est attribué le premier état du bâtiment public fouillé dans la zone centrale du site (déjà basilique ?) (Pierobon, 1991a, p. 10, 1991b et 1992, p. 5-6 ; Pierobon-Benoît, 1993b) ; c'est sans doute dès le deuxième quart de ce siècle que sont édifiés les aménagements de berge de la rivière, en grand appareil, et un premier état de construction qui leur est lié (JQR.97 et 01, JTE.99) ; et le plus modeste aménagement de la berge droite, un peu plus en amont (JTS.98), est sans doute attribuable à la seconde moitié de ce siècle. De même, le premier état monumental de l'entrée du probable bâtiment public mis au jour en JTD.04 est datable de la première moitié du $\mathrm{I}^{\mathrm{er}}$ s., alors que la construction de l'édifice de spectacle (voir infra, p. 200) peut être attribuée à la seconde moitié de ce siècle (JBN.99). Et il en est ainsi apparemment de deux voies est-ouest (voir infra, p. 190-192), le decumanus des fouilles Peyre et celui de JPN.00, ou encore de plusieurs constructions privées, en JLG.02, JSE.98, JSF.99, JCN.97 : l'extension maximale vers le sud-ouest est ainsi sans doute déjà atteinte alors, tant en rive droite du Triboulin (JTM.00/01) qu'en rive gauche (JMP.99), mais aussi par exemple sur la pente des collines est, au moins en JRE.02.

C'est à cette époque, et au plus tard $\mathrm{au} \mathrm{II}^{\mathrm{e}}$ s., que fonctionnent les trois carrières mises en évidence, au nord (JMA.02), à l'ouest (JLB.99) et au sud (JLM.01) et les incinérations fouillées en JPO.01/02 sont datables du milieu du I ${ }^{\text {er }}$ s. ; de nombreux bloc d'architecture sont de même attribuables à ce siècle (Noël, 2002, p. 115).

En effet, après cette importante phase d'urbanisation de la seconde moitié du I ${ }^{\mathrm{er}} \mathrm{s}$., des réaménagements parfois assez considérables sont opérés au cours du $\mathrm{II}^{\mathrm{e}} \mathrm{s}$. Ceci concerne notamment la poursuite de l'équipement public et monumental : ainsi, ce n'est vraisemblablement qu'au $\mathrm{II}^{\mathrm{e}} \mathrm{s}$. que sont édifiés les thermes orientaux (JQR.97/01), comme sans doute les thermes occidentaux (selon notre sondage JBR.97). Et c'est sans doute alors qu'est établi le grand bâtiment public que l'on identifie à la basilique civile (voir infra, p. 199), même si la datation de ce monument n'est à ce jour pas clairement assurée (2état : fouilles Pierobon).

De même, la construction et l'utilisation de plusieurs bâtiments privés ne semblent intervenir qu'au II ${ }^{\mathrm{e}} \mathrm{s}$. : au nord en JLD.00, à l'est en JLV.99, au sud-est en JTM.00/01, au sud-est en JSF.00, ou plus au centre, avec JSE.98 (2 état), JEF.98, JLG.02, JCN.97, JPN.00 et JPN.02, de même qu'un habitat fouillé par R. Pierobon à la base des collines ouest (Pierobon, 1989b, p. 9) ou encore dans la même situation pour les collines est, au «Régimbal » (sauvetage : Chardonnet, 1995, p. 4). Ce constat pour le $\mathrm{II}^{\mathrm{e}}$ s. avait d'ailleurs déjà été fait pour les fouilles Peyre (domus et boutiques, voir infra, p. 204, voir Peyre, 1969b, p. 54 et 1978a et b ; Pierobon-Benoît, 1992, p. 97 et 1993b, p. 21).

Mais, comme souvent aussi dans les villes des Trois Gaules, après un acmé vers le milieu de ce siècle, comme le montre ici son extension maximale (voir supra, p. 182), un certain déclin semble se faire sentir dès la fin de ce siècle ou le tout début du III ${ }^{\mathrm{e}} \mathrm{s}$. Il est d'ailleurs possible qu'un incendie ait alors touché une partie relativement importante de la ville, comme on l'a constaté en plusieurs points : domus de JPN.02/04/07, sans doute thermes orientaux (JQR.97/01), secteur d'habitation de JLG.02, habitat de JLD.00, terrasse avec son remblai issu d'une destruction contemporaine, 
en JSF.99 et JSF.05. Et des incendies attribuables à cette période sont notés dans les fouilles anciennes (Ignon, 1840-1841, p. 171 ; Portal, 1890, p. 8 et p. 13 ; Morel, 1962, p. 102, p. 105 et p. 114-115) comme dans celles plus récentes (Barruol, 1971 ; Peyre, 1975a et b ; 1976b ; Fabrié, 1989, p. 42 ; Pierobon, 1987 , p. 6 ; 1989b, p. 9 ; 1990, p. $3-4$, p. 8 et plan 14 ; 1999 ; Piskorz, 2003).

Il est en effet remarquable - quant à cette phase de stagnation urbaine, voire de rétractation - que la plupart de ces bâtiments alors détruits ne sont pas reconstruits. D’ailleurs, c'était déjà le cas par exemple pour la resserre de JSF.99/00, pourtant détruite par incendie près d'un siècle plus tôt, au tout début du $\mathrm{II}^{\mathrm{e}}$ s. (Marot dir., 2007). Mais, quoi qu'il en soit, il s'agit selon toute apparence d'incendies accidentels, évidemment sans relation, ni chronologique ni causale, avec d'hypothétiques événements guerriers ou quelconques raids « barbares » de la seconde moitié du III ${ }^{\mathrm{e}}$ s. évoqués par l'historiographie ancienne (Germer-Durand, 1888 ; Portal, 1890, p. 16-26 ; Dalle J.-A., 1968, p. 20-21).

\section{De la rétractation à la désaffection du chef-lieu : III $^{\mathrm{e}}-$ VII $^{\mathrm{e}} \mathrm{s}$.}

Quelles qu'en soient les causes, la ville ne se relève en tout cas pas vraiment de cette destruction partielle mais massive par incendies, apparemment synchrones, et qui n'est sans doute qu'un épisode fortuit dans ce processus, même si ses conséquences s'ajoutent évidemment de manière prégnante à la tendance alors amorcée : cette récession est sans retour et la ville ne fait ensuite que décliner et s'amoindrir, en surface, en équipements, comme en statut ; même s'il est possible que, de-ci de-là, l'érosion postérieure ait préférentiellement fait disparaître des aménagements et reconstructions plus tardives, dans ce cas sans doute fugaces et marginales.

On a notamment pu dater de la fin du III $^{\mathrm{e}}$ s. la destruction de l'édifice de spectacle (JBN.99) ou, en tout cas, sa désaffection comme tel, car peut-être a-t-il alors été réutilisé dans une autre fonction de caractère public, comme l'indiquerait le « milliaire »-dédicace de Postume (264-266 apr. J.-C.) découvert très vraisemblablement dans son arène. Et c'est sans doute également à la fin de ce siècle qu'est abandonnée la «basilique »(Pierobon, 1999, p. 3-4).

À peu près au moment où les Gabales font ainsi allégeance à Postume ${ }^{17}$, c'est sans doute alors, comme ailleurs pour la majorité des capitales de cité, que Javols perd son

17. Comme par exemple les Vellaves ou les Arvernes envers Tétricus (Rémy, 1995, p. 132, n 65 et 1996, p. 175, n 103). nom d'Anderitum pour celui d'ad Gabalos, qui lui conférera sa dénomination actuelle : ceci est d'ailleurs la preuve, comme on l'a dit, que cette ville reste encore, au moins jusque dans la première moitié $\mathrm{du} \mathrm{IV}^{\mathrm{e}} \mathrm{s}$., la capitale de la civitas des Gabales.

Ainsi, même si en rétraction, la ville poursuit son évolution : on y habite, on y construit, on y travaille bien encore durant le Bas-Empire. Une occupation aux $\mathrm{IV}^{\mathrm{e}}-\mathrm{V}^{\mathrm{e}} \mathrm{s}$. avait déjà été reconnue par les fouilles plus anciennes, notamment grâce à la présence de céramique tardive telles que les Dérivées-de-Sigillées Paléochrétiennes, la sigillée ou les lampes africaines, certaines amphores, ou encore de monnaies ou de verre... : dans les fouilles Peyre dans le centre du site ou au terrain de camping (Peyre, 1969a, p. $6 ; 1969$ b, p. 53 et p. $58 ; 1970$ a, p. 9 et p. $16 ; 1970$ b, p. 35 et p. 37 ; 1971a, p. 50 ; 1971b, p. 18 ; 1973, p. 12 ; 1974 ; $1975 \mathrm{a}$ et b ; 1976b et c ; $1977 ; 1978 \mathrm{~b}$; Calzone et al., 2001, p. 10, p. 12 et p. 27), ainsi que dans les fouilles Pierobon dans cette partie centrale du site (Pierobon, 1989b, p. 8-9 ; Pierobon-Benoît, 1993b, p. 39 ; Pierobon-Benoît et al., 1994, p. 238 et p. 244 ; Calzone et al., 1997, p. 77-78 ; Storti, 1998, p. 64 et p. 66).

De nos sondages, on retiendra en premier lieu que le decumanus nord (JPN.00) est encore entretenu au $\mathrm{V}^{\mathrm{e}}$ s., comme sans doute le cardo est (JTD.04), dans la mesure où l'entrée monumentale, reconnue ici, subsiste encore sous cette forme alors ostentatoire. Par ailleurs, en JLD.00 et JTM.00/01, du mobilier des $\mathrm{IV}^{\mathrm{e}}-\mathrm{V}^{\mathrm{e}}$ s. a été mis au jour dans des colluvions venant dans un cas de la colline du "Mas Astruc» au nord du site - les sondages conduits sur cette colline même (JMA.02) n'ayant cependant rien révélé pour cette période -, dans l'autre de la hauteur séparant le vallon du Triboulin de celui de son affluent d'Arbouroux, au sud du site. Enfin, un remblai à l'arrière de l'édifice de spectacle peut être attribué au IV ${ }^{\mathrm{e}}$ s., alors qu'en JPN.05/08 un bâtiment est construit aux III ${ }^{\mathrm{e}}-\mathrm{IV}^{\mathrm{e}}$ s. et que les " terres noires » (voir infra, p. 186-187) commencent sans doute à se déposer au $\mathrm{IV}^{\mathrm{e}} \mathrm{s}$.

Le monnayage de cette période est de fait abondant sur le site, mais ce sont surtout les petites monnaies de Tétricus et imitations de la fin du $\mathrm{III}^{\mathrm{e}}$ s. qui - on le sait continuent à circuler dans le premier quart du IV ${ }^{\mathrm{e}} \mathrm{s}$. ; les émissions $d u \mathrm{IV}^{\mathrm{e}} \mathrm{s}$. sont plus rares mais présentes, tant dans les fouilles anciennes que dans nos sondages ${ }^{18}$, les trois plus

18. Depuis 1996, les monnaies issues de nos fouilles ont été identifiées au Cabinet des Médailles, essentiellement par M. Amandry ; il en est de même (déc. 2007) des monnaies des fouilles Pierobon ; qu'il en soit ici remercié. 
récentes de Magnus Maximus et Théodose (383-387) et de Constantin III (408-409) ayant toutes été trouvées dans le centre du site.

\section{Le village de Javols, du $\mathrm{VI}^{\mathrm{e}} \mathrm{s}$. à nos jours}

À partir du $\mathrm{V}^{\mathrm{e}}$ s., la ville s'efface et disparaît et Javols ne subsiste ensuite que sous la forme d'un village rural (fig. 5).

\section{Le très haut Moyen Âge}

En l'absence de tout monnayage et les éléments céramiques datables étant rares pour cette période, le très haut Moyen Âge (VI ${ }^{\mathrm{e}}-\mathrm{VII}^{\mathrm{e}}$ s.) est difficilement identifiable ici mais a cependant été reconnu en plusieurs points de nos sondages : JSE.98, JSF.99, JPN.00, JPN.02 et JPN.05/07 (murets de pierre sèche, sans doute de clôture, et terres noires), JBN.99, JLD.00, JQR.97, JTD.04. De même, des éléments au moins du $\mathrm{VI}^{\mathrm{e}}$ s. sont signalés dans les fouilles Peyre et Pierobon (Pierobon, 1992, p. 6 ; Pierobon-Benoît, 1993a et 1993b, p. 36 et fig. 37 ; Pierobon-Benoît et al., 1994, p. 238 ; Calzone et al., 1997, p. 74, p. 76 et p. 78 ; 2001, p. 20, p. 21 et p. 34). Ainsi, la localisation à Javols du premier atelier monétaire mérovingien (antérieur à celui de Banassac), du début du VII ${ }^{\mathrm{e}}$ s., reste hypothétique (Lafaurie, 1973).

Les seuls éléments non mobiliers assurés alors sont d'une part la nécropole de la fin du $\mathrm{IV}^{\mathrm{e}}$-milieu du VI ${ }^{\mathrm{e}} \mathrm{s}$. (ou $\mathrm{VII}^{\mathrm{e}}$ s. ?) mise au jour en JEF.98 et récemment datée par ${ }^{14} \mathrm{C}$, d'autre part le petit groupe de sépultures découvert à l'emplacement de l'ancienne église (JAE.96) : trois de ces dernières inhumations ont été datées par ${ }^{14} \mathrm{C}$ (Ferdière dir., 1997, p. 7 et ann. 30), l'une (maçonnée) du VII ${ }^{\mathrm{e}}$ s., les deux autres des VIII ${ }^{\mathrm{e}}-\mathrm{IX}^{\mathrm{e}} \mathrm{s}$. Elles sont associées à deux murs d'un édifice qui pourrait être, sans aucune certitude, l'église primitive de Javols (Ferdière, 2000a). S'y ajoutent des sarcophages («tombes»), sans doute du haut Moyen Âge, signalés au pont et à l'ancien cimetière (Moré, 1858a, p. 108).

Se pose ici en effet pour cette période la question de la genèse de l'Église gabale et celle du transfert (ou non) du siège épiscopal et donc du lieu de pouvoir à Mende (Ferdière dir., 1998 et 2000a ; Ferdière, Prévot, 1998 ; voir Ferdière, Ode, 2004) : d'un côté on a vu plus haut que Javols est apparemment toujours chef-lieu de cité dans la première moitié du $\mathrm{IV}^{\mathrm{e}} \mathrm{s}$., de l'autre, ce n'est qu'au VIII ${ }^{\mathrm{e}} \mathrm{s}$. que la localisation du siège épiscopal à Mende est assurée (Prévot, 1989). Pourtant, la communauté chrétienne des Gabales est représentée par un diacre au concile d'Arles

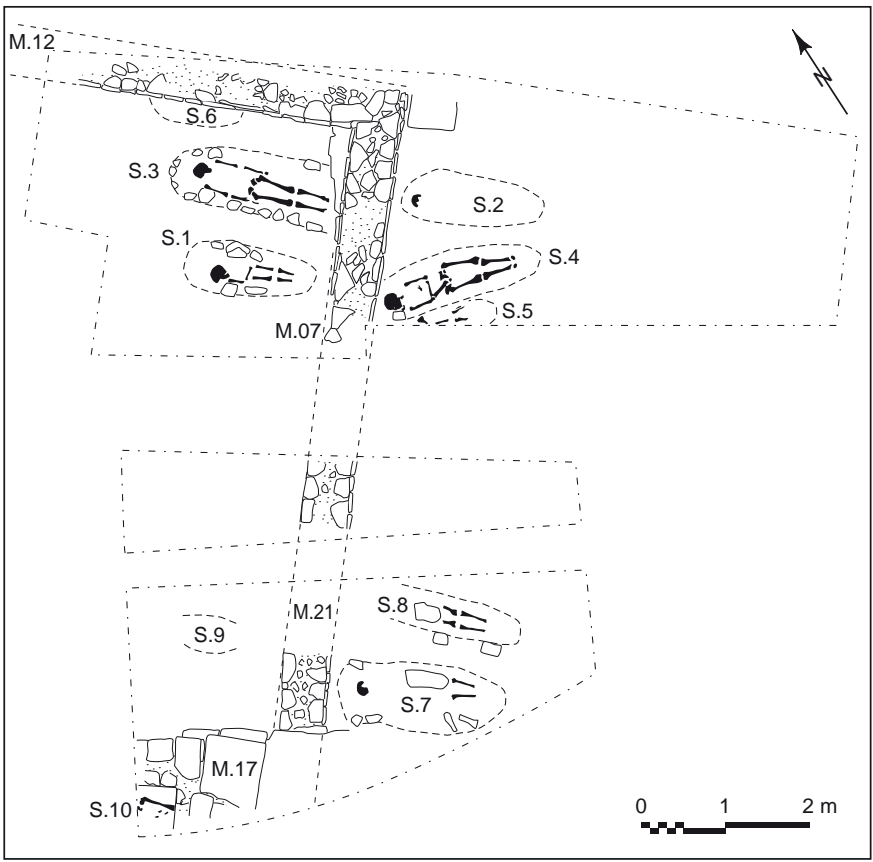

Fig. 7 - Plan de l'église primitive (?) et des sépultures en JAE.96 (DAO : PCR Javols/Anderitum).

en $314^{19}$ (Actes des Conciles, conc. Arelatense, a. 314 : 15/47, $15 / 39,18 / 34,20 / 36,21 / 34)$ : sa première église et le siège épiscopal correspondant doivent assurément être localisés dans la capitale de cité, qui est donc alors encore Javols, et l'édifice mis au jour en JAE.96 pourrait donc éventuellement correspondre à cette église primitive (fig. 7).

À cette première église pourrait peut-être être attribuée la table d'autel paléochrétienne inscrite (PEREGRINUS FECIT), découverte sur la rive opposée, devant l'édifice de spectacle (CIL, XIII, 1560 ; Ignon, 1840-1841, p. 165 ; Moré, 1858a, p. 104 ; Visite..., 1959 ; voir Buffière, 1985, p. 124). Et il faut encore mentionner la tradition hagiographique de saint Louvent, martyr du VI ${ }^{\mathrm{e}}$ s. qui serait originaire de Javols (Darnas, Duthu, 2002, p. 95), mais en fait le texte original mentionne seulement la «ville gabale » qui pourrait être déjà alors Mende (Grégoire de Tours, H. F., VI, 37).

Il est enfin nécessaire d'aborder ici le délicat problème des « terres noires », phénomène reconnu sur la plupart des villes d'Europe occidentale pour l'Antiquité tardive et le haut Moyen Âge (Galinié, 2000 et 2004 ; pour Javols, voir Fondrillon, 2007, p. 466-474), et qui ont été observées à Javols dans pratiquement tous nos sondages de la partie basse du vallon (JPN.00, JPN.02, JPN.04, JPB.02, JTD.04...) :

19. Il est remarquable que la cité gabale soit la seule de toute la province d'Aquitaine, à l'exception des Élusates (Éauze), à être représentée à ce concile précoce. 
leur étude fine a été réalisée en 2005-2006 (JPN.05/07). Il semble, en l'état des connaissances ici, s'agir d'abord de dépotoirs liés à un habitat proche (vraisemblablement du $\mathrm{IV}^{\mathrm{e}} \mathrm{s}$.), puis de remblais (dépotoirs secondaires), surtout composés de destruction et sans doute destinés à une mise en culture, ainsi que de possibles couches d'inondations ; l'essentiel de ces dépôts, de couleur grise, où la lecture stratigraphique est souvent impossible, sont stratifiés, comme l'indique l'intercalation de murs comme d'autres structures (sols, trous de poteau, voire maçonneries, interprétés comme murs de pierre sèche de clôture/terrasse), en JPN.00, JPN.02, JPN.04 et JPN.05/06, JTD.04 ; ils se sont apparemment constitués entre la toute fin du $\mathrm{IV}^{\mathrm{e}} \mathrm{s}$. et le $\mathrm{VII}^{\mathrm{e}} \mathrm{s}$. inclus : ces éléments semblent donc correspondre à une ruralisation certaine du site.

\section{Javols du VIII s. au XV $V^{e}$.}

$\mathrm{Au}$ plan strictement archéologique, aucun de nos sondages ni d'ailleurs aucune des fouilles antérieures n'a livré de structures ou mobiliers attribuables au reste du Moyen Âge, si ce n'est JAE.96, à l'emplacement de l'ancienne église, au centre même du bourg actuel.

Les indications ici concernées pour cette période correspondent donc exclusivement à des documents textuels, les plus nombreux pour le XIII ${ }^{\mathrm{e}}$ s. ${ }^{20}$ :

- à la période carolingienne, Javols est seulement mentionné, sous la forme Gabalis ou Gavalis (Longnon, 1878, p. 181 et 1887, p. 63 ; Grimaud, Balmelle, 1925, p. 72, n. 1), et n'apparaît pas dans les vigueries attestées en Gévaudan au haut Moyen Âge (André, 1886) ;

- pour le XII ${ }^{\mathrm{e}}$ s., l'église et la viguerie de Javols sont mentionnées en 1109 (ligne 26 : Brunel 1916, p. 16 ; Grimaud, Balmelle, 1925, p. 72, n. 1 ; voir Dufort, 1966, p. 223 ; Trémollet de Villers, 1998), avec le «mas » des Combettes (maso in Cumbetas) (ligne 9 : Brunel, 1916, p. 15) ; en 1123, « Gavols » est cité (Remize, 1921, p. 177 ; Dufort, 1966, p. 223) ;

- au XIII ${ }^{\mathrm{e}}$ s., Javols apparaît rattaché au «Territoire de Peyre » (Prunières, 1866 ; André, 1885, p. 398 ; voir Portal, 1890, p. 56 sq. ; Boullier de Branche, 1938b, p. 221-224 ; arch. départ. de Lozère, cote G.1298) ; en 1244, un arrière-fief est cité pour « le Régimbal »- alors nommé Mas dels Gilbarts (Portal, 1890, p. 44 et p. 56 sq. ; arch. départ. de Lozère, cote G.576) ; en 1261, les habitants de treize paroisses de la seigneurie de Peyre sont affranchis, dont celle de

20. On n'a toutefois pas inclus dans notre programme d'évaluation une recherche systématique en archives pour cette période et pour les Temps modernes.
Javols (Bulletin de la Société des lettres, sciences et arts de Lozère, 1869, p. 86 ; Portal, 1890, p. 56 sq. ; Grimaud, Balmelle, 1925 , p. 72, n. 1 ; Boullier de Branche, 1938b, p. 221-224; Chazottes, s. d., p. 8 ; arch. départ. de Lozère, cote G.104) et des fours et moulins sont alors mentionnés ici (Prunières, 1866, p. 234 sq.). ; à cette même date apparaît la dédicace de l'église de Javols à saint Gervais (Boullier de Branche, 1938b, p. 223) ; en 1255 puis 1276 sont aussi cités, pour la paroisse de Javols - outre la «villa de Javolis »-, le « mansum de Monteto " (mas du Montet), le «manso de Ermet» (mas de l'Hermet), le mas d'Oliviers (?), ainsi que « Crozeo Brunello » (le Cros ?) (Portal, 1890, p. 59 ; Boullier de Branche, 1938b, p. 160 ; Dufort, 1966, p. 223 : arch. départ. de Lozère, cote G.462) ; le domaine du Bois du Mont (nemus ou bosco Mundi, « en la paroisse de Gaboul ») est alors mentionné (1276) (nemore del Mont), plus tard comme fief (Prunières, 1866, p. 188 sq. ; Portal, 1890, p. 45 et p. 47 ; Boullier de Branche, 1938b, p. 160 ; Chazottes, s. d., p. 8 sq.) ; en 1270, c'est «Guavols» qui est cité dans la lutte qui oppose l'évêque au pouvoir royal à propos des seigneuries d'Apcher et de Peyre (Porée, 1919, p. 439 ; Dufort, 1966, p. 223 ; arch. départ. de Lozère, cote G.735) ; Tiracols, hameau au nord-ouest du site, est quant à lui mentionné dès 1275 comme fief de la seigneurie de Lestival (paroisse de Fontans) (Prunières, 1866, p. 205-206) ; en 1292, Javols apparaît malgré tout à la tête d'un des quatre archiprêtrés qui subdivisent l'évêché de Mende (André, 1885, p. 401 ; Portal, 1890, p. 62 ; Boullier de Branche, 1938b, p. 226-227), circonscription comportant alors 57 paroisses ; en 1293 enfin, le prêtre de la paroisse a titre de recteur, sécularisé à Javols et alors qualifié de prieur (Portal, 1890, p. 63 : acte mentionnant "Cougoussac », « le Prat Veyral » et la maison du prieur - prieuré - proche de l'église) ;

- au XIV ${ }^{\mathrm{e}}$ s., l'enquête des Feuda Gaballorum (archives départ. de Lozère, cote G.757 ; Boullier de Branche, 1938a, p. 103 et 1938b, p. 160 ; voir Grimaud, Balmelle, 1925, p. 72, n. 1) nous apprend, pour 1307, que le domaine épiscopal de Mende comporte des terres à Javols : villa de Javolis, terres du Chaylaret (Portal, 1890, p. 44) et d'Orbagnac..., et mentionne aussi le Bois du Mont ; en 1352 (Font-Réaulx, 1961-1962, p. 537-538 ; Dufort, 1966, p. 223 ; arch. départ. de Lozère, cote G.34, fol. $8 \mathrm{v}^{\circ}-9$ ) et 1383 (Javolis : FontRéaulx, 1961-1962, p. 546-548 ; Dufort, 1966, p. 223 ; arch. vaticanes, Collectorie, vol. 85 , fol. 284, v-288), Javols reste à la tête d'un des archiprêtrés du diocèse de Mende ; Tiracols passe en 1375 à la seigneurie de Clauze (près de Saugues ?) (Portal, 1890, p. 60);

- on n'a pas relevé de mention pour le $\mathrm{XV}^{\mathrm{e}} \mathrm{s}$. 
La paroisse de Javols conserve donc au Moyen Âge un rang honorable, même si elle a largement perdu son statut de tête de réseau.

Quant à l'église ancienne (détruite pour être remplacée par l'actuelle en 1895), elle est très mal documentée et son plan n'est, schématiquement, connu que par le cadastre «napoléonien »: attestée en 1109, elle devait être de style roman, même si l'on en conserve des éléments architecturaux de facture gothique (Peytavin, 1996 ; Noël, 2002, p. 117, $\mathrm{n}^{\circ} 98.118$ et p. $\left.145, \mathrm{n}^{\circ} 00.192\right)$; elle fut, avant d'être définitivement détruite, maintes fois réparée, notamment à cause des désordres occasionnés par sa proximité avec la rivière.

C'est de nos sondages à cet emplacement (JAE.96) que proviennent donc l'essentiel des éléments médiévaux archéologiquement attestés, auxquels on ajoutera quelques monnaies aux alentours, signalées au XIX ${ }^{\mathrm{e}}$ s., notamment dans les fouilles des thermes occidentaux (Moré, 1858b, p. 213 et 1859, p. 53).

\section{Javols aux Temps modernes et jusqu'au $\mathrm{XXI} \boldsymbol{e}^{e} s$.}

Les références d'archives notées ici pour les périodes plus récentes de l'histoire de Javols sont loin d'être exhaustives :

- pour le XVI ${ }^{\mathrm{e}}$ s., en 1528 , ce sont 58 paroisses qui sont mentionnées pour cet archiprêtré du diocèse de Mende (Bernard, 1982, p. 27 ; arch. départ. Lozère, cote G.35), de nouveau cité dans une liste de bénéfices du diocèse, en 1546 (Font-Réaulx, 1961-1962, p. CLXI) ; en 1574, on mentionne «Javoulz » au sujet d'une rencontre entre catholiques et protestants (Documents..., 1886, p. 210 ; Dufort, 1966, p. 223) ;

- pour le XVII ${ }^{\mathrm{e}}$ s., un terrier est établi pour Javols en 1619 (Portal, 1890, p. 39) ; le «prieuré Saint-Gervais-etProtais de Javols » (titulature actuelle de l'église) n'est en fait mentionné qu'au début de ce siècle (Font-Réaulx, 19611962, p. 557-560 : B.N., coll. Moreau, vol. 787, fol. 228-245 ; arch. départ. de Lozère, cote G.2086 [copies]) ; Javols est désigné en effet avant la Révolution comme prieuré, dont plusieurs titulaires sont connus aux XVII ${ }^{\mathrm{e}}$ s. et $\mathrm{XVIII}^{\mathrm{e}} \mathrm{s}$. (Foulquier, 1913, p. 303-306) ; une communauté protestante est en outre attestée alors (Portal, 1890, p. 100-107 ; Buffière, 1985, p. 267), peut-être même dès la fin du XVI ${ }^{\mathrm{e}} \mathrm{s}$. (réf. précédente) ;

- ce n'est enfin qu'au milieu du XVIII ${ }^{\mathrm{e}}$ s. qu'apparaît le château du Barri, anciennement «Mas de la Conche " (Portal, 1890, p. 43 ; Buffière, 1985, p. 266).

Ce plan terrier confronté aux plans cadastraux «napoléonien » et actuel révèle l'une des plus vastes communes du département, avec aujourd'hui 3121 ha. Quant à la popu- lation, qu'on ne peut évidemment évaluer pour l'Antiquité, elle n'a cessé, globalement, de décroître depuis la première recension connue en 1364 (29 feux) jusqu'à nos jours (276 habitants au recensement de 1999), en passant par exemple par les 852 habitants du début du XVIII ${ }^{\mathrm{e}}$ s. ou les 1103 en 1900 (Vidimus..., 1863, p. 111 ; voir Portal, 1890, p. 24 et p. 128 ; Buffière, 1985, p. 257 et p. 266 ; Cord, Cord, 1900, p. 192 ; Pierobon-Benoît, 1993b, p. 4).

$\mathrm{Au}$ plan archéologique, seuls quelques-uns de nos sondages ont livré des structures (murs...) attribuables à la période moderne (voire à la fin du Moyen Âge), correspondant pour l'essentiel à des éléments de clôture : JSE.96 (S.5), JPN.00, JPB.02, JTM.01, JBN.01, JPO.01 (S.48 : captage de source), JQR.97 et JQR.01 (aménagement de berge). Mais des paléochenaux du Triboulin ou des ravines récents (modernes) ont aussi été mis au jour ça et là : JQR.97/01, JTS.98, JTE.99, JTC.01, JPB.02 ${ }^{21}$. Doivent enfin être évoqués des aménagements agraires apparemment attribuables à la période moderne dans tout l'environnement de Javols, sous forme de "banquettes de cultures" (rideaux) : des tessons modernes ont notamment été mis au jour dans des coupes pratiquées en JMP.00 et JPO.01. Il en est de même dans les régions voisines de Corrèze ou de Margeride (Valadas, 1987, p. 92-94 ; Bernard-Allée, Valadas, 1993, p. 10-13 ; Étienne, 1996).

Et enfin doit être mentionnée pour ces périodes récentes de l'histoire du site la question de la récupération, de l'utilisation des ruines du site antique comme carrière, phénomène qui a d'ailleurs dû toucher Javols bien avant les Temps modernes, sans doute dès l'Antiquité tardive : c'est d'ailleurs à l'occasion de la recherche de pierres pour la réfection de l'église que fut découvert le « milliaire » de Postume au début du XIX ${ }^{\mathrm{e}}$ s. Ceci a bien sûr dû concerner prioritairement les pierres exogènes (calcaire), en particulier pour la production de chaux, précieuse dans ce pays granitique.

\section{UNE DIMENSION ENVIRONNEMENTALE}

Inscrite dès son origine dans le programme de recherche, cette dimension a principalement été traitée ici par P. Poupet et R. Harfouche-Poupet, associés au programme jusqu'en $2005^{22}$. L'essentiel de ces données ayant fait l'objet d'une

21. Datations ${ }^{14} \mathrm{C}$ pour JPO.01 (captage : milieu du XVIII ${ }^{\mathrm{e}}$ s.), JQR.01 et JTC.01 (bois gorgés d'eau dans des paléochenaux : XI ${ }^{\mathrm{e}}-\mathrm{XIII}^{\mathrm{e}} \mathrm{s}$. et $\mathrm{XV}^{\mathrm{e}}$-XVII ${ }^{\mathrm{e}}$ s.)

22. Voir leurs contributions aux différents rapports ; un mémoire de Maîtrise d'archéologie a aussi porté sur ces questions : Goumy, 2001. 
publication récente (Ferdière, Poupet, 2005 ; voir aussi Poupet et al., 2006), ceci nous dispense ici de trop longs développements. Trois volets ont été traités.

\section{ÉROSION ET COLLUVIONNEMENT}

L'érosion des bords de plateau et des pentes entourant la cuvette de Javols a été intense et a sans doute quasi totalement éradiqué les traces d'occupation, notamment préromaine, comme pour la colline ouest. Les apports de colluvions (arène granitique) issues de cette érosion sur les bas de pente sont considérables et atteignent parfois plusieurs mètres.

Plusieurs observations faites au cours de nos sondages permettent d'envisager que l'une des phases les plus intenses de cette érosion est à situer dans l'Antiquité tardive et au début du Moyen Âge : plus que la traduction ici d'une phase de dégradation climatique observée ailleurs (Sud-Est, Auvergne...) pour cette période (Berger, 2001 ; Magny, 2001 ; Leveau et al., 2002 ; Trément et al., 2002 ; Durand, Leveau, 2004), on y voit l'effet d'une déprise sur le milieu environnant la ville, les terrasses agricoles comme les drainages n'étant sans doute plus alors entretenus, pour des versants déjà largement dénudés. Une seconde phase érosive semble prendre en outre place aux Temps modernes.

\section{L'ÉVOLUTION DE LA RIVIÈRE}

Nos observations démontrent qu'à la fondation de la ville sous Auguste, puis avant le milieu du I ${ }^{\mathrm{er}}$ s. apr. J.-C., des travaux considérables ont été entrepris pour assainir la partie centrale et basse du site, par l'apport massif de remblais et surtout par l'établissement des aménagements de berge (voir infra, p. 193-195) contraignant le Triboulin sur le côté oriental de son lit majeur.

Le cours même de la rivière a ainsi été en quelque sorte canalisé dans sa traversée du site urbanisé, mais la nature, ici aussi, a assez rapidement repris ses droits quand s'est affaiblie l'emprise anthropique, comme l'attestent notamment les paléochenaux de divagation du Triboulin reconnus en maints endroits pour les périodes postromaines.

Ainsi, également, le niveau de l'eau a considérablement monté, sans doute d'au moins $2 \mathrm{~m}$ depuis l'Antiquité ; cet ennoiement du site, constaté dans toutes les fouilles anciennes ou récentes dans la partie basse du vallon, est apparemment, ici aussi, à la fois la cause et la conséquence de la déprise et de la régression progressive de la ville à partir du III ${ }^{\mathrm{e}}$ s. (voir supra, p. 185).

\section{L'ENVIRONNEMENT VÉGÉTAL DU SITE}

Un certain nombre d'analyses palynologiques (Richard, 2002 ; Latour-Argant, Argant, 2005), carpologiques (Marinval, 2002 ; Matterne, 2003), dendro-xylologiques (Girardclos, 2006) et anthracologiques (Fabre, 2006 ; Belingard, 2007) ont été effectuées depuis le début de notre programme, mais demandent à être développées.

Ces analyses révèlent, dès la période préromaine, un paysage déjà largement déboisé sur la chênaie mixte, avec la présence de prairies humides. Alentours, des cultures de céréales (blés et orge), légumineuses et fourragères sont attestées, notamment dans les dépôts funéraires incinérés, ainsi que par exemple dans les couches d'utilisation de la cuisine de la domus de JPN.02, avec en particulier une présence notable d'avoine cultivée. L'environnement boisé révélé par les bois gorgés d'eau de JTS.98 montre une domination du Hêtre, du Sapin et du Pin sylvestre pour les bois travaillés, avec une présence notable ici de Vigne cultivée, alors que les charbons de bois indiquent des éléments de charpente en chêne à feuilles caduques, Frêne et Orme, mais aussi de Chêne vert, de Pin sylvestre et de Hêtre, selon les besoins techniques, avec diverses autres espèces minoritaires et divers arbustes, en particulier en bois de feu.

\section{UNE VILLE DE GAULE INTÉRIEURE DANS SA COMPLEXITÉ}

\section{URBANISME ET VOIRIE À ANDERITUM}

La ville s'étend donc, selon les éléments fournis par notre évaluation, dans sa période la plus florissante, sur une surface d'une quarantaine d'hectares (voir supra, p. 182) ${ }^{23}$, dans le vallon du Triboulin, au confluent avec son petit tributaire d'Arbouroux, et environ jusqu'à mi-hauteur des collines qui l'enserrent à l'est et à l'ouest (fig. 4) : ceci placerait le chef-lieu gabale parmi les «villes moyennes » des Gaules (Bedon, 1999, p. 277-278), notamment entre ses voisines Saint-Paulien/Ruessio pour les Vellaves (estimée à environ 30 ha) (Bedon, 2001, p. 287) et Rodez/Segodunum pour les Rutènes (environ 44 ha) (Dausse, Schaad, à paraître), et par exemple assez proche de Tours/Caesarodunum (40-60 ha) (Galinié, 2007, p. 17), pour autant que ces estimations aient

23. C'est d'ailleurs l'estimation donnée par R. Pierobon, entre autres (Pierobon, 1991b ; Pierobon-Benoît, 1993a ; voir Massy et al., 1992, p. 157), et déjà auparavant par J.-A. Dalle (1968, p. 18-19) ainsi que R. Dalle (1977, p. 360). 
quelque valeur, car les critères de calcul s'avèrent souvent fort différents d'une ville à l'autre.

Au sud du site, la confluence avec l'Arbouroux est suivie, un peu plus au nord, par la butte du Barri, sorte de promontoire venant des collines orientales et qui barre ici le vallon. Mais l'urbanisme s'étend donc sensiblement au sud et au sud-ouest de cette butte. Toutefois, la partie plane et relativement vaste du vallon concerne moins de 10 ha qui seront utilisés pour l'urbanisme régulier de la ville et son centre civique (voir infra, p. 197-199). Il faut enfin retenir qu'il s'agit d'une agglomération de moyenne montagne, située entre les altitudes NGF $972 \mathrm{~m}$ au fond du vallon et $1000 \mathrm{~m}$ et plus pour ses deux nécropoles.

De fait, ce n'est qu'une surface de quelque 5,7 ha qui a subi une urbanisation sur un plan de voirie régulier, dans cette partie basse, plane et centrale du site, et sur la seule rive gauche du Triboulin. Ailleurs, sur l'autre rive et les pentes des collines, tant au sud qu'à l'est et à l'ouest, les orientations reconnues du bâti divergent pour s'adapter au terrain, comme il est d'ailleurs courant dans la majorité des villes de Gaule romaine, et les constructions s'étagent en terrasses.

Il faut en outre souligner d'emblée le rôle majeur que joue dans l'urbanisme de Javols et sa genèse les aménagements de berge du Triboulin, qui marqueront le site de manière prégnante et pérenne.

\section{LA VOIRIE URBAINE ORTHONORMÉE ET LES AUTRES RUES}

D'une part, les portions de rues reconnues et, d'autre part, les emplacements et orientations des constructions mises au jour dans cette partie basse du vallon, rive gauche, permettent de proposer un plan de voirie orthogonal constitué de trois rues nord-sud (cardines C1 à C3, numérotés d'ouest en est, dont les deux derniers sont archéologiquement bien attestés), et six rues est-ouest (decumani D1 à D6, numérotés du nord au sud, dont deux sont bien attestés : D1 et D3 ; voir à ce sujet : Trintignac et al., 2008) (fig. 4). On ne s'aventurera pas à proposer un decumanus maximus et un cardo maximus, dont l'existence réelle dans une telle ville n'est d'ailleurs pas certaine. L'orientation générale de ce réseau est d'environ 20-21ํ ouest (Nord Lambert).

Curieusement, les premières données sur cette voirie urbaine ne sont apparues qu'avec les fouilles relativement récentes de l'abbé Peyre (cardo C2 et decumanus D3). On les décrira dans l'ordre de notre numérotation, en commençant par les decumani.

\section{Decumani}

- D1 est conjectural : en effet, il peut prendre place entre D2 et l'étranglement nord du vallon qui interdit l'extension septentrionale de ce réseau, dans le prolongement de la «déviation " de la voie vers Rodez, destinée aux chariots, par le vallon du Cros (voir supra, p. 179) ; faut-il imaginer un passage de la rivière à son extrémité est ? Ce decumanus marquerait sans doute, en tout cas, l'extrémité nord des trois cardines.

- D2 a été identifié dans le sondage JPN.00 sur une partie de sa largeur ( $4 \mathrm{~m}$, trottoir-portique inclus) et une longueur est-ouest de seulement $5 \mathrm{~m}$, avec une faible portion de son trottoir-portique (?) nord. Cinq états de la rue ont été reconnus, recharges en partie constituées de scories de réduction et surtout de forge : le plus ancien du $\mathrm{I}^{\mathrm{er}} \mathrm{s}$. apr. J.-C., le plus récent sans doute du début du V $\mathrm{e}^{\mathrm{e}} \mathrm{s}$. Si l'on restitue ici, à son extrémité est, un passage du Triboulin, c'est cette rue qui peut être reliée à la «déviation » de la voie vers Lyon, et non D1. D2 croiserait C2 juste à l'ouest de JPN.00, C3 juste au sud de JPB.02 et au nord du JPN.04, et son extrémité ouest serait sur C1.

- D3 est conjectural mais pourrait prendre sa place entre D2 et D4 - quant à eux attestés -, soit (d'axe à axe) à environ $61 \mathrm{~m}$ de $\mathrm{D} 2$ et $70 \mathrm{~m}$ de $\mathrm{D} 4{ }^{24}$, définissant ainsi des îlots de dimensions comparables aux autres reconnus ici ; il laisserait la place, au sud de la domus fouillée de JPN.05/08, à une autre domus à son contact au nord. Il s'étendrait de C1, à l'est, au Triboulin, à l'ouest.

- D4 est quant à lui bien attesté par les fouilles Peyre, et vérifié par nos sondages JLP.03 (fig. 8). Il a été reconnu sur une longueur d'environ $45 \mathrm{~m}$ et une largeur de plus de $16 \mathrm{~m}$ au total ; il comporte un probable trottoir-portique sur son côté nord et un égout en dalles de schiste sur son côté sud (interprété comme " trottoir " par l'abbé Peyre, 1969b, p. 50). Il présente en outre, dans cette portion, une vaste excavation centrale, allongée dans son axe (largeur : $4 \mathrm{~m}$ à l'ouverture ; profondeur : environ 0,80 m), qui, selon les observations effectuées en 2003 (Trintignac et al., 2008), pourrait correspondre à une sorte de « chenal » d'évacuation des eaux de précipitations orageuses, ici dans le sens de la pente (" portandeau »), aménagement sans doute tardif $\left(I^{\mathrm{e}} \mathrm{s}\right.$. ?) de cette rue. En l'état des fouilles, cette dernière paraît buter à l'est sur les constructions antérieures à la «basilique » (fouilles Pierobon), mais il n'est pas exclu

24. Ce calage nord-sud n'est qu'hypothétique, en fonction d'un espace constaté sur un plan de fouille du XIX ${ }^{\mathrm{e}} \mathrm{s}$. pour des bâtiments longeant le cardo C3 (voir infra, p. 193). 


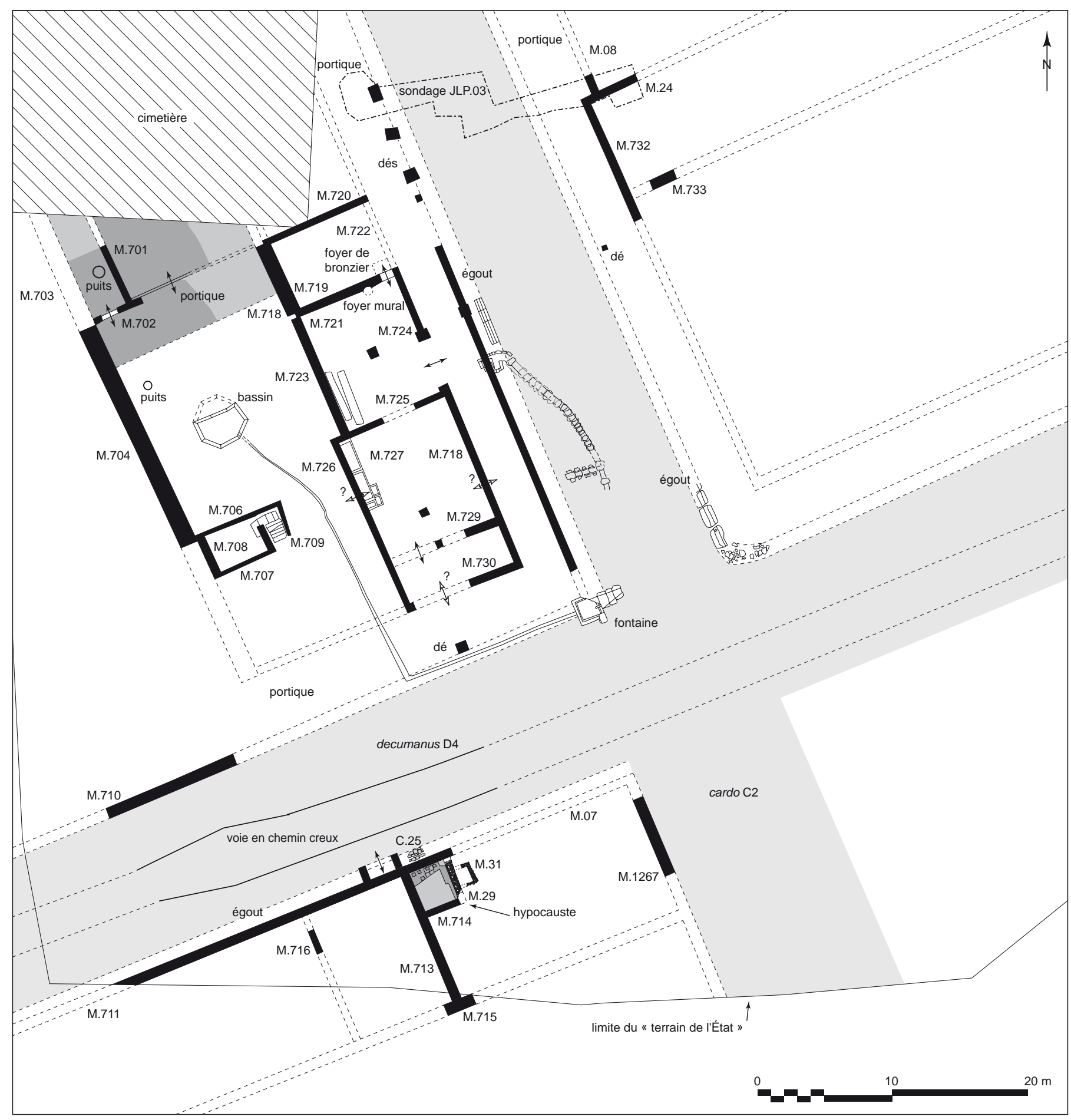

Fig. 8 - Plan des fouilles Peyre au sud du cimetière ("terrain de l'État "), selon le recalage effectué à l'occasion des sondages de vérification en JLP.03. Les sondages multiples de vérification réalisés en 1999 et 2003 n'ont pas été représentés, à l'exception de celui réalisé en travers du cardo C2, au nord de la zone de fouille Peyre, qui a permis d'en réaliser la coupe (DAO : PCR Javols/Anderitum). 
que son établissement soit postérieur à cet état précoce des bâtiments et que cette rue ait alors été poursuivie ici sur la destruction de ceux-ci, avant d'être totalement éradiquée par l'érosion, particulièrement forte sur cette pente ${ }^{25}$. Partant sans doute de C1, son prolongement au-delà de C2 puis de C3, et jusqu'à la rivière, reste toutefois hypothétique. Pour sa partie occidentale attestée, cette rue sépare la domus fouillée par l'abbé Peyre (voir infra, p. 204), au nord, d'une autre probable domus, avec salle chauffée, au sud (JLP.03).

- D5 est, comme D1 et D3, une restitution conjecturale, établissant des îlots de dimensions certes plus réduites. Dans cette hypothèse, ce decumanus s'interromprait, comme il est courant, au niveau du forum, que l'on place ici entre C2 et C3 (voir infra, p. 197). Sa portion ouest borderait au nord les « thermes occidentaux » et sa portion est pourrait être au nord des « thermes orientaux » (voir infra, p. 201), cette dernière butant sur le bâtiment des fouilles Morel, d'axe différent (Morel, 1962, plan ; si celui-ci est correctement situé, ce qui n'est pas certain) ; son extrémité ouest serait sur C1.

- D6, enfin, est aussi conjectural, mais est restitué par la prise en compte du passage obligé de la voie Lyon-Rodez dans la ville, tracé « officiel » (voir supra, p. 177), praticable par les seuls piétons et cavaliers : cette voie, après avoir traversé la rivière sans doute par le gué de JTS.98 (voir infra, p. 195), emprunterait ainsi une courte portion méridionale du cardo C3 avant de prendre une direction perpendiculaire, correspondant donc à ce D6, croisant ensuite C2 et se prolongeant encore sur cet axe sur une assez grande longueur avant de reprendre la direction plus nord-ouest du départ de cette voie vers Rodez. D6 borderait ainsi au nord les structures reconnues dans un sondage Pierobon (Pierobon, 1990, p. 3-4). En revanche, on ne propose pas de prolonger D5 vers l'est au-delà de C3, car on constate que leur croisement est dans le prolongement presque exact du « quai » rive gauche (voir supra, p. 193) et que cette rue devait donc buter ici sur la rivière canalisée.

\section{Cardines}

- C1, la rue nord-sud la plus occidentale, est également une pure hypothèse, fondée sur le constat de l'espace encore à peu près plan restant ici contre la base de la colline ouest, et la présence d'un tronçon de mur dans le sondage 2 de JLG.02, encore axé (est-ouest) sur ce quadrillage viaire (fig. 4). Ce cardo pourrait partir de D1, former l'aboutis-

25. En l'absence de rapport de synthèse sur les fouilles Pierobon, les données font ici cruellement défaut.

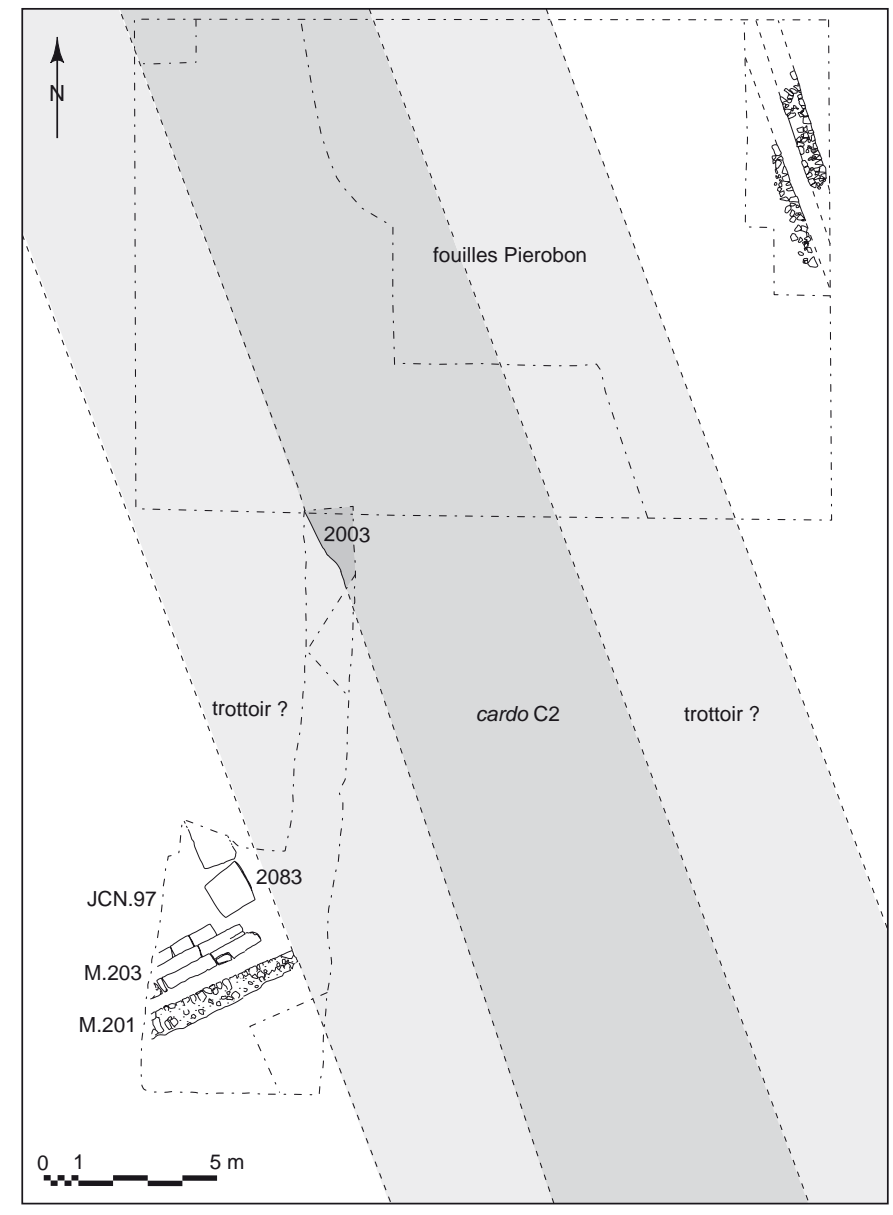

Fig. 9 - Plan de l'état 2 du cardo C2 en JCN.97, avec au nord le sondage Pierobon (DAO : PCR Javols/Anderitum).

sement ouest de D2, D3 et D4, mais s'interrompre sur D4 sans atteindre D6, car il buterait au-delà sur les thermes occidentaux (calés topographiquement par l'emplacement de la piscine encore visible, voir infra, p. 201) ; il serait alors peu probable qu'il reprenne au sud de D6 (longueur trop faible avant le Triboulin).

- C2 est en revanche la rue la mieux connue d'Anderitum. Ce cardo est matériellement attesté sur une longueur d'au moins 120 m, entre le sud des fouilles Peyre (croisement de D4) (fig. 8) et le sondage Pierobon (Pierobon, 1989b, p. 9 ; 1990, p. 5-6, plan 1b et 11 ; 1991a, p. 6 ; Pierobon-Benoît, 1993a ; 1993b, p. 19) au nord du cimetière, ainsi que notre sondage JCN.97 (fig. 9). Dégagée sur toute sa largeur dans les fouilles Peyre, cette rue a environ 8,5 m de large, entre deux trottoirs-portiques situés de part et d'autre (non compris), et comporte un égout sur son côté est (Peyre, 1977 et 1982 ; Pierobon, 1991a, p. 6), ainsi que des caniveaux en grandes dalles de granite creusées d'une rigole, apparemment de 
part et d'autre. On note aussi, à l'angle nord-ouest de cette rue et de D4, une fontaine en dalles de granite (voir AgustaBoularot, 2008), alimentée par une canalisation passant par le bassin de la cour privée de la « domus Peyre » (voir infra, p. 204). Une coupe réalisée en 2003 (JLP.03) en a révélé trois états, le premier sans doute précoce (au plus tard du milieu du I ${ }^{\text {er }}$ s.), le dernier postérieur au II $^{\mathrm{e}} \mathrm{s}$. Partant sans doute de D1 au nord, ce cardo longeait, plus au sud de D3, d'abord la «basilique » (avec à sa hauteur un rétrécissement côté est), puis le forum (qu'il séparait des «thermes occidentaux ») et devait se prolonger jusqu'au decumanus D6 et au moins la berge du Triboulin ; on note que le centre de l'amphithéâtre tel que restitué (voir infra, p. 200) se trouve dans l'axe de cette rue, formant ainsi une perspective architecturale : peut-être cet axe se prolongeait-il jusqu'à cet édifice après avoir passé la rivière sur un pont (?). Au nord, on ne sait s'il se prolongeait au-delà de D1. Il faut enfin noter que Ch. Morel figure des constructions dans l'axe de cette rue (V, à l'angle nord-est du $1^{\text {er }}$ état du nouveau cimetière), certainement mal localisées, et qu'il faut sans doute décaler vers l'est (Morel, 1962, plan).

- C3, enfin, est attesté par nos sondages JPB.02, JPN.04 et JTD.04 (fig. 5 et 10). Il était en fait déjà présumé à cause de la présence d'un alignement remarquable de bâtiments parallèles à C2 mis au jour dans les fouilles du XIX ${ }^{\mathrm{e}} \mathrm{s}$. (Moré, 1858a, p. 107 ; Caumont, 1856) (fig. 4). Distant (d'axe à axe) de 68,60 m de D2, il présente un trottoir-portique sur ses deux côtés (attestés à l'ouest par JPN.04, à l'est par JPB.02 et JTD.04), et un égout (fond en dalles de schiste) en longe le côté oriental (reconnu déjà au XIX ${ }^{\mathrm{e}} \mathrm{s}$. ?) (Moré, 1856a et b). Ces deux derniers sondages ont révélé au moins trois états de cette rue, le plus ancien précoce (début du $\mathrm{I}^{\mathrm{er}} \mathrm{s}$.), le plus récent $d u \mathrm{IV}^{\mathrm{e}} \mathrm{s}$. Commençant au nord au-delà de D1, il longeait d'abord, côté ouest, des bâtiments privés dont la grande domus de JPN.02/04/05-08 et ceux signalés sur le plan du XIX ${ }^{\mathrm{e}}$ s., puis la «basilique » et le forum, qu'il séparait des « thermes orientaux », avant de couper probablement D5 et se prolonger ensuite jusqu'au Triboulin et sans doute au gué qui permettait ici de franchir la rivière. Faut-il en revanche, au nord, le prolonger au-delà de D1 ?

On ne propose pas de decumanus plus au nord que D1, compte tenu de l'étranglement proche du vallon dans cette direction, ni de cardo plus à l'est que C3, compte tenu de la faible longueur ici disponible dans le méandre du Triboulin. Au plan chronologique, seuls les cardines C2 et C1 semblent avoir été établis précocement, peut-être sous Auguste (voir supra, p. 183) : les decumani n'ont été établis que plus tard ? Par ailleurs, l'entretien encore tardif de ces rues n'est attesté que pour D2 et C3.
Les rues reconnues en fouille sont simplement empierrées et non dallées, et les portiques reposent sur des dés de pierre. Des égouts ont été en outre relevés en C2 et C3, ainsi qu'en D3. La largeur des rues bien attestées (C2 et C3) est d'environ 8,5 m, sans les trottoirs-portiques. À titre d'hypothèse, en méconnaissance de D2, l'îlot compris entre D2, D3, C2 et C3 pourrait mesurer (portiques exclus) $52 \mathrm{~m}$ (nord-sud) x 50,5-51 m (est-ouest). Les dimensions des autres îlots restitués sont tout aussi conjecturales, soit une surface d'un peu plus de $2500 \mathrm{~m}^{2}$, c'est-à-dire par exemple sensiblement plus petits et d'ailleurs moins nombreux que ceux de Jublains, certes en terrain plat plus favorable (Naveau dir., 1997).

Par ailleurs, un possible ambitus entre deux domus a sans doute été observé en JPN.02, à l'ouest de la cuisine de la grande domus en cours de fouilles. Ailleurs, quelques rares éléments de voirie urbaine secondaire ont été découverts, mais aucune vraie rue :

- un autre probable ambitus entre deux domus, en JSE.98 ;

- une hypothétique rue vers le sud-est, bordant au nord les bâtiments de la domus de JSF.99/00, et qu'on propose comme éventuel départ de la voie méridionale vers Banassac et Mende ;

- une « rue » proposée par Ch. Morel (1962, p. 101), mais qui ne semble pas devoir être retenue car cet espace allongé se termine en impasse devant l'édifice de spectacle (voir infra, p. 200).

\section{LES AMÉNAGEMENTS DE LA RIVIÈRE : « QUAIS », GUÉS OU PONTS}

Dans ce fond de vallon, les aménagements hydrauliques, concernant tant la «canalisation " de la rivière que sa traversée, sont donc particulièrement prégnants dans l'urbanisme d'Anderitum (fig. 4)

\section{Les « quais »}

Monument emblématique de la ville antique depuis le $\mathrm{XVII}^{\mathrm{e}}$ s., les fameux «quais » de Javols sont des aménagements de berge du Triboulin dans la partie sud-sud-ouest/ nord-nord-est de son cours à sa traversée de l'agglomération : le tirant d'eau de la rivière - selon toute vraisemblance identique dans l'Antiquité - ne permettrait pas en effet une véritable navigation sur celle-ci et donc ne nécessiterait pas de débarcadères, sinon pour de petites embarcations à fond plat, d'usage local (voir Ferdière, Ode, 2001b). 


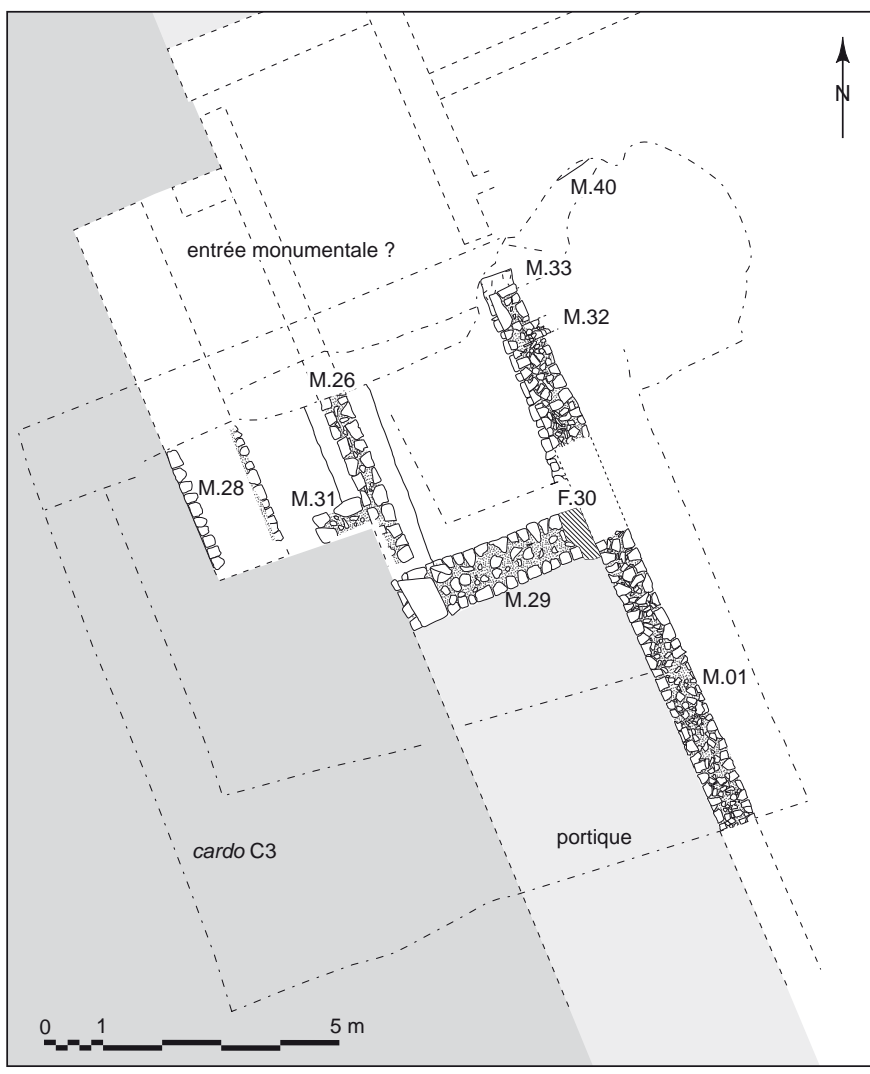

a

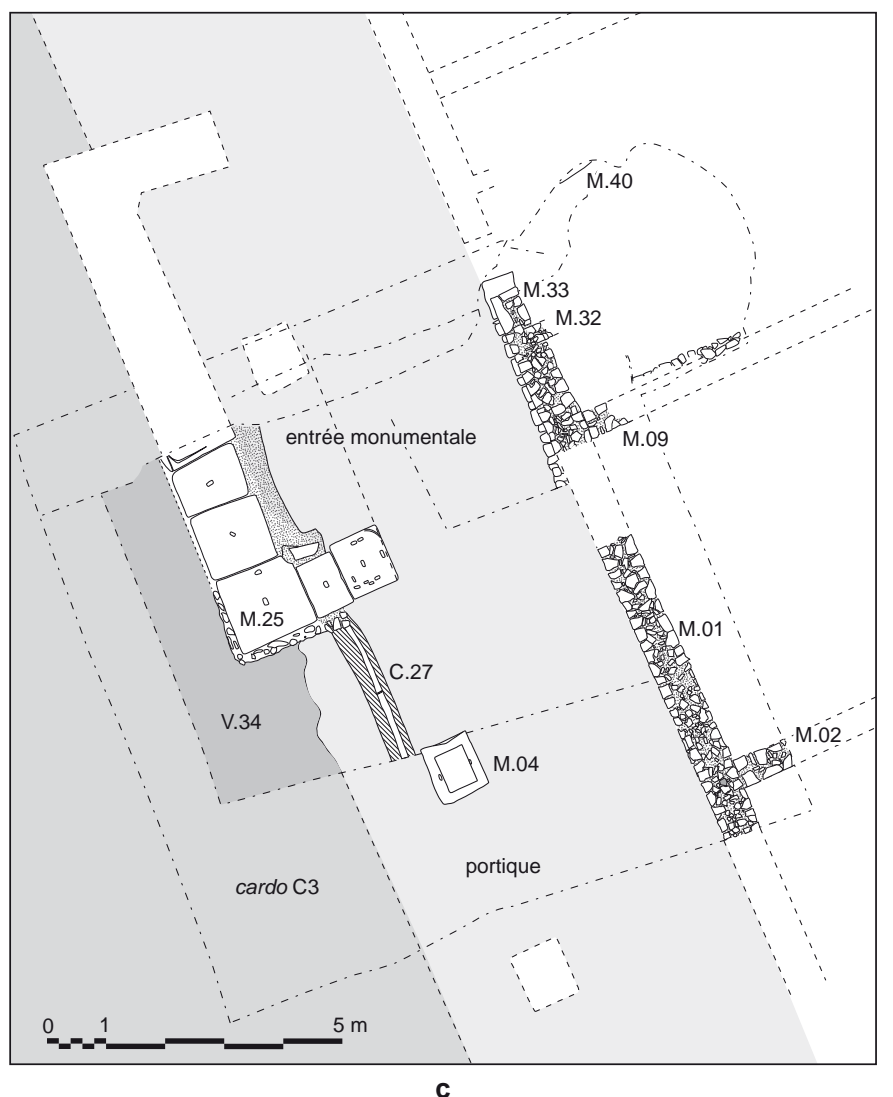

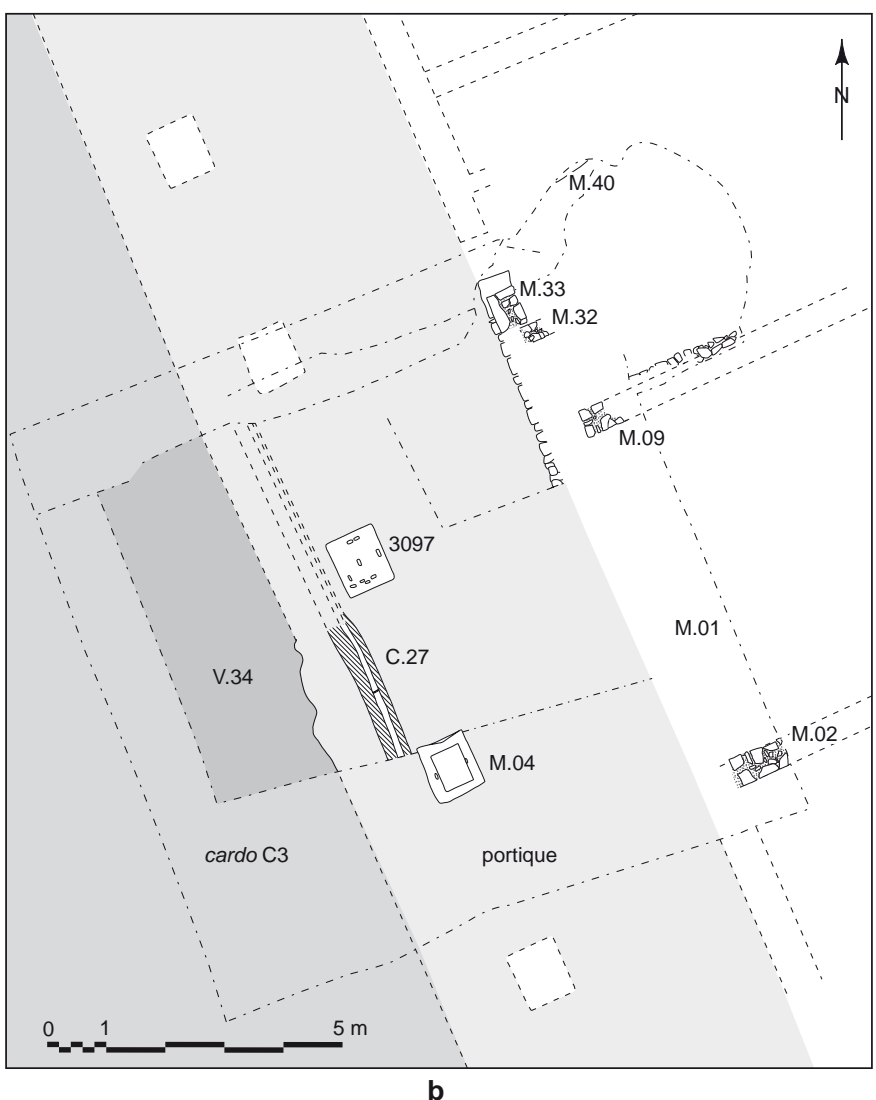

Fig. 10 - Plans des constructions en JTD.04, en bordure est $d u$ cardo C3 : a, état 2 (milieu du I Ir s. apr. J.-C.) ; b, état 3 ( $2^{e}$ moitié du I $I^{e r}$ s.-début du II ${ }^{e}$ s.) ; c, état 3bis ( $I^{r e}$ moitié du II ${ }^{e}$ s.) (DAO : PCR Javols/Anderitum).

Ces aménagements sont signalés « de part et d'autre » de la rivière, sur une longueur de « 300 à 400 pas » ${ }^{26}$. Ils sont encore en partie visibles dans la partie nord de la portion sud-sud-ouest/nord-nord-est de la rivière, où ils ont été relevés par $\mathrm{R}$. Pierobon, et ont été partiellement mis au jour dans nos sondages JQR.97/01 (rive gauche) et JTE.99 (rive droite) (fig. 11 et 12) : l'espace entre ces deux alignements est de près de $11 \mathrm{~m}$ (et non $8 \mathrm{~m}$, comme indiqué au XIX ${ }^{\mathrm{e}} \mathrm{s}$.).

Il s'agit d'aménagements des berges du Triboulin, de caractère monumental, en grand appareil de granite, sur une seule épaisseur. Ils sont constitués d'au moins quatre rangs de blocs (le rang inférieur reconnu seulement dans le sondage JQR.01). Ces blocs comportent quasi tous des trous de louve à la partie supérieure, et, selon les indications du $\mathrm{XIX}^{\mathrm{e}}$ s. (Ignon, 1840-1841, p. 152), des « crampons » de fer

26. Même en comptant des pas de seulement $0,5 \mathrm{~m}$, une longueur de plus de $150 \mathrm{~m}$ est difficilement compatible avec les données de terrain. 


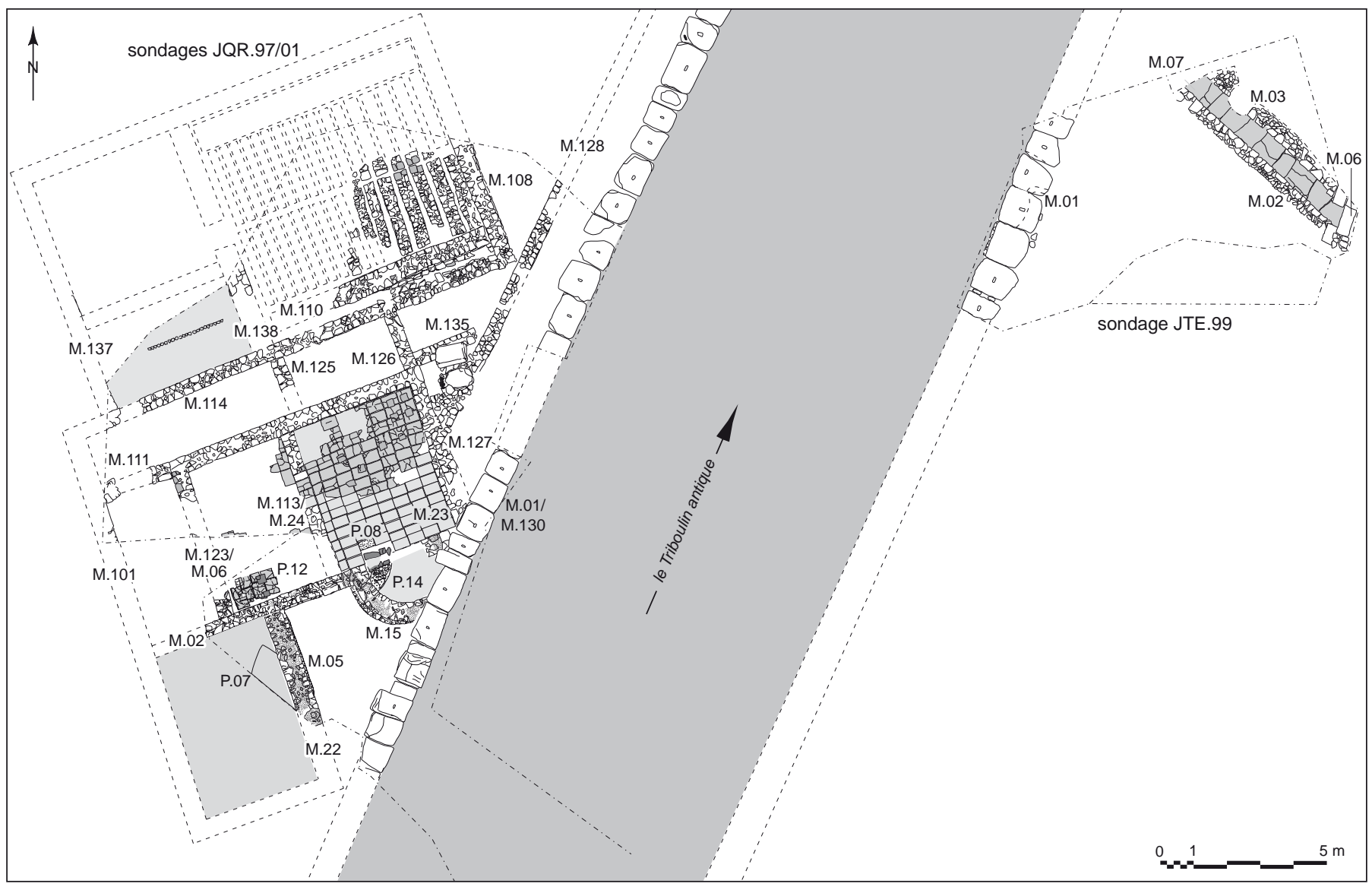

Fig. 11 - Plan des thermes orientaux et de l'aménagement de berge de la rive gauche du Triboulin, en JQR.97/01, avec l'aménagement de berge de la rive droite (JTE.99) (DAO : PCR Javols/Anderitum).

les liant entre eux ; nous n'avons cependant pas observé ces agrafes de scellement dans les portions mises au jour dans nos sondages, ni leur trace dans la pierre. Cet aménagement ne devait pas s'élever plus haut que ce qui est conservé aujourd'hui, compte tenu de la montée des eaux de la rivière depuis l'Antiquité (voir supra, p. 189).

Réexplorés par le chanoine Portal - qui signale une « dalle » de $2 \mathrm{~m}$ de long à son extrémité, dont la localisation n'est pas précisée -, puis par Ch. Morel, ils s'étendent de manière certaine, sur une longueur de $75 \mathrm{~m}$ pour la rive gauche (Portal, 1890, p. 7 ; Morel, 1962, p. 112). On propose, notamment selon les indications anciennes, de les prolonger sans doute jusqu'à l'angle des rues D6 et C3 (voir supra, p. 192-193).

Ce large chenal artificiel ainsi construit, sans doute dans la première moitié $\mathrm{du} \mathrm{I}^{\mathrm{er}} \mathrm{s}$. apr. J.-C. (voir supra, p. 184), est donc un aménagement particulièrement massif du «paysage » urbain d'Anderitum : il est manifestement destiné à repousser vers l'est et la base des collines le cours de la rivière, divaguant auparavant dans la partie plus occidentale du vallon, comme observé notamment en JTD.04 (voir aussi infra, p. 202). Cet équipement permettait alors de dégager un espace plus important pour l'urbanisme de la partie centrale du site et a donc sans doute précédé l'édification de l'état du moins le plus monumental du « centre civique » : forum-basilique (voir infra, p. 197-199).

D’autres aménagements plus modestes des berges de la rivière ont été reconnus ailleurs ; ils ne sont orientés ni comme ces derniers, ni par rapport au " quadrillage » de voies : le mieux identifié se trouve en JTS. 98, en rive droite, et était en fonction jusqu'au début du II $^{\mathrm{e}} \mathrm{s}$. (terrasse bordée d'assez grosses pierres irrégulières) (fig. 13) ; les autres, tous sauf le dernier situé sur la rive gauche, concernent un sondage Pierobon (Pierobon, 1990, p. 3 et plan 5), des observations faites à l'occasion de l'installation de la station d'épuration (Fages, 1991, p. 3, fig. 5-6 et p. 9-11), d'autres aménagements (anciens ?) signalés à proximité du pont principal et plus en amont (renseignements oraux et 


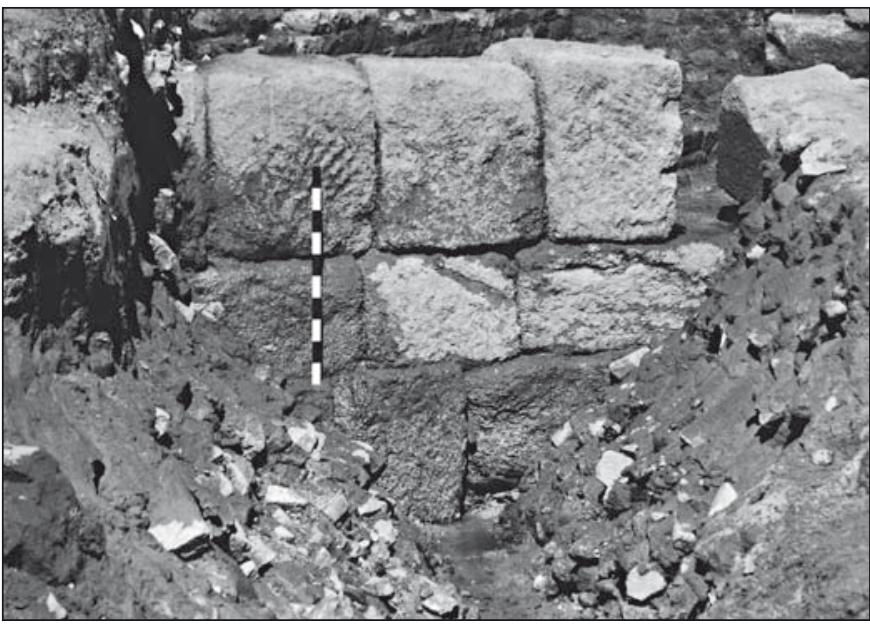

Fig. 12 - Élévation de l'aménagement de berge de la rive gauche du Triboulin observée dans le sondage JQR.01 : 4 assises, dont la plus basse à l'extrême fond de la fouille (cliché : PCR Javols/Anderitum).

Morel, 1962, p. 112) et, encore plus en amont, en JMP.00 (sondage 3) ; s'y ajoute le mur nord-sud de JPB.02, plutôt limite de l'urbanisme côté rivière qu'aménagement de berge, en bordure est du cardo oriental et dans ce seul cas axé sur ce quadrillage urbain central ; enfin, le dernier mis au jour est en aval, en rive droite, en contrebas de la butte du «Mas Astruc» (JMA.06).

\section{Gués et ponts}

On croit avoir repéré les vestiges d'un gué dans un imposant empierrement mis au jour dans le lit ancien du Triboulin, dans la partie est-ouest de son cours (JTS.98), aménagement apparemment attribuable au $\mathrm{II}^{\mathrm{e}} \mathrm{s}$. apr. J.-C.

Il fallait bien en effet qu'on puisse aisément passer d'une rive à l'autre de la rivière, même si celle-ci est en général de faible débit, et il fallait également assurer le passage de ce cours d'eau tant à la voie Lyon-Rodez qu'à celle de Clermont-Ferrand vers la Narbonnaise occidentale : c'est même sans doute à ce passage à gué de la rivière que - on l'a vu - Anderitum doit son nom.

Mais, hormis ces hypothétiques vestiges de gués, force est de constater que ni les fouilles anciennes ni nos recherches récentes n'ont permis de reconnaître de tels passages du Triboulin, à gué ou par pont. Et pourtant, il faudrait sans doute imaginer au moins un autre passage plus au nord, pour la «dérivation » de la voie principale, destinée aux chariots, sans doute donc à l'extrémité est soit du decumanus D1, soit de D2. Et de même la restitution proposée du quadrillage urbain de la rive gauche et de l'édifice de spectacle

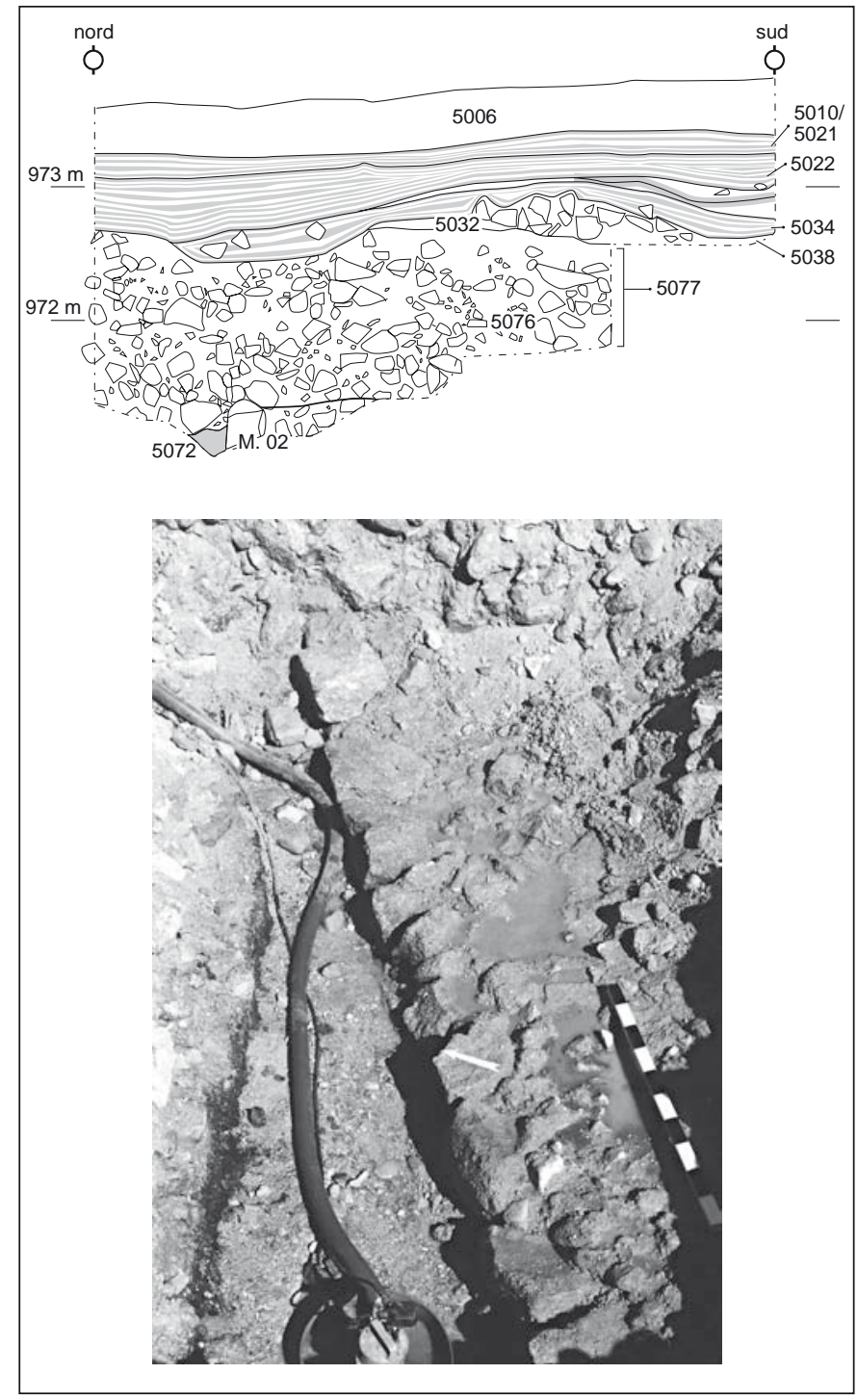

Fig. 13 - Coupe et photographie de l'aménagement de berge de la rive droite du Triboulin en JTS.98 (DAO et cliché : PCR Javols) Anderitum).

sur la rive droite, avec la perspective architecturale ainsi créée, laisse supposer une traversée de la rivière par le cardo C2, alors sans doute par un pont (fig. 4).

\section{URBANISME ET ORIENTATIONS}

C'est donc en définitive, on l'a vu, un plan orthogonal d'urbanisme limité qui concerne la ville, comme c'est d'ailleurs la plupart du temps le cas dans les capitales provinciales romaines. Hors de la surface restreinte de la partie basse du vallon, en rive gauche, les axes d'urbanisme et de construction constatés varient considérablement d'un point 
à l'autre (fig. 4). Ce plan ne paraît pas se mettre en place en une seule fois, sur un temps court, mais progressivement, certaines rues semblant établies dès le règne d'Auguste (C2 et C3), d'autres plus tard, et les constructions publiques ou privées qu'il enserre étant également édifiées progressivement, à partir surtout du milieu du I ${ }^{\mathrm{er}}$ s. apr. J.-C.

En outre, un constat particulièrement intéressant, en termes tant urbanistiques que chronologiques, est celui de l'existence de constructions parallèles aux «quais » du Triboulin (rive gauche) et donc contemporaines de cet aménagement monumental de la berge, selon toute apparence antérieures en tout cas à l'extension maximale du «plan orthonormé » (voir supra, p. 190 et suivantes), puisque notamment recoupé par l'établissement (vers le milieu du $\mathrm{I}^{\mathrm{er}} \mathrm{s}$. ?) des thermes orientaux. Ce premier état concerne aussi apparemment un bâtiment (balnéaire ou de stockage ?) mis au jour par Ch. Morel (1962, p. 98-99). Ce premier état de construction, parallèle et donc sans doute contemporain des " quais », c'est-à-dire de la première moitié du $\mathrm{I}^{\mathrm{er}}$ s. apr. J.-C., est ensuite progressivement abandonné et/ou détruit pour laisser place à l'urbanisme quadrillé qui concerne désormais tout ce secteur central de la ville, en rive gauche de la rivière, et ce «bâtiment Morel » peut même avoir subsisté. Un peu plus au sud, les « thermes orientaux » se superposent à ce premier état, vers le milieu $\mathrm{du} \mathrm{I}{ }^{\mathrm{er}}$ s., sur les orientations du quadrillage viaire.

Ailleurs (fig. 4), les orientations des constructions sont donc très diverses, en fonction des contraintes du terrain, et d'ailleurs aussi, en un même point, d'une période à l'autre, comme on le constate notamment en JLG.02 (trois ou quatre orientations des murs) ou encore en JSE.98; ces orientations variées ont été observées tant à l'ouest (JLG.02, JBS.05, sondage Pierobon, diagnostic Piskorz, JSE.98, JEF.98, JMP.00, sondage est) qu'au sud (JTM.00/01, JSF.99/00 et 05, JBN.01/04) ou à l'est (JTE.99, JLV.99, sauvetage Charbonnier, JMA.06).

\section{MONUMENTS ET ÉQUIPEMENT PUBLICS}

On examinera les équipements publics d'Anderitum en commençant par son centre civique.

\section{LE GENTRE GIVIQUE ET LE FORUM}

Curieusement, ce n'est que récemment que l'identification du forum et du centre civique de la ville est entrée dans les préoccupations des chercheurs qui s'y sont succédé : les publications anciennes ne mentionnent pas d'hypothèse à son sujet et le grand édifice rectangulaire que l'on interprète aujourd'hui comme une basilique est identifié à un «temple d'Auguste» dans les publications du XIX ${ }^{\mathrm{e}} \mathrm{s}$. (Moré, 1858a, p. 104-106).

Ce n'est qu'à partir des fouilles Pierobon ${ }^{27}$ puis de nos propres recherches que la place centrale de ce forum a été identifiée au sud du vallon (rive gauche), entre la «basilique » et la partie est-ouest du cours de la rivière, et ce ne sont en fait que les photographies aériennes de 1998 (fig. 14) qui ont - de manière fugace et non renouvelée depuis - permis de localiser ici le forum avec certitude : place rectangulaire apparemment entourée de boutiques et de portiques au moins sur deux côtés (est et sud), formant un espace d'environ $50 \mathrm{~m}$ x $70 \mathrm{~m}$, axé nord-sud. Ceci a offert la possibilité de réinterpréter et d'ailleurs de mieux localiser des éléments signalés par Ch. Morel (Morel, 1962, p. 96-98, voir plan, pt. III) ${ }^{28}$, qui correspondent presque sûrement au côté ouest de cette place, également avec boutiques, portiques, ainsi qu'un pavage de grandes dalles côté est (fig. 4 et 15).

Dans un secteur où des constructions complexes sont connues depuis le XIX ${ }^{\mathrm{e}}$ s. (Ignon, 1840-1841, p. 167-171 ; Moré, 1858a, p. 104-106), les fouilles Pierobon (Pierobon, 1991a, p. 10 ; 1991b ; 1992, p. 5-6 et 1999, p. 11-13 ; Pierobon-Benoît, 1993b) (fig. 15) ont mis au jour une grande salle axiale par rapport à l'ensemble architectural restitué du centre civique, dont le sol est mosaïqué en " nid d'abeille » noir et blanc ${ }^{29}$; son côté sud, entièrement ouvert, présente deux bases de colonnes monumentales de $0,84 \mathrm{~m}$ de diamètre (Pierobon, 1990, p. 7 ; 1991a, p. 10, fig. 9-10, plans 8-9 ; Pierobon-Benoît, 1993b, p. 18 ; Massy et al., 1992, p. 157) : cet espace est interprété (Pierobon-Benoît, 1993b, p. 6) - sans doute à juste titre - comme la curie du centre civique, dans un premier état (fig. 15). Il est en effet recoupé - et donc condamné par la construction du grand édifice rectangulaire est-ouest, quant à lui interprété comme une basilique (2 $2^{\mathrm{e}}$ état).

Ce dernier édifice est en fait l'un des plus anciennement connu d'Anderitum (Ignon, 1840-1841, p. 167-171 ; Caumont, 1856, p. 470-472, fig. ; Moré, 1858b, plan h. t.) et a été partiellement remis au jour et réétudié dans les fouilles Pierobon (côtés nord et ouest) ; il s'agit d'un vaste rectangle

27. Il faut reconnaître qu'ici encore, on manque cruellement des données de ces fouilles pour consolider nos hypothèses sur la restitution du centre civique.

28. Situé par lui de manière erronée dans le prolongement de l'alignement nord-sud de bâtiments signalés au XIX ${ }^{\mathrm{e}}$ s., qui sont en fait la bordure ouest de C3.

29. Une portion représentative de ce pavement, impossible à conserver in situ, a été prélevée en 1999 et est présentée dans la Salle d'Exposition Permanente de Javols. 


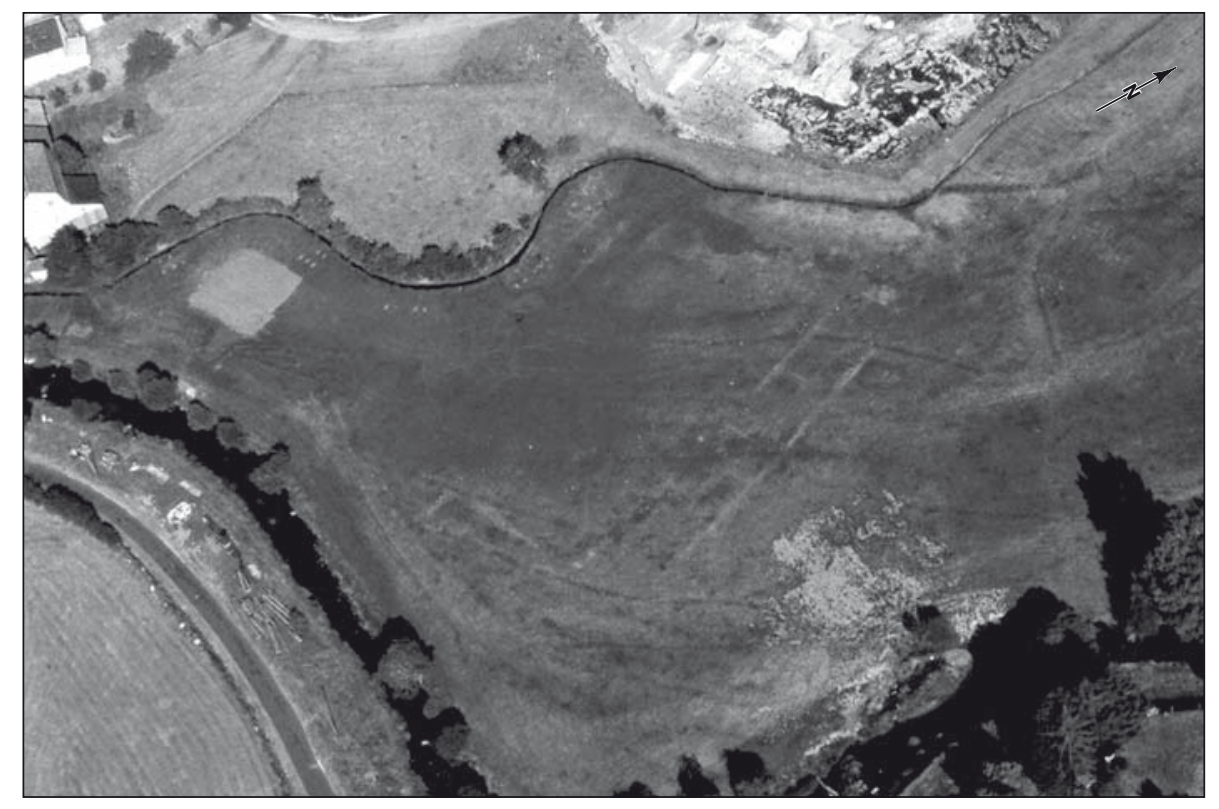

Fig. 14 - Photographie aérienne du forum d’Anderitum en 1998 (photo : A. Boëmare).

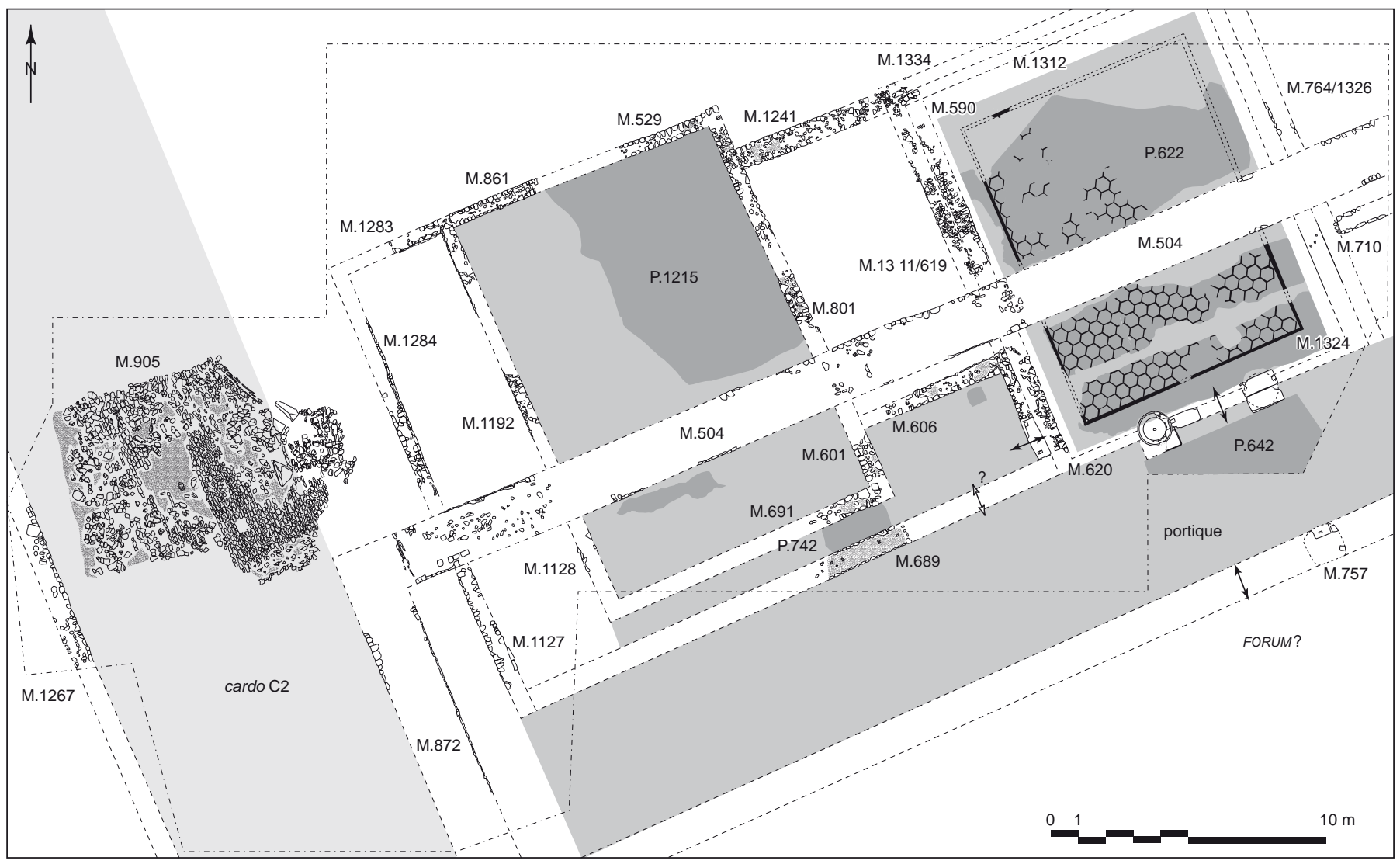

-..... limite de sondage $\quad \ldots$-...- mur restitué $\longleftrightarrow$ seuil avéré $\longleftrightarrow$ seuil probable $\square$ sol en béton avéré $\square$ sol en béton restitué

Fig. 15 - Plan de la fouille Pierobon en 1999 (plan synthétique réalisé d'après Pierobon, 1999). 
apparemment vide de subdivisions (74 m x $23 \mathrm{~m}$ selon les indications du XIX ${ }^{\mathrm{e}}$ s., voir Ignon, 1840-1841, p. $168^{30}$ ), que l'on interprète aujourd'hui comme la «basilique » du centre civique dans un second état, sans doute du $\mathrm{II}^{\mathrm{e}} \mathrm{s} .{ }^{31}$

La «basilique » actuellement connue correspond donc à un important réaménagement de ce centre civique, recoupant et supprimant ainsi la précédente curie (?), qui pouvait quant à elle être précédée, côté sud, d'une première basilique antérieure à celle connue, barrant l'extrémité nord du forum, sur le modèle par exemple du centre civique de Feurs (Loire) (Valette, Guichard, 1991, fig. 25).

Ainsi, rien ou presque n'étant à ce jour fouillé du forum lui-même, aucun argument ne permet d'exclure qu'il a été édifié dès le règne d'Auguste, en même temps que la « curie », construction quant à elle certainement précoce, et une première basilique, en l'état totalement inconnue et donc conjecturale.

Si l'on compare avec un forum relativement proche et récemment étudié, pour une cité d'importance comparable, celui de Feurs/Forum Segusiavorum (Valette, Guichard, 1991), la place centrale d'Anderitum est sensiblement plus petite (boutiques incluses), soit environ $3500 \mathrm{~m}^{2}$ contre plus de $4600 \mathrm{~m}^{2}$ à Feurs. Ce dernier présente cependant, comme à Javols, une basilique disposée transversalement à l'une de ses extrémités (nord à Javols, est à Feurs) ${ }^{32}$, suivie d'une curie axiale. En revanche, l'autre extrémité reçoit à Feurs le temple et son péribole-portique, ce qui, selon toute apparence, n'est pas le cas à Javols.

Reste donc qu'on ne sait en l'état où placer la curie du second état de ce centre civique (nouvelle basilique) et, surtout, pour les deux états, où situer le temple civique qui devrait logiquement compléter cet ensemble : au nord, se sont en effet des constructions apparemment privées qui ont été reconnues et au sud coule la rivière. On ne s'aventurera pas à proposer de placer ce dernier édifice sur la rive opposée du Triboulin, entre la rivière et l'édifice de spectacle ${ }^{33}$,

30. Cette longueur dépasse assez largement l'espace existant entre les cardines C2 et C3 (50,30 m ? ; voir supra, p. 192-193), mais on sait en tout cas que cet édifice empiète côté ouest sur C2 d'au moins la largeur de son portique est.

31. Il faut noter que c'est à proximité qu'ont été découverts au XIX ${ }^{\mathrm{e}} \mathrm{s}$. six fragments épigraphiques provenant peut-être d'une même inscription monumentale, avec une possible mention d'un empereur du $\mathrm{II}^{\mathrm{e}} \mathrm{s}$. (CIL, XIII, 1559a à f ; Ignon, 1840-1841, p. 170).

32. La basilique de Feurs fait $69 \mathrm{~m}$ x $24 \mathrm{~m}$, contre $74 \mathrm{~m}$ x $23 \mathrm{~m}$ (?) pour celle du second état de Javols.

33. Pourtant, Amiens présente par exemple un amphithéâtre directement accolé à l'extrémité ouest du forum, le temple se situant dans cette partie occidentale (voir Bayard, Massy, 1983). même si l'on soupçonne ici un pont dans l'axe du cardo C2 (voir supra, p. 193).

\section{DES LIEUX DE CULTE ?}

Le «temple de Rome et d'Auguste » à associer au centre civique est donc en l'état absent et force est de constater que la question des lieux de culte publics d'Anderitum reste l'une des moins bien documentées à ce jour.

Seuls quelques éléments de réflexion peuvent être fournis en la matière.

- La présence de trois fosses cultuelles précoces (fig. 6b) a fait interpréter une construction sur tranchées palissadées, sans doute donc préromaine, de JBN.01 comme un édifice de culte gaulois installé au sommet de cette butte centrale du site. Mais les constructions en pierre qui lui succèdent sont trop lacunaires pour permettre d'y voir un temple gallo-romain, d'autant que c'est apparemment un dépotoir privé puis un simple puits à eau qui succèdent à cet état précoce peut-être cultuel (JBN.01 et JBN.04).

- La «boutique » (voir infra, p. 204) devant laquelle ont été mis au jour les fragments de la fameuse statue de Silvain/Sucellus a été interprétée comme un lieu de culte d'où proviendrait cette figuration (Peyre, 1969b, p. 54 ; Béal, Peyre, 1987, p. 363-366), mais rien ne permet en l'état de maintenir cette hypothèse, cet espace étant par ailleurs concerné par un artisanat du bronze, et les fragments de la statue ayant en outre été découverts en position ne correspondent apparemment pas à un écroulement in situ ${ }^{34}$.

- L'hypothèse d'un podium de temple sous le cimetière actuel, sur la terrasse à laquelle permettent d'accéder par le nord les marches mises au jour en JCN.97 (Haut-Empire), reste purement conjecturale (fig. 9).

- Enfin, on rappellera ici l'hypothèse d'un édifice de culte chrétien primitif (IV ${ }^{\mathrm{e}} \mathrm{s}$. ?) à l'emplacement de l'ancienne église, dont on aurait mis au jour deux murs perpendiculaires en JAE.96 (voir supra, p. 186).

On ne traitera pas ici de l'histoire de l'église médiévale et moderne de Javols (voir supra, p. 187-188).

Restent donc encore, pour la période romaine, quelques rares éléments de statuaire ${ }^{35}$, dont on ne peut évidemment affirmer en l'état qu'ils appartiennent à des lieux de culte publics :

34. Une réinterprétation récente (Ebnöther, 2008), que nous ne retenons pas, serait de voir ici une schola de corporation (voir infra, p. 202).

35. Aucune des rares inscriptions découvertes à ce jour à Javols ne présente un caractère cultuel (voir Ferdière, 1997 ; Ferdière et al., dir., à paraître, ann. 6). 
- d'une part la fameuse statue en grès rouge de Silvain/ Sucellus dont on a indiqué le lieu de découverte, problématique (Béal, Peyre, 1987 ; Pailler, 1989 ; Hatt, 1991 et 2005, p. 22-23 ; voir Béal, 1999) ;

- d'autre part un grand chapiteau en calcaire, figurant Cybèle entre deux lions, de provenance inconnue (Noël, 2002, p. 80 et $\mathrm{n}^{\circ} 98.111$ );

- enfin un élément, également de provenance inconnue, de statuaire en granite, figurant un poitrail de cheval harnaché, faisant vraisemblablement partie d'une statue équestre de Jupiter (Deyts, 2003).

Seuls quelques autres éléments de statuaire de caractère au moins monumental pourraient encore être ajoutés ${ }^{36}$, sans qu'on puisse affirmer pour aucun qu'ils correspondent à des cultes, encore moins à des cultes publics...

\section{UN ÉDIFICE DE SPECTACLE}

Dans ce cas aussi, même si l'existence d'un « théâtre » était depuis longtemps soupçonnée (voir par ex. : Ignon, 18401841, p. 159), ce n'est qu'à partir des fouilles Morel, autour de la dernière guerre, que des recherches ont commencé à porter sur cette question (Morel, 1962, p. 100-106). En effet, un hémicycle apparaît nettement sur la pente nord de la colline du Barri donnant sur le centre-ville (fig. 4). Ce sont nos sondages en JBN.99 qui ont confirmé l'existence de cet édifice de spectacle, en en mettant au jour un tronçon significatif de la praecinctio, flanquée à l'extérieur de pilastres et sans doute entourée d'une galerie (fig. 16), observation d'ailleurs complétée par d'autres - alors non interprétées comme telles - de Ch. Morel un peu plus à l'est (Morel, 1962, p. 106, plan pt. F).

On avait dès lors privilégié l'hypothèse d'un théâtre ouvert vers la ville, d'environ $75 \mathrm{~m}$ de diamètre. Mais la relecture des découvertes anciennes dans ce secteur permet sans doute aujourd'hui de proposer ici un amphithéâtre, édifice d'ailleurs plus couramment représenté dans les capitales de cités des Gaules, même modestes.

En effet, tout d'abord on signale que c'est ici, en contrebas, qu'a été mis au jour le «milliaire » de Postume, au centre d'une «place circulaire " (Ignon, 1840-1841, p. 159 ; Moré, 1858a, p. 103) : plutôt que l'orchestra d'un théâtre, on supposera qu'il s'agit en fait de l'arène d'un amphithéâtre. Par ailleurs, les fouilles Morel ont mis au jour dans ce même secteur, en contrebas de la colline, un ensemble de murs qui

36. Au XIX ${ }^{\mathrm{e}}$ s., orteils en marbre, doigts en bronze... (Ignon, 18401841, p. 168), autour de la «basilique » et plus au nord.

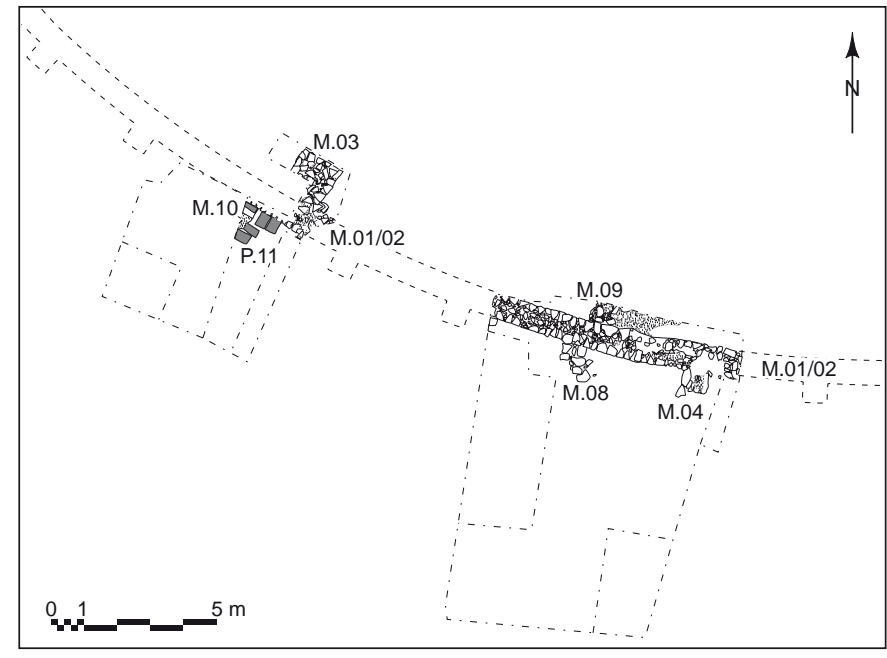

Fig. 16 - Plan de la praecinctio de l'édifice de spectacle en JBN.99 (DAO : PCR Javols/Anderitum).

peuvent être réinterprétés en faveur de cette hypothèse ${ }^{37}$ (Morel, 1962, p. 100-105, plan, pt. VI-VII). Leurs courbes éventuelles - si l'on ne se trouve pas vers le centre de la plus grande dimension de l'édifice - n'auraient alors pas été perçues sur les trop faibles longueurs mises au jour : la « rue dallée " nord-sud pourrait ainsi bien être l'un des vomitoria de cet édifice, avec ses murs " perpendiculaires » constituant les caissons de sa structure interne de ce côté ; dans ce couloir ont en outre été trouvés « renversés » sept blocs de grand appareil de forme parallélépipédique (Noël, 2002, p. 146, no 98.131), appuyés contre les murs et alors interprétés comme contreforts : il s'agit en fait de chaperons de couronnement de murs de vomitoria, de type assez classique (rens. J. Seigne ; Ginouvès, 1992, pl. 12, fig. 1) ; une porte et un escalier monumental s'ouvraient en outre vers l'est ; d'autres éléments de décor architectural furent aussi mis au jour à cette occasion et on notera la mise en ouvre du calcaire en parement (fouilles Morel) ou décor architectural (idem et JBN.99 : couches de construction).

Ainsi, on restitue ici un amphithéâtre de construction mixte, pour partie appuyé à la colline, pour partie construit en élévation. Avançons même l'hypothèse que cet édifice peut avoir été axé est-ouest et son petit axe être alors placé dans la prolongation du cardo C2, constituant la perspective architecturale évoquée plus haut (p. 193). Son arène apparaissant circulaire, on lui attribue des dimensions trapues, les deux axes étant ainsi supposés autour de plus ou moins

37. On sait en effet par expérience que ni les plans, ni les localisations, ni les orientations du plan Morel ne sont fiables. 
$75 \mathrm{~m}^{38}$. Cependant, comme par exemple dans de modestes chefs-lieux de cité tels que Jublains (Mayenne) ou Vieux (Calvados), il pourrait tout aussi bien s'agir d'un édifice de spectacle de «type gallo-romain », mixte, susceptible d'accueillir des représentations théâtrales aussi bien que des jeux du cirque.

Le sondage JBN.99 a permis de proposer une date de construction de cet édifice dans la seconde moitié du $\mathrm{I}^{\mathrm{er}} \mathrm{s}$. et sa destruction - du moins pour la partie arrière de l'édifice - dans la seconde moitié du $\mathrm{III}^{\mathrm{e}}$ s., date à laquelle l'arène au moins est réaffectée à un autre usage (civique ?), avec l'érection du milliaire-dédicace de Postume (en 264-268).

\section{DES THERMES PUBLICS}

À l'édifice balnéaire qui est ici l'un des monuments les plus anciennement connus d'Anderitum, à l'ouest, nos travaux ont ajouté un second ensemble thermal, oriental, en berge du Triboulin.

\section{Les thermes occidentaux}

C'est un vaste ensemble, fouillé pour l'essentiel au XIX $^{\mathrm{e}}$ s. (Moré, 1956a et b, 1858b et 1859 ; Delapierre, 1864 ; Germer-Durand, 1888) (fig. 4). Sa localisation précise et même l'échelle de ce plan sont toutefois sujettes à caution et la multiplicité des murs et des pièces laisse penser que plusieurs états y ont été confondus : seule la piscine encore visible permet de le caler approximativement et d'en vérifier l'orientation. Ch. Morel y reprit des fouilles autour de la dernière guerre (Morel, 1962, p. 107-108, plan, pt. XII et pt. XIII), et quelques observations complémentaires y ont été réalisées par l'abbé Peyre (Peyre, 1970a, p. 8 et p. 18, 1970b, p. 37), puis par R. Pierobon (Pierobon, 1988, p. 4). On y a enfin réalisé un sondage, en bordure de cette même piscine (JBR.97), qui a permis de dater sa construction du $\mathrm{II}^{\mathrm{e}}$ s., au moins pour cette partie.

Non moins de 43 salles sont signalées par É. de Moré (1859). Outre cette piscine froide, une salle sur hypocauste est signalée, plusieurs « aqueducs » (?) (voir infra, p. 201-202), des "galeries » voûtées (?) et des éléments de décor : enduits peints, stucs, plaquages de marbre, éléments de mosaïque, terres cuites décoratives... Des traces d'incendie sont mentionnées à plusieurs reprises. Même s’il est donc impossible en l'état de comprendre le plan de cet ensemble

38. Parmi les « petits » amphithéâtres donc : par exemple entre celui de Cimiez (67,20 m x 56 m) et celui de Rodez (110 m x 97 m) (Grenier, 1958 , p. 601 et p. 669$)$. et d'en déterminer la typologie, il s'agit à l'évidence de thermes publics de dimensions assez considérables, situés immédiatement à l'ouest du forum et y occupant sans doute la quasi-totalité d'une insula à l'ouest du cardo C2.

\section{Les thermes orientaux}

Les thermes orientaux (fig. 11), en revanche, n'ont été mis en évidence qu'à l'occasion de nos sondages en bordure du Triboulin et ses aménagements de berges (JQR.97/01). Même si la fonction balnéaire des salles mises au jour pour les premières phases, à partir du milieu du I ${ }^{\text {er }}$ s. apr. J.-C., n'est pas absolument attestée, c'est à cette période que l'on attribue la première installation de ces thermes, bâtiment dès lors axé sur le quadrillage de rues urbaines et non plus parallèlement aux « quais ».

Les salles correspondant de manière certaine à des bains ne correspondent en effet qu'à la phase 4 , du $\mathrm{II}^{\mathrm{e}} \mathrm{s}$. (fig. 11), et c'est leur développement qui laisse penser à un équipement public plutôt que privé ; on y reconnaît un frigidarium au sol en béton de tuileau, un tepidarium sur hypocauste, avec sa piscine froide en abside, et deux caldaria sur hypocauste avec leur praefurnia; l'un d'eux est sur hypocauste à canaux parallèles, d'un type rare mais toutefois présent ailleurs en Gaule (voir entre autres Degbomont, 1984, p. 126-127 ; Bouet, 2003, p. 250-251). Les nombreuses tesselles de mosaïque polychrome découvertes dans les couches de destructions supérieures permettent en outre d'imaginer une partie du décor des états les plus tardifs de cet édifice. Le développement de ce balnéaire est donc trop important pour y voir des bains privés.

Un couloir s'ouvre vers la rivière et un puits à eau, ce dernier ne devant toutefois pas suffire à l'alimentation en eau de cet ensemble balnéaire, qui pouvait être assurée par la rivière et/ou par un aqueduc pour l'instant inconnu.

\section{L'ALIMENTATION EN EAU : DES AQUEDUCS ?}

La question de l'eau est prégnante à Javols et l'abbé Peyre ne s'y est pas trompé, en lui consacrant une étude (Peyre, 1982). Toutefois, contrairement à un certain nombre d'autres chefs-lieux de cité des Gaules, on ne connaît pas ici de système d'aqueduc important allant chercher l'eau bien à l'extérieur de la ville, et sans doute le climat et la présence de la rivière ne nécessitaient-ils pas un tel équipement.

Pour les thermes occidentaux, ce sont non moins de trois aqueducs venant du nord qui sont indiqués au XIX ${ }^{\mathrm{e}} \mathrm{s}$. Certains, comme d'ailleurs dans les fouilles Morel, corres- 


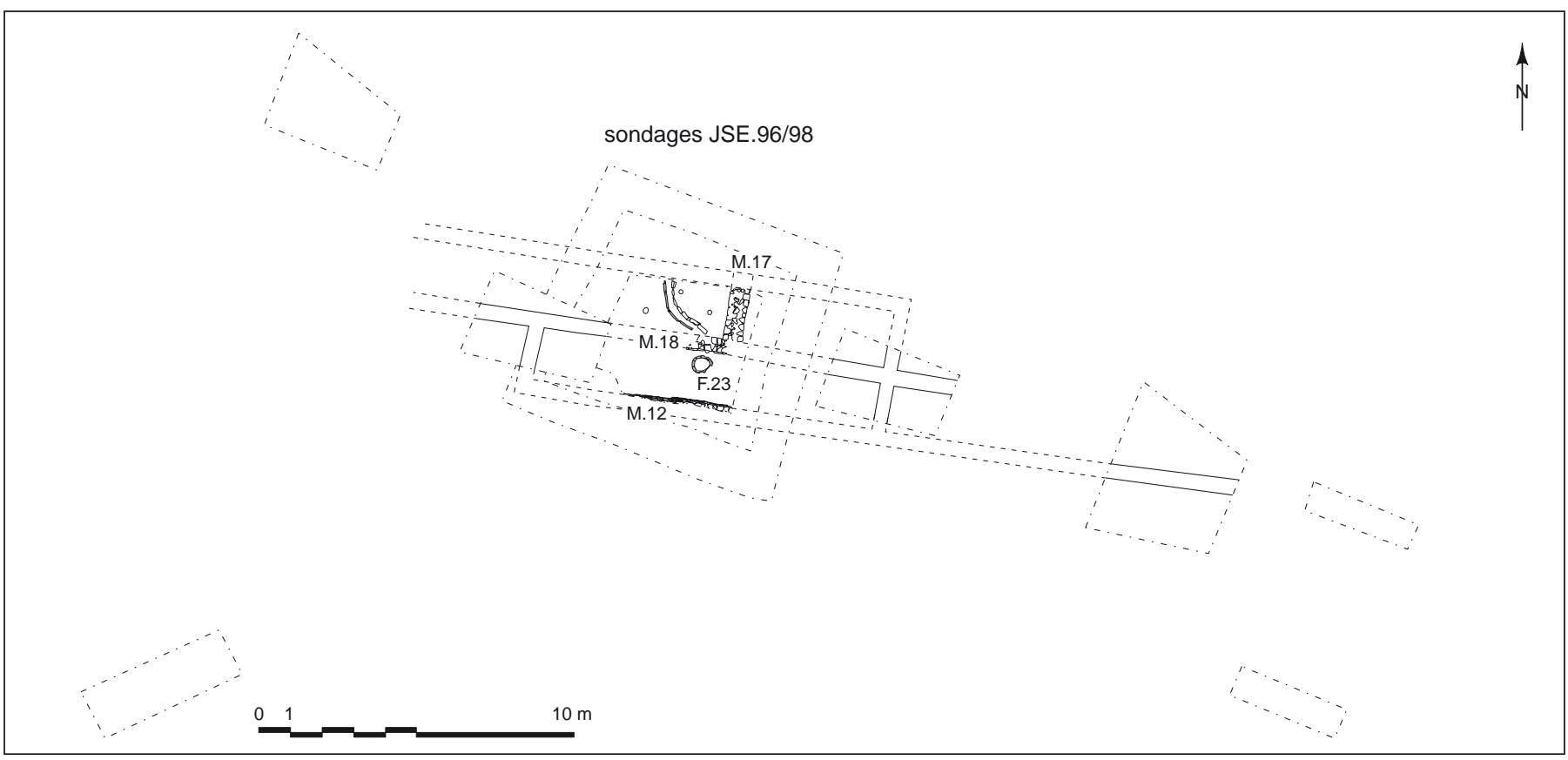

Fig. 17 - Plan synthétique de la $1^{r e}$ phase (I ${ }^{\text {er }}$ s. apr. J.-C.) des constructions reconnues en JSE.96/98 (DAO : PCR Javols/Anderitum).

pondant sans doute plutôt à des évacuations et égouts qu'à des alimentations. On n'en connaît pratiquement rien mais il est plus que plausible que ce balnéaire soit alimenté depuis le vallon du Cros, où des sources sont attestées (GermerDurand, 1888 ; Morel, Bardy, 1959, p. 16), et la fontaine publique du carrefour D4-C2 est aussi alimentée depuis cette direction, en passant par le bassin de la «domus Peyre ».

Rien de probant ne peut être en revanche proposé côté est et en rive droite de la rivière, mais il reste en revanche possible que la canalisation (deux états) mise au jour dans le sondage 9 de JMP.00 (rive gauche) corresponde à une adduction de caractère public ${ }^{39}$. Enfin, même si elle aboutit à un réceptacle disposé apparemment dans un ambitus, la petite adduction d'eau de JSE.98 semble plutôt de caractère privé (fig. 17 et 18).

Il est donc en définitive possible qu'Anderitum n'ait pas été alimentée essentiellement par un ou plusieurs aqueducs " classiques », partant de sources éloignées de la ville, mais plutôt directement par prélèvement sur la rivière (pompes, noria ?), ainsi qu'au moins en partie par des captages de sources et par puits, dont plusieurs sont connus.

Cependant, une petite adduction, traversant d'abord une demeure privée où elle alimente un bassin, fournit en eau une fontaine publique (Agusta-Boularot, 2008), à l'angle du decumanus D4 et du cardo C2 (voir infra, p. 204).

39. Datée par ${ }^{14} \mathrm{C}$ de la fin du $\mathrm{I}^{\mathrm{er}} \mathrm{s}$. ou du début du $\mathrm{II}^{\mathrm{e}} \mathrm{s}$.

\section{D'AUTRES ÉDIFICES PUBLICS ?}

On mentionnera, à titre d'hypothèse, peut-être comme schola, siège d'une corporation, l'édifice localisé sur le côté est du cardo C3 dont l'entrée monumentale en grand appareil a été explorée en JTD.04 (fig. 10), en rappelant qu'une hypothétique schola a été proposée par d'autres pour la boutique de la «domus Peyre » devant laquelle fut mise au jour la statue de Silvain/Sucellus (Béal, Peyre, 1987).

Faut-il enfin interpréter comme de possibles entrepôts publics (horrea) les bâtiments mis au jour en bordure des « quais » en rive gauche et parallèles à ceux-ci (fig. 4), par Ch. Morel qui propose d'y voir des bains, interprétation difficile à retenir au vu de sa description (Morel, 1962, p. 98-99 et plan, pt. IV) ? Ces édifices présentent en effet un système d'hypocauste connu dans certains bâtiments de stockage du nord de la Gaule, mais ceci reste bien sûr très conjectural.

\section{HABITAT PRIVÉ ET VIE QUOTIDIENNE}

Des éléments d'habitations privées ont été mis au jour en de nombreux points de l'agglomération antique, mais seuls trois d'entre eux constituent des ensembles suffisamment complets et cohérents pour permettre d'y voir de véritables domus urbaines. 


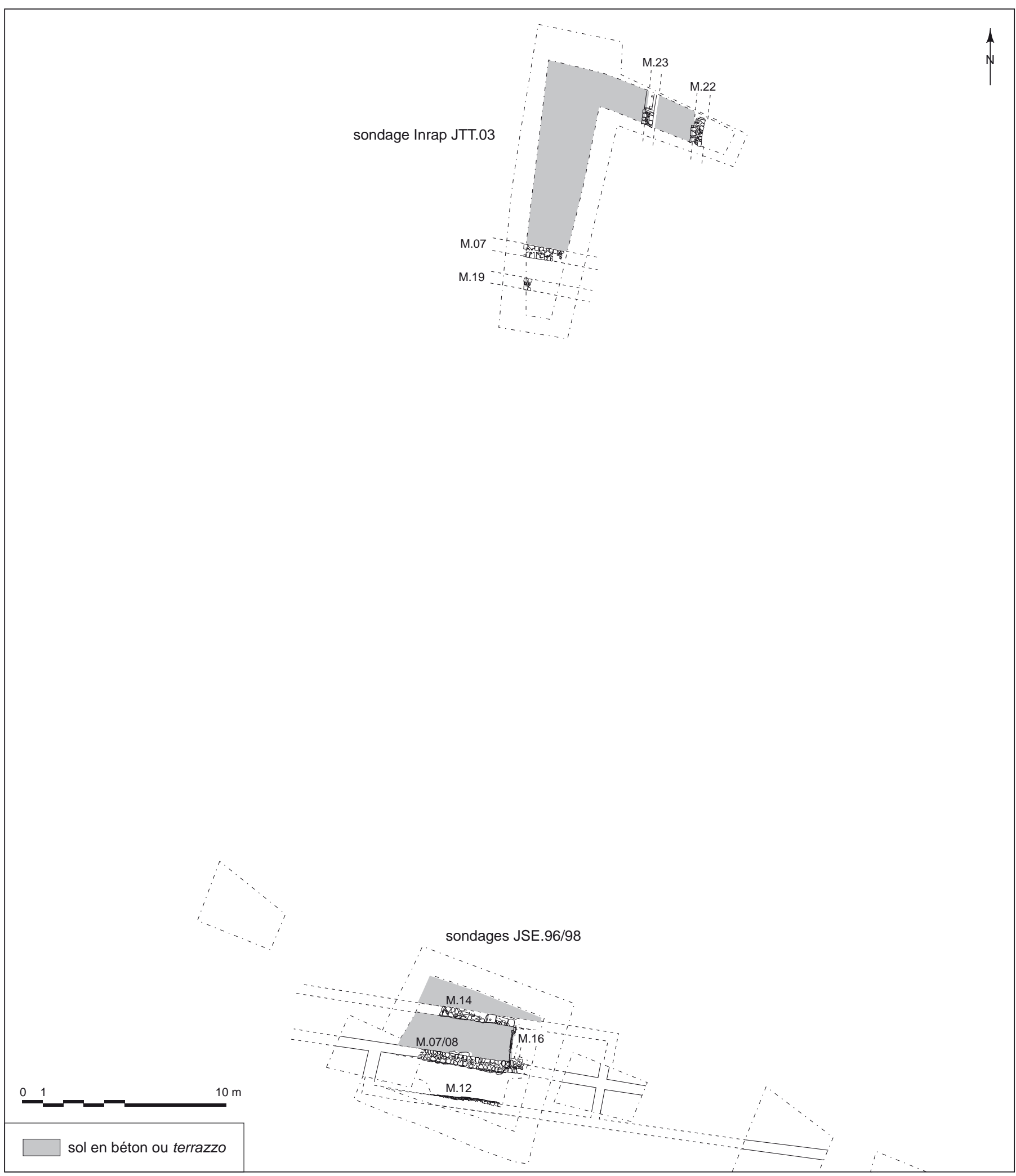

Fig. 18 - Plan synthétique de la $2^{e}$ phase (II ${ }^{e}$ s.) des constructions reconnues en JSE.96/98, avec les éléments du diagnostic Piskorz en 2003 (DAO : PCR Javols/Anderitum). 


\section{LA « DOMUS PEYRE »}

La première correspond à l'ensemble - non interprété alors comme telle - mis au jour par l'abbé Peyre à l'ouest du cardo C2 (Peyre, 1969a et b, p. 51-56, 1970a et b, 1971a et b, 1972, 1973, 1974, 1975a et b, 1976b et 1978a ; Béal, Peyre, 1987) ${ }^{40}$. Elle comporte trois ou quatre corps de bâtiments établis en terrasses autour d'une cour centrale (fig. 8).

- À l'est, le long du cardo, se développent quatre - voire cinq (au nord, non fouillée) - «boutiques » ouvrant sous le portique de la rue ; un étage devait se développer au-dessus, compte tenu de la dénivellation supérieure de la cour intérieure ; du nord au sud, outre celle supplémentaire supposée, la première boutique comporte un atelier de bronzier et on y a découvert la statue de Silvain/Sucellus. La deuxième présente un foyer mural d'un type connu, y compris à Javols, tant en contexte domestique qu'artisanal, et par ailleurs deux colonnes déposées horizontalement au fond de la pièce ; elle présente aussi un bassin en dalles de granite à l'extérieur, sur rue, et a également livré des éléments de travail du bronze ; l'abbé Peyre y restitue aussi un laraire, fort conjectural. La troisième boutique pouvait comporter un escalier d'accès à la cour. Enfin, la quatrième enfin, plus étroite, clôt l'ensemble du côté du decumanus D4 (et ici un portique ?). De telles boutiques sur rue peuvent parfaitement dépendre de la domus privée d'un riche propriétaire gabale.

- Au nord, les fouilles ont été superficielles et les pièces fouillées seulement en partie : deux salles au sol de terrazzo s'ouvrent sur la cour, celle de l'ouest par un seuil massif ; celle-ci comporte un puits ; un portique a pu exister côté cour.

- À l'ouest, seul un mur de terrasse nord-sud a été mis au jour, mais il pouvait maintenir un corps de bâtiment se développant ici et aujourd'hui quasi totalement arasé par l'érosion. Le cardo C1 que l'on restitue à l'ouest passerait nettement plus à l'ouest, au-delà des limites de la fouille.

- Au sud enfin, les substructions sont également très arasées et il n'en subsiste qu'une cave, côté cour ; ce dernier corps de bâtiment ouvrait, peut-être avec l'entrée principale de la domus, sur le decumanus $\mathrm{D} 4$.

- Quant à la cour - où l'abbé Peyre voit une petite place publique -, le bassin en dalles de granite mis au jour pourrait être situé au centre, notamment si l'on admet un portique au nord ; un second puits est également présent au nord-ouest. C'est de cette direction que devait être assurée l'alimentation en eau du bassin, qui se déverse ensuite par

40. Fouilles complétées par des observations de R. Pierobon (1987, p. 5-6 et 1988) et par une série de nos propres sondages (JLP.99 et JLP.03) ; voir aussi Trintignac, 2007a. une canalisation dans la fontaine publique à l'angle de C2 et D4.

Les datations proposées par l'abbé Peyre pour cette maison urbaine concordent apparemment avec les données de nos sondages de vérification : construction vers le milieu du I ${ }^{\mathrm{er}}$ s. apr. J.-C., puis évolution jusqu'à une destruction au début du $\mathrm{III}^{\mathrm{e}} \mathrm{s}$.

\section{UNE DOMUS EN JSF.99/00/05}

La deuxième maison urbaine regroupe les différents états de construction mis au jour en JSF.99/00/05 (fig. 19) : une possible cour centrale est entourée de divers bâtiments et accompagnée à l'est d'une vaste terrasse entaillée dans le granite et ouvrant vers le vallon au sud, qui présente deux états du Haut-Empire et est remblayée au début du $\mathrm{III}^{\mathrm{e}} \mathrm{s}$. C'est au nord de cette dernière qu'a été fouillée la resserre incendiée au début du $\mathrm{II}^{\mathrm{e}} \mathrm{s}$. qui a fait l'objet d'une récente publication (Marot dir., 2007) ; juste au nord-ouest, un puits a en outre été mis au jour. Les différents états de cette habitation s'étagent pour l'essentiel du début du I ${ }^{\mathrm{er}} \mathrm{s}$. apr. J.-C. au début du III $^{\mathrm{e}}$ s., avec, en partie basse, une occupation tardive, jusqu'au $\mathrm{VI}^{\mathrm{e}} \mathrm{s}$.

Il est en fait possible qu'on ait affaire non à une mais à deux maisons, l'une sur la cour ouest, l'autre sur la « terrasse » est ; d'autres éléments d'habitat avaient été repérés auparavant un peu plus au sud (observations du " terrain de camping ", Peyre, 1975b et 1976b ; voir Barruol, 1978, p. 459 ; Fages, 1992 et 1999 , p. 2). On a supposé le passage d'une rue au nord de cet ensemble (voir supra, p. 193).

\section{UNE DOMUS EN JPN.02/04/05-07}

La troisième domus, enfin, est en cours de fouille pour ces états les plus anciens et constituera sans nul doute la domus la plus complètement étudiée à Anderitum, mais on ne peut en présenter ici qu'un premier aperçu, d'autant que la jonction entre les deux sondages au nord et la grande fouille au sud n'a pas encore été étudiée. Cette vaste domus s'ouvre à l'est sur le portique ouest du cardo C3 et paraît limitée à l'ouest par un long mur ininterrompu, peut-être bordé à l'extérieur d'un ambitus (fig. 20). On ne connaît pas sa limite nord, sans doute au mur nord de la cuisine fouillée en 2002 mais n'atteignant vraisemblablement pas le decumanus $\mathrm{D} 2$, et sa limite sud au bord de la fouille 2005-2007 n'est pour l'instant qu'une hypothèse, alors peut-être à proximité du decumanus D3 extrapolé ici (sur cette rue et cet ambitus, voir supra, p. 190 et 193). 


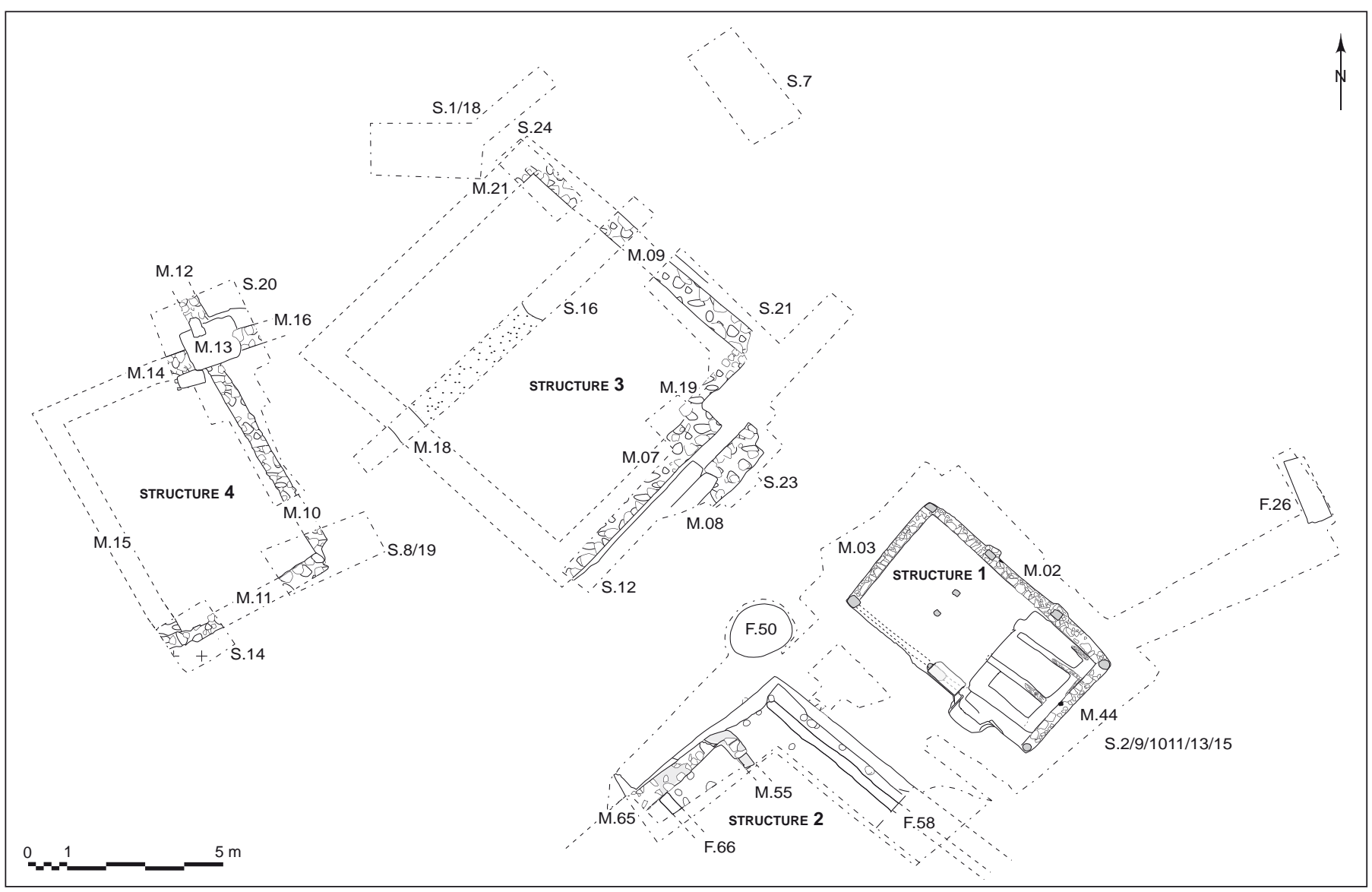

Fig. 19 - Plan de la (ou des) domus en JSF.99/00/05 (DAO : PCR Javols/Anderitum).

Elle pourrait présenter, au moins dans son premier état, vers le sud de la fouille, une cour peut-être à péristyle et de nombreuses pièces d'habitation, la plupart pourvues de sols de béton au Haut-Empire. Au nord-ouest est installée une vaste cuisine, équipée de trois fours (fig. 21). Plus au sud, une pièce présente un foyer mural en demi-cercle ; elle possède en outre, dans son état du $\mathrm{II}^{\mathrm{e}} \mathrm{s}$., un important réseau de drainage-évacuation des eaux.

Un premier état pourrait être assez précoce (augustéen?), et elle subit ensuite de nombreux agrandissements et modifications, jusqu'à une destruction assez radicale au début du $\mathrm{III}^{\mathrm{e}}$ s. (incendie). Pour le Bas-Empire, seul un édifice plus réduit, au sud-ouest, est reconstruit.

\section{AUTRES MAISONS URBAINES}

Les autres vestiges d'habitations privées mis au jour ici ne concernent que des éléments très partiels, mais présentant dans certains cas plusieurs états.

\section{À l'ouest de la ville (rive gauche)}

- En JSE.98 (fig. 17), un ambitus sépare apparemment deux maisons, dont seule celle située au nord a été en partie explorée, avec quelques murs, constituant des espaces établis en terrasse ouest-est, un seuil et un possible portique ; une petite adduction d'eau (deux états) la traverse pour se déverser dans un réceptacle situé dans l'ambitus. L'évolution constatée va de la première moitié du I ${ }^{\mathrm{er}}$ s. apr. J.-C. au VI ${ }^{\mathrm{e}}$ s., ce réaménagement tardif n'étant apparemment que partiel. Il faut sans doute associer à cette maison septentrionale les constructions mises au jour dans le diagnostic 2003, un peu plus au nord (Piskorz, 2003). Ce dernier ensemble, constitué d'une grande salle nord-sud avec galerie à l'est, constituerait alors une seule domus, assez importante.

- Des éléments apparemment liés à des habitats ont été signalés lors de travaux, d'une part au sud de la place du bourg actuel, de l'autre près du pont moderne (Fages, 1991a, p. 1, fig. 5 et p. 3 sq., fig.). 


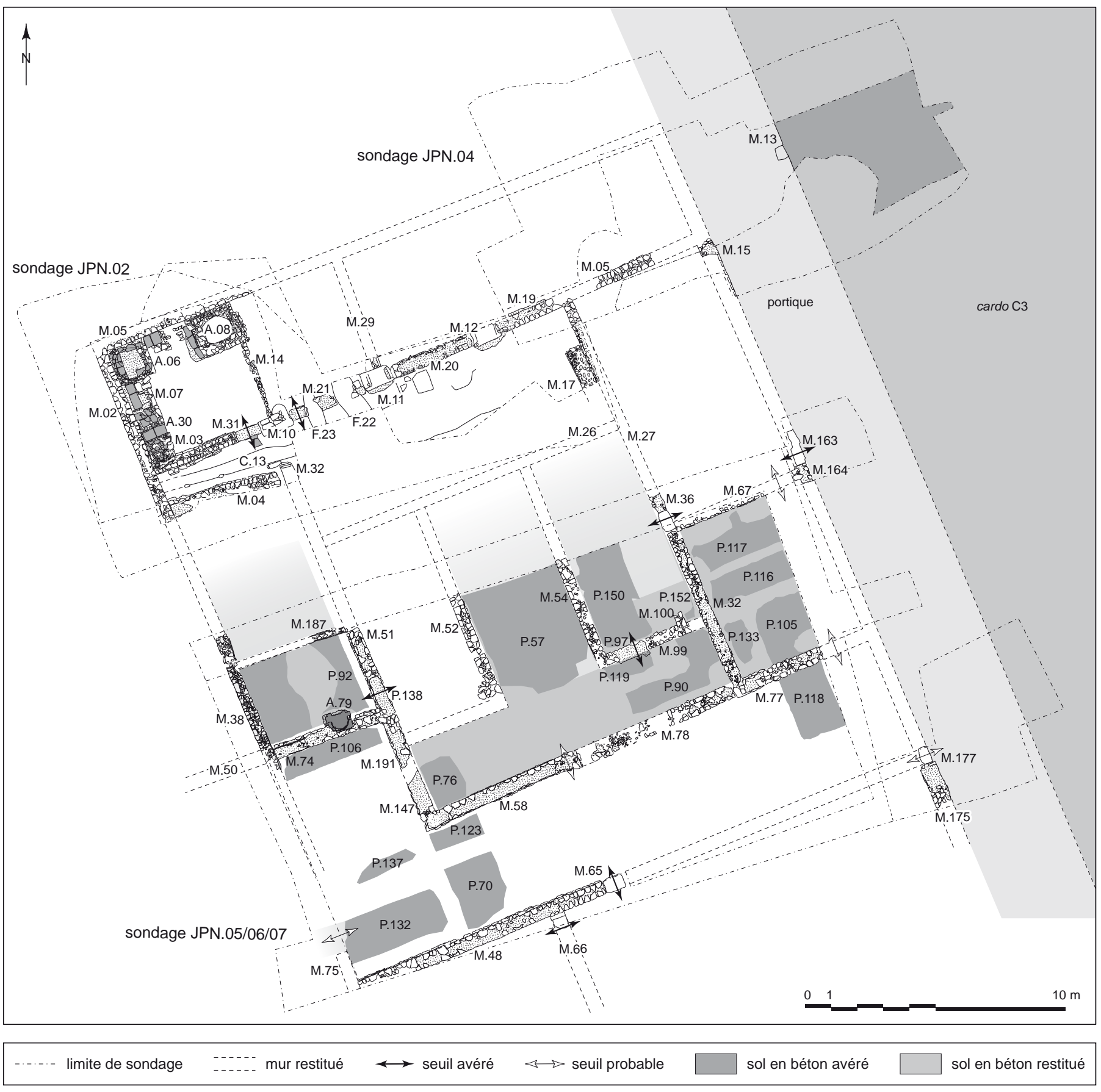

Fig. 20 - Plan de l'état $2 a$ (II s.) de la grande domus en JPN.02/04/05-07 (DAO : PCR Javols/Anderitum).

- En JEF.98 (fig. 22), une portion de domus, avec des salles chauffées (un praefurnium et une autre salle sur hypocauste desservie par un autre praefurnium non mis au jour) et avec des décors relativement luxueux (enduits peint, stucs...), est datée du $\mathrm{II}^{\mathrm{e}} \mathrm{s}$. et fut apparemment détruite au $\mathrm{III}^{\mathrm{e}} \mathrm{s}$.
- En JMP.00, le sondage le plus proche du pont et du bourg, à l'est, n'a mis au jour que quelques éléments de murs, en partie récupérés, pour une occupation des $\mathrm{I}^{\mathrm{er}} \mathrm{s}$. et $\mathrm{II}^{\mathrm{e}} \mathrm{s}$.

- En JLG.02 (fig. 23), plusieurs états d'une habitation installée en terrasses successives sur la pente de la colline 


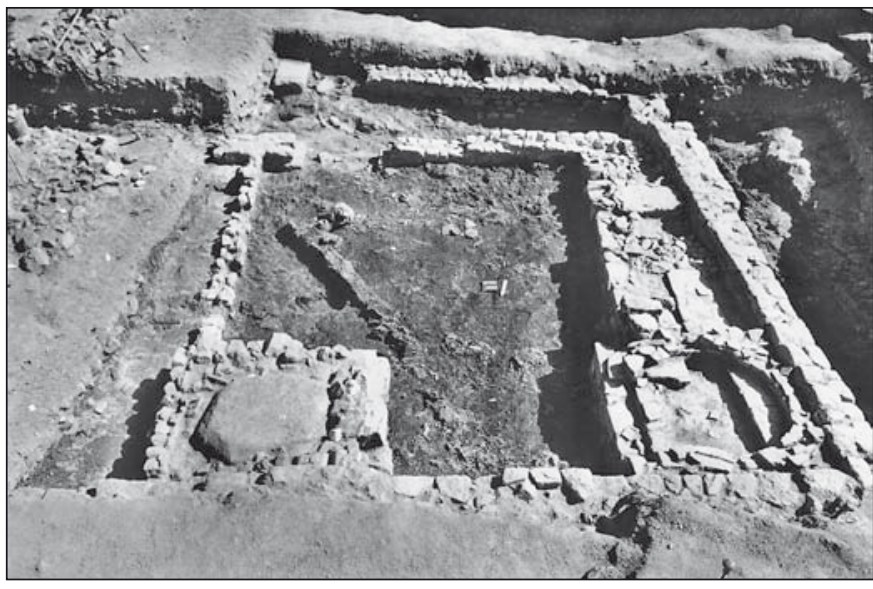

Fig. 21 - Vue du nord de la cuisine de la domus nord (JPN.02), en fin de fouille, avec ses trois fours (celui d'en haut à droite, condamné dans un second état); derrière le four de gauche, vers le centre: éléments de charpente brûlée (cliché : PCR Javols/Anderitum).

ouest ont été mis en évidence, avec des foyers aménagés. Cet ensemble est sans doute à associer au sondage Pierobon un peu plus au sud (Pierobon, 1989a et b, p. 9, fig. 18-19 ; Pierobon-Benoît, 1993b, p. 19), avec son foyer mural, et aux observations faites entre les deux en 2005 (JBS.05) ${ }^{41}$. On suppose, à titre d'hypothèse, que le mur le plus au nord-est des sondages JLG.02 est en bordure du cardo $\mathrm{Cl}$ qu'on restitue ici (voir supra, p. 192) et que cette (ou ces) habitation(s) borderai(en)t côté ouest sans en garder l'axe, ici d'ailleurs divers et adaptés au terrain. Sur ces différents points d'observation, l'occupation ne concerne que le Haut-Empire et s'interrompt (par un incendie ?) au début du III $\mathrm{e}$.

\section{Dans la partie centrale du site (rive gauche)}

- Rappelons qu'on ne voit pas pour l'instant, en l'état des connaissances ${ }^{42}$, un quartier d'habitation immédiatement au nord de la basilique ; ces bâtiments correspondant apparemment plutôt à un état antérieur de l'ensemble civique (curie ?, voir supra, p. 197).

- Au sud du decumanus D4, en face de la «domus Peyre " (fig. 8), c'est apparemment une habitation privée qui prenait place, dont on ne connaît que la bordure nord sur rue, avec une salle chauffée sur hypocauste (Peyre, 1970b, p. 34 ; Pierobon, 1999, p. 16 ; Pierobon-Benoît, 1993b, p. 31 ;

41. Ainsi qu'à des observations de l'abbé Peyre un peu au nord-est de JLG.02 (Peyre, 1970a, p. 9 et p. $16 ; 1970$ b, p. 27 et p. 35).

42. On souffre malheureusement ici aussi beaucoup de l'absence de données précises, et notamment chronologiques, pour les fouilles Pierobon.

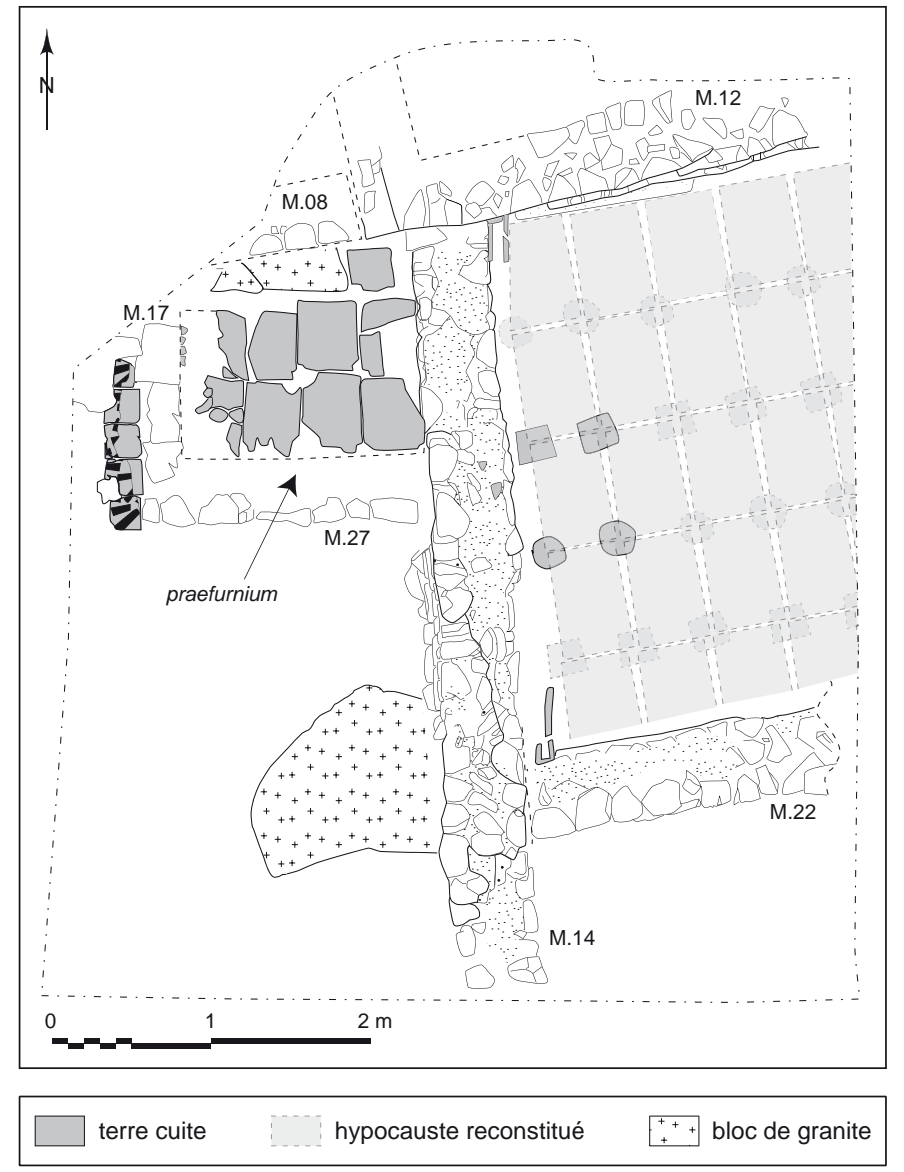

Fig. 22 - Plan de JEF.98 (DAO : PCR Javols/Anderitum).

Trintignac, 2007a) ; son mur pignon oriental est effondré, couché en place sur le cardo C2 (élévation d'au moins $8 \mathrm{~m}$ de haut, apparemment sans ouverture, et comportant un rampant en tuiles en bordure supérieure), ainsi qu'une portion importante de son mur nord sur le decumanus $\mathrm{D} 4$.

- Le bâtiment à entrée monumentale de JTD.04, s'il ne s'agit pas d'un édifice public (voir supra, p. 202), constituerait certainement une domus importante.

- Dans le sondage Pierobon au sud du centre civique (Pierobon, 1990, p. 3-4, plans 6 et 7, fig. 1-2), dans l'insula près de l'angle sud-ouest du forum, c'est un « atelier » qui est signalé, mais il pourrait s'agir d'un habitat.

-Enfin, rappelons que l'on n'interprète pas le bâtiment IV de Ch. Morel (1962, p. 98-99 et plan) comme une habitation privée (voir supra, p. 202).

\section{Au sud (rive droite)}

- Les éléments d'une ou deux habitations sont signalés dans les fouilles du XIX ${ }^{\mathrm{e}}$ s. (Ignon, 1840-1841, p. 157 ; Moré, 


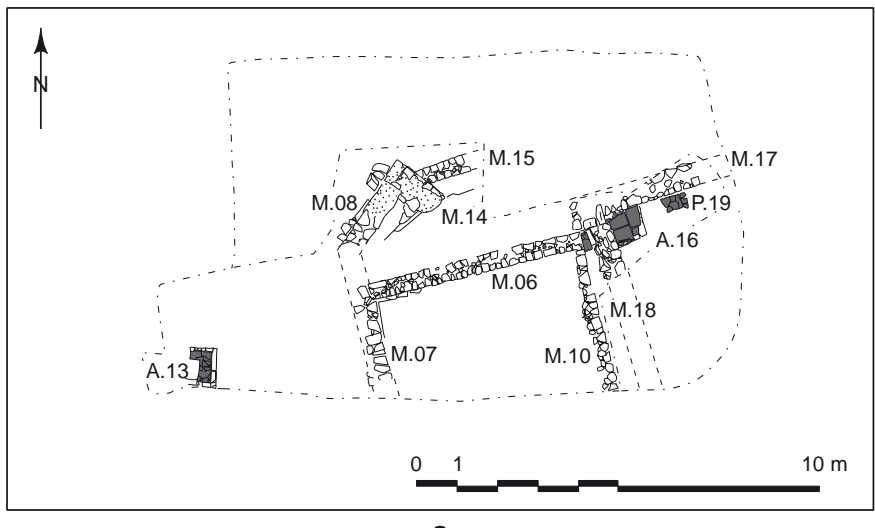

a

Fig. 23 - Plans des différents états des constructions en JLG.02, complétés par les données des observations de JBS.05 (travaux) et du sondage Pierobon du terrain Sylve: a, états 1 et 2 ( $I^{e r}$ s.-début du II $\left.s.\right)$; b, état 3 (fin du II $I^{e}$ s.début du III ${ }^{e}$ s.) (DAO : PCR Javols/Anderitum).

1856a et b, 1858a, p. 100-102), sans doute entre l'édifice de spectacle et « l'Oustal Neuf » : au moins deux salles, dont l'une pourrait correspondre à des bains (?), et présentant des sols bétonnés, voire mosaïqués (?).

- C'est apparemment un ensemble privé qui succède à une phase cultuelle préromaine et précoce de JBN.01/04 ; le plan de ces constructions est très lacunaire.

- Le bâtiment découvert en JTM.00/01 (fig. 24), apparemment constitué d'une pièce unique et isolée, pourrait être une remise, liée à un habitat situé un peu plus à l'est (renseignements oraux P. Tranchard, 2000) et sans doute à un captage de source observé juste au sud-est (JEE.01). Recoupant une fosse du $\mathrm{I}^{\mathrm{er}}$ s., cet édifice semble condamné au $\mathrm{III}^{\mathrm{e}} \mathrm{s}$. au plus tard; il faut noter que c'est dans les colluvions supérieures qu'a été mis au jour l'unique tesson de sigillée d'Argonne découvert sur le site.

- Ch. Morel a repéré, juste à l'ouest de "l'Oustal Neuf ", des constructions (Morel, 1962, p. 105-106 et plan, pt. VIII, IX et $\mathrm{X}$ ) : quelques murs, pour trois états, avec des traces d'incendie ; le premier état pourrait être précoce, voire préromain.

- On rappellera enfin ici que l'on attribue les murs mis au jour par Ch. Morel immédiatement au nord de l'édifice de spectacle à la structure même de ce monument et non à une construction privée (voir supra, p. 200-201).

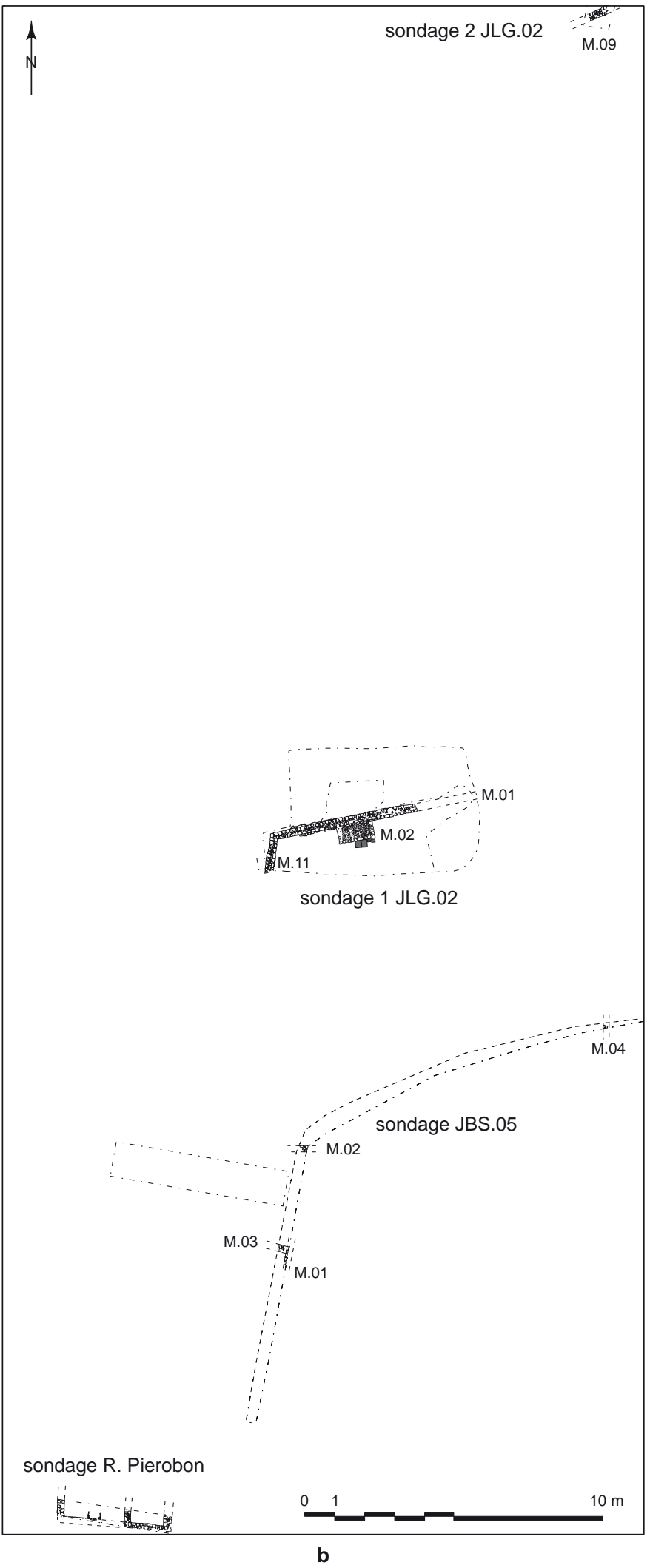




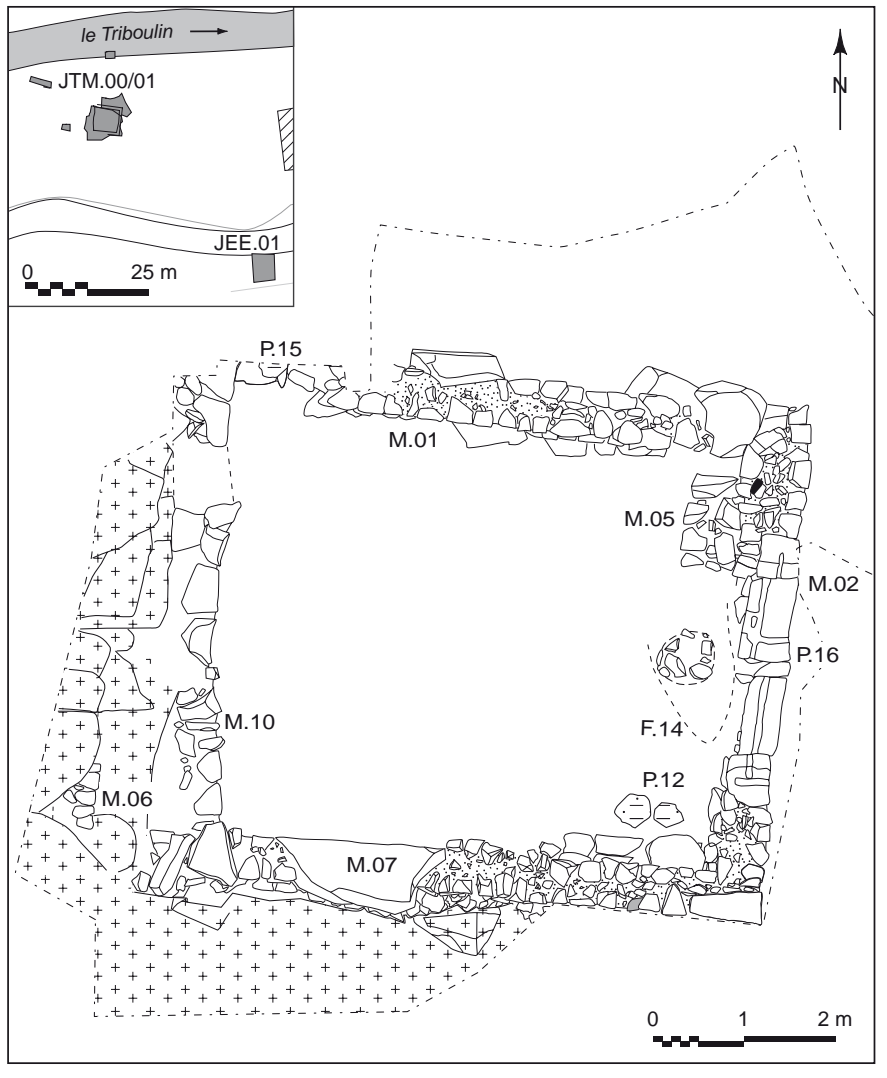

Fig. 24 - Plan du bâtiment en JTM.00/01 : en vignette, emprise de la fouille et emplacement de l'observation en JEE.01 (captage) (DAO : PCR Javols/Anderitum).

\section{À l'est (rive droite)}

- En JLV.99, quelques éléments très arasés par l'érosion d'une habitation (trois murs et une structure de stockage excavée) sont attribuables au $\mathrm{II}^{\mathrm{e}} \mathrm{s}$.

- En JRE.02, en revanche, le dépotoir de bronzier découvert n'est pas associé à des constructions ; un bâtiment mis au jour immédiatement à l'ouest (sauvetage Chardonnet, 1995) est interprété comme un atelier (forge).

- En JMA.06, en bordure du Triboulin, deux murs perpendiculaires ont été mis en évidence, pour une occupation datée de la seconde moitié du I $^{\text {er }}$ s. et qui a pu perdurer jusqu'au Bas-Empire.

- En JLD.00 enfin, en limite nord de la ville, ce sont quelques murs récupérés et deux canalisations (évacuations), qui ont été mis au jour, datés du $\mathrm{II}^{\mathrm{e}} \mathrm{s}$. ; en effet, le mobilier tardif découvert ici l'a été dans des dépôts de colluvions postérieurs, issus de la colline du « Mas Astruc », à l'est.
Force est donc de constater qu'on ne connaît en l'état à Anderitum aucune grande domus urbaine "classique » à péristyle central, telle qu'on en connaît de nombreux exemples dans les villes de Narbonnaise et d'autres provinces gauloises (voir par exemple : Maison..., 1996a et b).

\section{L'ESPACE DES MORTS À ANDERITUM}

En termes d'espaces publics, de nouveau, il est nécessaire d'aborder la question de la place des morts à Anderitum. La localisation des nécropoles, toujours rejetées hors de l'urbs, est un élément déterminant pour définir l'espace urbain de ce site. Nous avons eu la chance, en 2001 et 2002, de découvrir, assez fortuitement, deux «nécropoles " de la ville gallo-romaine du Haut-Empire (voir Godignon, 2004 et 2005), alors que l'emplacement de ces espaces funéraires était jusqu'alors inconnu et que le seul élément signalé en la matière était le cippe funéraire épigraphe d'Albinus Senator, dont on ignore le lieu de découverte (Ignon, 1840-1841, p. 153 ; CIL, XIII, 1558).

\section{LA NÉGROPOLE OCCIDENTALE}

Les sondages JPO.01 ont permis de localiser cet espace funéraire à l'ouest de l'agglomération, au-delà du plateau qui la domine de ce côté et à la tête du vallon remontant du "Cros », et peu éloigné du tracé traditionnellement admis pour le passage de la voie vers ad Silanum et Rodez.

À proximité d'une première incinération fouillée en 2001, sur un espace d'environ $50 \mathrm{~m}^{2}$, trois autres ont été mises au jour en JPO.02 (fig. 25), toutes datées du milieu du I ${ }^{\text {er }}$ s. apr. J.-C. (40-50/60-70 apr. J.-C.), avec des indices montrant l'érosion d'autres sépultures gallo-romaines dans le secteur. Il s'agit d'incinérations en urnes (cruches ou bols), accompagnées dans les fosses du rejet en vrac du mobilier d'accompagnement du défunt sur le bûcher.

Cette localisation, non directement au contact de la voie vers Rodez, est un argument pour étayer l'hypothèse d'une «déviation » de cette voie par le vallon du Cros (voir supra, p. 178-179, praticable par les chariots, et au contact de laquelle aurait été établie cette nécropole occidentale de la ville, dès la première moitié du $\mathrm{I}^{\mathrm{er}} \mathrm{s}$.

\section{LA NÉCROPOLE ORIENTALE}

Les indices d'une deuxième nécropole ont été mis en évidence au-delà des limites de l'extension urbaine, sur la pente de la colline surplombant le site à l'est, en JRE.02, et 


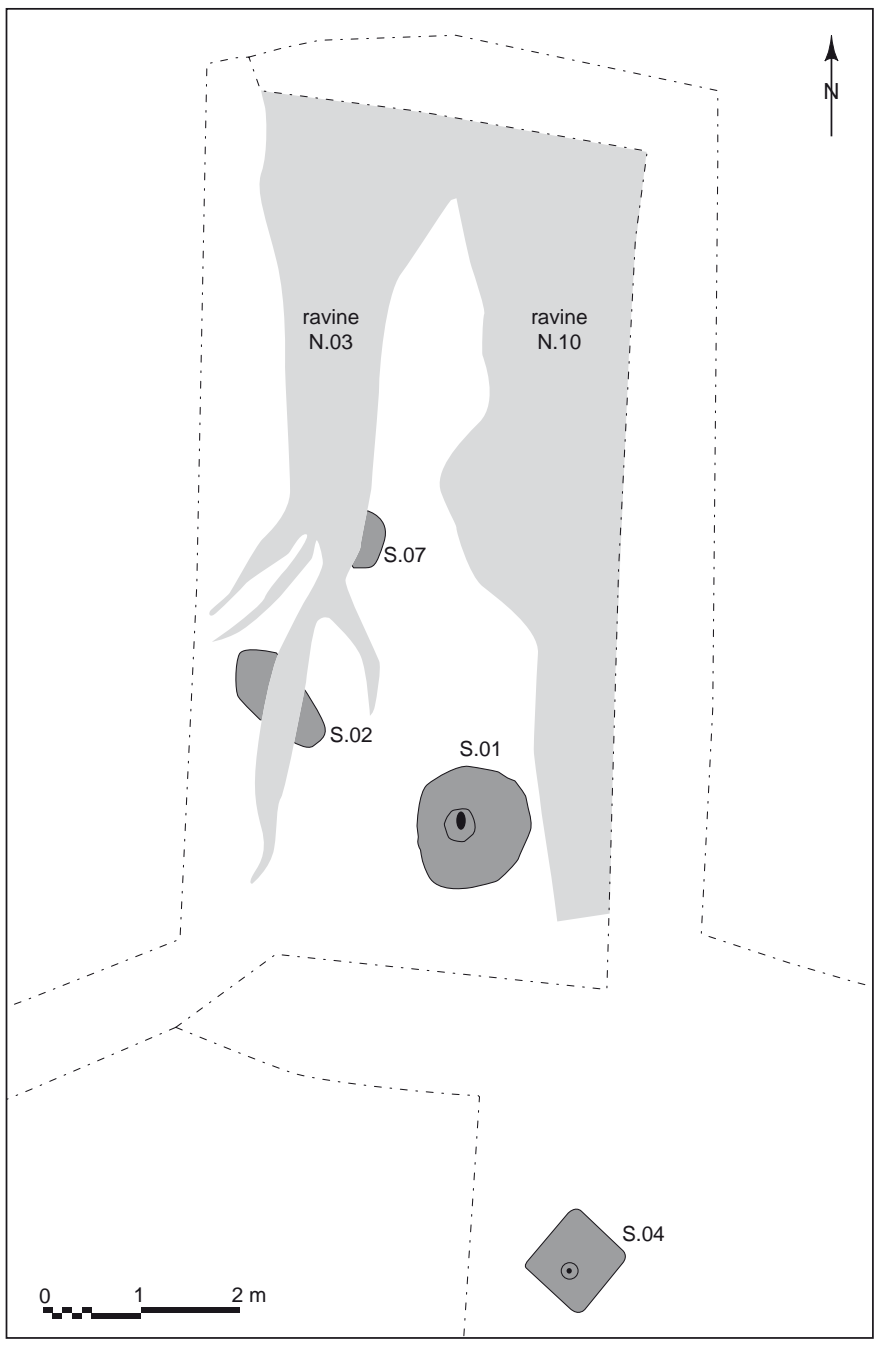

Fig. 25 - Plan des sépultures à incinération connues de la nécropole occidentale en JPO.01/02 (DAO : PCR Javols/Anderitum).

à une certaine distance (plus de $150 \mathrm{~m}$ ) au nord de la voie partant vers Lyon pour son tracé « traditionnel ».

Ici, une incinération respectant les mêmes pratiques que pour la nécropole occidentale, mais un peu plus tardive (milieu du II $^{\mathrm{e}}$ s. : 120/130-160/170) a été mise au jour, ainsi qu'une inhumation, parallèle, à proximité : celle-ci est sans corps, détruit par l'acidité du sol, et sans mobilier (hormis une imbrex à l'emplacement présumé de la tête) et donc indatable, mais sans doute aussi attribuable par sa typologie au Haut-Empire. Ici aussi, des indices d'autres incinérations érodées ont été recueillis.

Quasi symétriquement à ce qu'on suppose à l'ouest, on a émis l'hypothèse que la «déviation » mentionnée pour le vallon du Cros remontait ici par le vallon du « Mas Astruc », immédiatement au nord de ces sépultures, pour rejoindre la voie principale sur le plateau plus à l'est : ce second espace funéraire pourrait donc avoir été installé ici au contact de cette « rocade ", peut-être un peu plus tard que la nécropole occidentale (voir supra, p. 178-179).

\section{DEUX NÉCROPOLES DE L'ANTIQUITÉ TARDIVE ET DU HAUT MOYEN ÂGE}

Pour la fin de l'Antiquité, une nécropole doit être située au sud-ouest du site, fouillée en JAE.98 mais s'étendant au-delà (informations orales) : 11 inhumations en caissons de pierre, parfois avec dalles de couverture, sans mobilier, datée récemment par ${ }^{14} \mathrm{C}$ de la fin du IV ${ }^{\mathrm{e}}$ s. au milieu du VI ${ }^{\mathrm{e}}$ s. ou du VII ${ }^{\mathrm{e}} \mathrm{s}$.

Un autre cimetière du haut Moyen Âge (VII ${ }^{\mathrm{e}}-\mathrm{IX}^{\mathrm{e}}$ s.) a été mis en évidence dans le bourg, à l'emplacement de l'ancienne église (JAE.96) (fig. 7), en relation avec un édifice que l'on suppose être la première église chrétienne de Javols (voir supra, p. 186).

Il s'agit d'inhumations en pleine terre, à l'exception de la plus ancienne, en coffre maçonné, et sans mobilier, datée par ${ }^{14} \mathrm{C}$. Un groupe d'une dizaine d'inhumations a été mis au jour ici, auquel on peut éventuellement rattacher la sépulture isolée fouillée à une quarantaine de mètres au nord du presbytère, en JBR.97.

Ce lieu funéraire du haut Moyen Âge, sans doute lié à la toute première église, donnera naissance au cimetière paroissial qui, jusqu'au XIX ${ }^{\mathrm{e}}$ s., s'étendait à l'ouest et au nord-ouest de l'ancienne église. On signale d'ailleurs la découverte, à proximité, de « tombes» en pierre (sarcophages), notamment dans cet ancien cimetière (Moré, 1958a, p. 108).

\section{QUELQUES ESPACES FUNÉRAIRES MODERNES ET CONTEMPORAINS}

Mentionnons enfin, pour être complets en matière de lieux funéraires à Javols, quelques informations orales sur des tombes découvertes fortuitement, par exemple à l'ouest de l'Oustal Neuf, ou encore une inhumation isolée près du pont, fouillée lors de la surveillance archéologique de l'assainissement du bourg (Fages, 1991, p. 4).

\section{LA CONSTRUCTION ET LE CONFORT : MATÉRIAUX ET TECHNIQUES}

De fait, la construction à Anderitum, qu'il s'agisse des matériaux ou de leur mise en œuvre, ne présente pas de caractères particuliers par rapport à d'autres chefs-lieux de 
cité des Trois Gaules, si ce n'est quelques aménagements, apparemment essentiellement dus à une volonté d'adaptation aux conditions naturelles du site (pierre locale, eau, climat).

La construction la plus courante, classique pour la période, est en petit appareil, aux joints parfois tirés au fer : les murs sont en général plutôt étroits (autour de $0,50 \mathrm{~m})$ - du moins dans la construction privée - et les moellons mis en œuvre se touchent en général presque par leur pointe à l'intérieur du mur, laissant peu de place au blocage. La brique (ou plutôt des tegulae récupérées) est assez rarement utilisée. L'ensemble est lié au mortier maigre - la chaux étant il est vrai sans doute en partie altérée par l'acidité du sol -, de telle sorte que les fondations font, en tout cas aujourd'hui, office de drains. Les fondations ne sont pas toujours très profondes mais la plupart du temps sont également maçonnées, et les angles sont assez souvent marqués de carreaux et boutisses plus importants.

Les élévations sont en général méconnues, du moins sur une grande hauteur, sauf par exemple pour le mur pignon complet abattu d'une domus à l'ouest du cardo C2, à hauteur de la «basilique » (voir supra, p. 207). Il n'est donc pas impossible qu'une partie de ces élévations ait été en «matériaux légers » (terre et bois) : c'est par exemple ce qu'on restitue (pans de bois et bauge) pour la resserre incendiée en JSF.99/00 (Marot dir., 2007). Des cloisons étroites en bois, sur sablière basse, sont en tout cas attestées en plusieurs points.

Outre ce mortier - et en rappelant que dans ce pays granitique, la chaux devait être une denrée rare, importée ; des bacs au chaux ont été mis au jour au XIX ${ }^{\mathrm{e}} \mathrm{s}$. dans les thermes ouest (Moré, 1859), ainsi que récemment dans la domus JPN.07 -, les matériaux de construction sont très majoritairement locaux, comme il est habituel : granite et granulite (plus dure, notamment pour les moellons de parement) : on en connaît d'ailleurs trois carrières antiques aux portes de la ville (voir supra, p. 177). Ce matériau local constitue donc les moellons de parement comme le blocage interne des murs. Le grand appareil est apparemment réservé, comme c'est souvent le cas, à la construction publique, si ce n'est pour des seuils monolitiques ou quelques marches d'escaliers.

C'est aussi aux édifices publics que sont majoritairement réservés les matériaux de construction importés, à savoir le grès en petite quantité, d'une dizaine de kilomètres au nord, le schiste (utilisé à l'époque romaine en couverture ou surtout en fond de canalisations, apparemment jamais en toiture comme récemment ici), de quelques kilomètres au sud, et surtout divers calcaires - sans compter l'intense récupération dont ces pierres ont dû faire l'objet après l'Antiquité, notamment pour la chaux -, de plusieurs dizaines de kilomètres au sud au moins. Mais on en connaît aussi des exemples en contexte privé (par exemple dans la grande domus de JPN.05/07). Ainsi, des éléments architecturaux en calcaire, tendre, dur, ou encore " du Midi ", exceptionnellement en parement (édifice de spectacle), sont signalés dans les fouilles anciennes (Ignon, 18401841, p. 157, p. 159 et p. 167-171 ; Portal, 1890, p. 7 ; Morel, 1962, p. 101) et répertoriés ça et là sur le site (Noël, 2002) : éléments de fûts de colonnes ou colonnettes, bases et chapiteaux, pilastres, corniches...

Enfin, pour les matériaux courants, les terres cuites architecturales sont classiques : tegulae et imbrices en toiture, quelques rares briques, plus couramment des tegulae en arases de construction dans l'opus mixtum (assez rare), carreaux carrés ou circulaires pour les pilettes d'hypocauste (exemple unique de pilettes monolitiques en granite dans les thermes orientaux) et briques striées ou surtout tubuli pour les parois des salles chauffées, ainsi que les tuiles « en ogive ", en terre cuite, des thermes occidentaux (voir supra, p. 201). Il faut noter ici la mise en évidence d'un type particulier d'imbrex, cannelé et à pâte claire, précoce ; en revanche, un seul antéfixe est attesté à ce jour, en JSF.05. Le seul atelier de terres cuites architecturales connu à proximité se situe à Serverette (JPR.07) et n'a produit que des tuiles au Haut-Empire.

Pour la décoration, divers marbres, voire calcaires durs, sont aussi assez systématiquement mis en œuvre pour la décoration architecturale, en contexte public aussi bien que privé (Maljean, 2006 ; avec la collaboration de A. et $\mathrm{Ph}$. Blanc) : certains sont d'origine lointaine, méditerranéenne, et constituent, en plaquettes, des revêtements muraux, voire parfois des corniches ou autres éléments de décor architectural.

Les sols sont souvent bétonnés, parfois en terrazzo (« domus Peyre », etc.), exceptionnellement mosaïqués : hormis la mosaïque de la supposée curie (voir supra, p. 197 et Pierobon, 1997, p. 17), une seule mosaïque en place est signalée au XIX ${ }^{\mathrm{e}} \mathrm{s}$. dans une habitation en rive droite du Triboulin (voir supra, p. 208 et Moré, 1856a et b) ; ailleurs pourtant, partout ou presque, des tesselles de mosaïque ont été mises au jour, parfois en grand nombre, en pierre noire ou blanche, ou encore en pâte de verre de couleurs variées, ainsi que quelques fragments de pavements solidaires, par exemple vers la basilique, au XIX ${ }^{\mathrm{e}}$ s. (Ignon, 1840-1841, p. 170) ou encore récemment en JPN.06. Les dallages de pierre sont aussi réservés à la construction publique, alors 
que quelques rares cas de pavages en tegulae sont attestés. Mais des planchers de bois, sur lambourdes, devaient exister dans certaines pièces, à l'exemple du réaménagement de la resserre en JSF.99/00 (Marot dir., 2007).

Les enduits peints sont assez courants, mais consistent essentiellement en éléments de plinthes rouges, avec toutefois des éléments d'autres couleurs par endroits (blanc, beige, jaune, vert, bleu...), et quelques panneaux en place, comme à proximité de la curie, déposé : fouille Pierobon (Pierobon, 1999, p. 18), ou en JEF.98 dans la domus ouest (Piskorz, 2003). Des motifs végétaux se retrouvent quelques fois, très rarement des éléments figurés : un des rares exemples est mentionné sous le cimetière actuel (Morel, Bardy, 1959, p. 15 ; Visite..., 1959). Enfin, le stuc est exceptionnel ; on n'en a rencontré des fragments qu'en JEF.98 et JPN.07, et peut-être au XIX ${ }^{\mathrm{e}}$ s. dans les thermes occidentaux (Germer-Durand, 1888).

Dans cette région aux hivers rigoureux, l'existence de pièces chauffées par hypocauste n'est pas rare dans l'habitat privé : en JEF.98 (avec un praefurnium) et au sud du decumanus D4 (JLP.03), par exemple. Ailleurs, ce sont des foyers muraux en demi-cercle, chemisés de briquettes, qui ont été mis en évidence, dans une boutique de la «domus Peyre " (voir supra, p. 204), dans le sondage Pierobon à la base de la colline ouest (Pierobon, 1989b, p. 9) ou encore dans la grande domus de JPN.05/07 (sans compter bien sûr les trois fours de sa cuisine, au nord), ainsi que (d'un autre type) en JLG.02.

L'adaptation aux conditions naturelles s'observe aussi dans l'aménagement quasi systématique des constructions, publiques ou privées, en terrasses, avec mur de soutènement en général parementé du seul côté extérieur, comportant parfois des barbacanes (JSE.98, JPB.02...), remblayé côté interne, en aval, en général excavé dans le granite en amont et surmonté d'un autre mur de terrasse de ce côté ou non. Le drainage des eaux est en outre dans plusieurs cas facilité par l'établissement d'une rigole extérieure en amont (par ex. JSF.99), voire par le doublement de ce mur amont (JLV.99).

Quant à la gestion privée de l'eau, on a noté de petites adductions, comme en JSE.98, mais une bonne part de l'alimentation en eau devait se faire à l'aide de puits, dont cinq sont actuellement connus (deux dans la « domus Peyre », un en JQR.97, un en JBN.01/04 et un en JSF.05). Un captage de source, sans doute privé, est cependant connu en JEE.01, à proximité de l'édifice de JTM.00/01, une canalisation en bois avec frettes de fer devant le bâtiment de JTD.04 et une autre devant la «domus Peyre » (Peyre et al., 1979, p. 101-114 ; Peyre, 1982), et des tuyaux de plomb sont par exemple attestés dans les fouilles du $\operatorname{XIX}^{\mathrm{e}}$ s. le long du cardo C3 (Moré, 1856a et b).

Les autres canalisations découvertes, en tuiles ou en lauzes de schiste (pour le fond), correspondent apparemment plus à des évacuations d'eaux usées : sans compter les égouts publics mis au jour dans la plupart des rues connues, on en note un dans les fouilles du $\operatorname{XIX}^{\mathrm{e}} \mathrm{s}$. en rive droite (Ignon, 1840-1841, p. 157), un en JLG.02, deux en JLD.00, tout un réseau dans la domus de JPN.05/07 et vers sa cuisine (JPN.02), un autre (privé ?) en JTE.99, en bordure du Triboulin et de son aménagement de berge est, et enfin un dans le sondage 3 de JMP.00. Compte tenu des conditions hydrauliques du site, notamment dans la partie basse du vallon, il est certain que ces canalisations jouent aussi ici le rôle de drains pour les eaux souterraines.

\section{L'ÉCONOMIE DE LA VILLE : PRODUCTIONS ET ÉCHANGES}

En l'état des connaissances, la ville d'Anderitum apparaît certes plus comme une ville « de consommation » que comme un centre de production important, dans le débat sur le rôle économique de la ville dans le monde antique (voir par ex. Leveau, 1983 ; Ferdière, 2001b).

\section{LA PRODUCTION ARTISANALE}

Il est en effet notable que les productions d'objets manufacturés actuellement attestées à Javols sont extrêmement limitées : deux ateliers de bronziers, une activité de forge, de la tabletterie, quelques indices concernant l'artisanat du bois, des textiles, du cuir, de la céramique... (voir en général : Trintignac, 2002 et 2005b).

\section{Les bronziers}

Qu'il s'agisse de l'atelier mis au jour dans les fouilles Peyre (deux «boutiques » de la domus, donnant sur le cardo C2) ou des rejets mis en évidence dans un de nos sondages à l'est (JRE.02 : «joaillier-bijoutier »), les déchets recueillis, avec des creusets et des fragments de moules, montrent qu'il s'agit d'une petite production urbaine "de proximité ", concernant des objets d'usage courant tels que des pièces de harnachement et des manches de clefs, et mettant en œuvre des alliages à base de cuivre (bronze et laiton) ${ }^{43}$ (SaintDidier, 2006 et 2007).

43. Étude en cours de É. Rabeisen et G. Saint-Didier. 
À ceci s'ajoute le travail de certains métaux précieux (or et argent) dans l'atelier de JRE.02 et ça et là le travail du plomb (coulées, masses recueillies...), métal qui ne demande pas une haute technicité.

\section{La sidérurgie}

Plusieurs points de fouille ont livré des scories ferreuses, en plus ou moins grande quantité, dans les fouilles anciennes en particulier au terrain de camping (Peyre, 1976b) et dans les fouilles Pierobon (Pierobon-Benoît, 1993b, p. 23, n. 44 et p. 36) ; des ateliers de forges sont signalés vers le « Le Régimbal », à l'est (Chardonnet, 1995, p. 4) et au sud du forum (Pierobon, loc. cit.) ; dans nos propres sondages, les principales concentrations sont en JPN.00 (recharges de la voie) et JSF.05 (domus au sud).

Il s'agit dans tous les cas d'activité d'affinage, d'élaboration ou d'entretien (forges), et seules quelques rares scories de réduction ont été identifiées, sans doute amenées ici de l'extérieur pour constituer des matériaux de remblais : le minerai ne se trouvant pas à proximité, une réduction sur place doit être exclue (Saint-Didier, 2006 et 2007).

\section{La tabletterie}

Un certain nombre d'ébauches brisées d'objets en os en cours d'élaboration et de déchets montrent l'existence, courante dans les villes gallo-romaines, d'activités de travail de l'os, provenant sans doute en partie de la récupération des boucheries urbaines (Béal, Hamm, 1976 ; Béal, 1981, p. 5 ; Trintignac, 2001a, vol. II, p. 120, fig. 110) : rien d'important en tout cas.

\section{Le bois}

La statue de Silvain/Sucellus (voir supra, p. 200) et surtout la panoplie d'outils du travail du bois qui l'orne au dos est un élément déterminant en faveur de l'importance de cette activité à Anderitum, et en général pour les Gabales. Le reste de la documentation consiste en déchets de taille (copeaux) découverts notamment en JTS.98 (Girardclos, 2006) et quelques outils de travail du bois (Peyre et al., 1979 ; Peyre, 1981a).

La fabrication de tonneaux peut notamment être envisagée à partir de la présence d'une herminette de tonnelier (ibid.), ainsi que d'un signaculum au nom de MATERNUS (Trintignac, 2001a, vol. I, p. 140 et vol. II, p. 117, fig. 107).

\section{Le textile et le cuir}

Les activités artisanales liées à la production textile sont étonnamment rares pour une ville gallo-romaine : une paire de force, sans doute à tondre, dans les fouilles Peyre (Peyre et al., 1979, p. 13-30) et une autre en JTD.04, quelques fusaïoles à filer (activité sans doute plus domestique qu'artisanale), ça et là, mais aucun peson de métier à tisser.

Quant au cuir, tout au plus peut-on signaler quelques outils qui pourraient correspondre à une telle activité : alènes, alésoirs et poinçon à river (Peyre et al., 1979, p. 5-6).

Mais, soit pour le tannage du cuir, soit pour le foulage des tissus, la présence de quelques amphores à alun des îles Lipari confirme toutefois de telles activités (voir infra, p. 214 et Di Napoli, 2003 et 2004).

\section{La céramique}

Une production de poterie à Javols même est, pour le moment, extrêmement hypothétique (Pierobon-Benoît et al., 1994, p. 248 sq. ; Calzone et al., 1997, p. 74) et ne semble pas en l'état devoir être retenue (Marot, 2007).

En revanche, un atelier de tuilier sans doute important, fonctionnant notamment au I ${ }^{\mathrm{er}}$ s. apr. J.-C., est maintenant attesté à proximité, à Serverette (JPR.07).

Rien par conséquent qui ne dépasse ici la satisfaction des besoins courants de la ville, un artisanat essentiellement «de proximité » (voir par ex. Ferdière, 2001b et à paraître a), sans aucun indice de productions s'ouvrant vers un marché extérieur plus large.

\section{COMMERGE ET CONSOMMATION}

En ce qui concerne les produits importés, la ville d'Anderitum ne se différencie pas de manière notable de ses consœurs des Trois Gaules, à l'échelle de ses dimensions modestes.

Pour la poterie (Marot, 2007 ; voir 2006), les céramiques précoces (20 av. J.-C.-30 apr. J.-C.) semblent surtout issues de la sphère arverne (terrae nigrae, céramiques à pâte et engobe blancs) : elles marquent la continuité d'un commerce avec cette cité. On note toutefois quelques produits de provenance différente, comme bien sûr les premières sigillées, italiques ou lyonnaises, puis de la Graufesenque : c'est cet atelier rutène (et ses satellites) qui semble ensuite rapidement supplanter toutes les autres officines dans l'approvisionnement du chef-lieu gabale, en fournissant une très grande majorité et variété des céramiques importées et ce 
jusqu'au milieu du II ${ }^{\mathrm{e}}$ s. Au-delà de 160-170 apr. J.-C. au plus tard, l'approvisionnement en poterie change radicalement, avec l'essoufflement voire l'arrêt de ces importations ; curieusement, ni la sigillée de Banassac, atelier pourtant gabale, ni celles du Centre de la Gaule (contrairement à ce qui est dit dans Peyre, 1979 et 1981b), ni les productions de la moyenne vallée du Rhône ne profitent alors de la place laissée libre sur le marché gabale. Au contraire, les habitants d'Anderitum semblent alors se tourner vers des productions originales, régionales, en céramique commune (céramique grise lissée, parfois à décor estampé) ou fine (céramique à pâte sableuse et engobe blanc). Quant à l'Antiquité tardive, peu documentée faute d'ensembles céramiques homogènes, elle paraît marquée par quelques importations de Dérivéesdes-Sigillées Paléochrétiennes languedociennes et atlantiques, des productions africaines, et à ce jour un unique tesson de sigillée d'Argonne.

Les amphores, quoique relativement rares, sont présentes et diversifiées pour du vin, de l'huile, des saumures et sauces de poisson, de l'alun..., et proviennent d'Italie, d'Espagne, d'Afrique, d'Orient, de Narbonnaise (Béal, 1986 ; Storti, 1998 ; Di Napoli, 2003 et 2004).

On a déjà noté une importante variété de pierres décoratives importées (voir supra, p. 211) et on retiendra encore par exemple des importations de meules en lave du Cantal. Des boîtes à sceller (Peyre, Béal, 1979 ; Peyre, 1981c, p. 6, pl. III-IV), des hipposandales (Peyre, 1969b, p. 54 et p. $58-60 ; 1978$ b, pl.), une clavette de moyeu de char (JPN.07), d'autres éléments de charronnerie ou de harnachement (Peyre, 1981c, p. 6-8) témoignent encore de ces transports.

Quant à l'alimentation, peu d'études de faune ont a ce jour été effectuées (voir par exemple : Marot dir., 2007), mais on constate la présence abondante, et classique, des ovicapridés (moutons et chèvres), du bœuf et du porc, avec parfois - quand l'acidité du sol n'a pas altéré ces dépôts -, une quantité significative de volaille et de poisson (salé ?) ; les fruits de mer - surtout les huîtres - sont également présents, comme dans toute ville gallo-romaine. Deux grandes meules en lave témoignent sans doute de la présence de boulangeries. Des amas de grains brûlés sont signalés dans les fouilles anciennes : dans les thermes occidentaux (Morel, 1962, p. 107) et dans la boutique au Silvain/Sucellus (Béal, Peyre, 1987), des blés, de l'orge et de l'avoine ayant en outre été identifiés avec quelques légumineuses, dans les premières analyses carpologiques (voir supra, p. 189).

\section{EN GUISE DE CONCLUSION : UNE VILLE « ROMANISÉE », UNE CAPITALE ÉPHÉMÈRE...}

Sans reprendre ici le concept galvaudé de « romanisation » (voir par ex. Woolf, 1998), c'est d'acculturation qu'on parlera pour traiter des influences méditerranéennes et extérieures subies par les populations indigènes de ces régions de moyenne montagne, aboutissant à une intégration culturelle certes bien perceptible dans ce milieu urbain.

La richesse de l'épigraphie est souvent considérée comme l'aune à laquelle mesurer ce degré d'acculturation dans les cités et leurs centres urbains : ici, seulement une douzaine de documents épigraphiques, pour la plupart fragmentaires (Ferdière, 1997), alors que la richesse des graffiti sur poterie (Marot, 2007) indique globalement une bonne maîtrise de l'écriture : s'y ajoute par exemple plusieurs styles à écrire (Peyre et al., 1979, p. 31-56) et des tablettes d'écriture (en JTS.98). Cette carence en inscriptions lapidaires est donc ici plutôt à mettre sur le compte de la récupération postérieure des pierres calcaires, support privilégié pour celles-ci, en vue de la production de chaux.

L'urbanisme est également bien empreint des influences romaines, comme il est d'usage dans de telles capitales de cité, avec une voirie quadrillée dans le centre-ville, un centre civique, un édifice de spectacle, des thermes... Il en est de même pour le plan des demeures privées (domus, assez classiques), en outre parfois équipées de chauffage par hypocauste ${ }^{44}$. Et l'essentiel de la construction est bien « à la romaine ", même si - on l'a vu - les techniques s'adaptent apparemment aux conditions du milieu : construction en petit appareil, toitures en tegulae et imbrices, décor de mosaïques, placages de marbres, enduits peints et stucs.

La vaisselle de table et de cuisine, comme par exemple les déchets alimentaires de faune et de coquillages, reflètent aussi, et sans doute dès la création de la ville, une assez forte acculturation, marquée par une nette pénétration des habitudes alimentaires et de table de type méditerranéen (Marot, 2007). Cependant, on note une faible représentation des lampes à huile pour un tel milieu urbain, avec moins d'une centaine d'exemplaires dans nos propres sondages, et par exemple une lampe en bronze dans les fouilles Peyre (Peyre, 1981c, p. 11, pl. XIII). De même, quant aux habitudes vestimentaires, les fibules restent relativement rares (par exemple : Peyre, 1981c, p. 5-6), dénotant

44. Et peut-être parfois de bains privés ; voir par ex. les quatre strigiles découverts dans une des "boutiques » de la "domus Peyre " (Peyre, 1969 b, p. 54 et p. 58-59). 
sans doute un engouement pour les vêtements cousus, compréhensible sous un tel climat.

L'acculturation « à la romaine » reste donc globalement comparable à celle d'autres chefs-lieux de cité des Trois Gaules et notamment d'Aquitaine, tels que par exemple Clermont-Ferrand/Augustonemetum ou surtout Rodez/ Segodunum, mais sans commune mesure avec celle connue dans les villes de Narbonnaise : la barrière des Cévennes reste bien prégnante.

Si l'on en juge par son histoire - une cité un peu artificielle, peut-être créée pour contrebalancer le primat arverne, avec le choix d'un chef-lieu assez arbitraire, enfin un déclin rapide pour cette ville, dès la fin du $\mathrm{II}^{\mathrm{e}} \mathrm{s}$, succédant de près à son apogée -, tous ces éléments laissent tout de même l'impression d'une création sans doute un peu trop ambitieuse et volontariste pour pouvoir survivre aux mutations de l'Empire à partir du III ${ }^{\mathrm{e}} \mathrm{s}$.

Même si tout ceci reste très idéologique, n'est-on pas en effet ici dans ce concept d'" échec urbain » cher aux historiens et archéologues britanniques (voir par ex. : Slater dir., 2000) ? Anderitum Gabalorum ne fait-elle en effet pas partie de la quarantaine de chefs-lieux de cité à travers les Gaules qui perdent leur statut de capitale régionale dans l'Antiquité tardive (Ferdière dir., 2004) ?

Si Javols est donc une de ces " capitales éphémères » au projet sans doute trop ambitieux, cette ville romaine reste somme toute assez typique des capitales de cité des
Trois Gaules telles qu'on les connaît ailleurs, et force est d'avouer que l'originalité de ce modeste chef-lieu d'une tout aussi modeste civitas de la province d'Aquitaine n'est pas flagrante : elle est un peu artificiellement due à une perception archéologique globale plus aisée ici que pour les villes romaines qui, en plus grand nombre, ont été pérennisées dans leur statut de ville de pouvoir jusqu'à nos jours, à l'exemple de Tours/Caesarodunum (Galinié, 2007).

Ce phénomène de rétraction urbaine est en effet commun à la quasi-totalité des villes des Gaules et l'érosion de son statut est surtout perceptible dans l'absence d'enceinte urbaine du Bas-Empire (castrum), et est entérinée par la délocalisation du siège épiscopal à Mende dans le courant du haut Moyen Âge.

Quelques caractères originaux restent toutefois tangibles ici dans l'adaptation de l'urbanisme, de la construction, des conditions de vie quotidienne à un milieu relativement hostile qui est celui d'un pays de moyenne montagne, au climat rude, avec ses contraintes tant topographiques qu'économiques : sans être la cause de son déclin, ces conditions particulières ont certainement joué un rôle en la matière, dans un processus dialectique d'interactions entre société et milieu.

Le mérite de notre programme d'évaluation aura en définitive été de mettre en lumière les traits les plus typiques, et quelques autres plus atypiques, de cette petite capitale de cité du sud du Massif central. 


\section{LISTE DES AUTEURS}

Michel AMANDRY, Cabinet des Médailles, Bibliothèque nationale, 58 rue Richelieu, F-75084 Paris Cedex 02. Courriel : michel.amandry@bnf.fr

Caroline BIDEAU, responsable de secteur ; agent de la Communauté de communes de la Terre de Peyre pour la salle d'exposition, F-48130 Javols. Courriel : javols.anderitum@wanadoo.fr

Anne-Lise CoHEN, responsable de secteur, 29 rue Edmond-Guyaux, F-31200 Toulouse. Courriel : annelisemoalc@aol.fr

Julien COURTOIS, responsable de secteur, topographie et SIG, 33 rue du Plessis, F-37520 La Riche. Courriel : julien. courtois@wanadoo.fr

Jane DE Rose-Evans, professeur d'archéologie classique, Department of Art History, Temple University, $8^{\text {th }}$ Floor, Ritter Hall Annex, Philadelphia, Pennsylvania 19122, USA. Courriel : jevans@temple.edu

Francesca DI NAPOLI, Inrap, 148 bis avenue Maginot, F-37100 Tours. Courriel : francesca.di-napoli@inrap.fr

Alain FERDIÈRE, coordinateur du programme de 1996 à 2003, professeur émérite d'archéologie, Laboratoire archéologie et territoires, UMR CITERES du CNRS, Tours, 42 rue de la Mairie, F-45740 Lailly-en-Val. Courriel : ferdiere@club-internet.fr

Mélanie FONDRILLON, responsable de secteur, docteur en archéologie, 5 rue Lavoisier, F-18000 Bourges. Courriel : fondrillonm@gmail.com

Benoît GIRAUD, responsable de secteur, 26 chemin de Niboul, F-31200 Toulouse. Courriel : bengir@gmail.com

Thomas GUILLEMARD, responsable de secteur, Inrap, 10 route de Josnes, Villemarceau, F-45190 Villorceau. Courriel : thomas.guillemard@inrap.fr

Romana HARFOUCHE-POUPET, responsable de secteur, docteur en archéologie, pédologue et géo-archéologue, 10 avenue des Guardians, F-30132 Caissargues. Courriel : pierre.poupet.cnrs@club-internet.fr

Aurélien LEFEUVRE, responsable de secteur, app. 514, 7 rue des Marais, F-95300 Pontoise. Courriel : lefeuvre.aurelien@ wanadoo.fr

Emmanuel MAROT, responsable de secteur, docteur en archéologie, 5 rue Lavoisier, F-18000 Bourges. Courriel : manu_ marot@hotmail.

Mathilde NOËL, responsable de secteur, Inrap, 10 route de Josnes, Villemarceau, F-45190 Villorceau. Courriel : mathilde. noel@inrap.fr

Benoît ODE, coresponsable du programme de 1996 à 2004, ingénieur d'études au Service régional archéologique du Languedoc-Roussillon, DRAC, Hôtel de Grave, 5 rue de la Salle-l’Évêque, F-34967 Montpellier Cedex 2. Courriel : benoit. ode@culture.gouv.fr

Raffaela PIEROBON-BENOÎT, titulaire des fouilles programmées 1987-1994, professeur d'archéologie, Université de Naples, Dipartimento discipline storiche, via Porte di Maza, I-80133 Napoli. Courriel : pierobon@unina.it

Grégory POITEVIN, responsable de secteur, Inrap, 148 avenue Maginot, F-37100 Tours. Courriel : gregory.poitevin@inrap.fr

Pierre POUPET, chargé de recherches au CNRS, pédologue et géo-archéologue, 10 avenue des Guardians, F-30132 Caissargues. Courriel : pierre.poupet.cnrs@club-internet.fr

Alain TRINTIGNAC, responsable de secteur puis coordinateur du programme à partir de 2005 ; Conseil général de Lozère, rue de la Poste, F-48000 Barjac. Courriel : al.trintignac@infonie.fr 


\section{BIBLIOGRAPHIE}

$\begin{array}{ll} & \text { ABRÉVIATIONS } \\ \text { AFEAF } & \text { Association française pour l'étude de l'âge du Fer. } \\ \text { BAR } & \text { British Archaeological Reports. } \\ B . G . & \text { Bello Gallico. } \\ \text { CAG } & \text { Carte archéologique de la Gaule. } \\ \text { CIL } & \text { Corpus Inscriptionum Latinarum. } \\ \text { CUF } & \text { Collection des universités de France. } \\ \text { DAF } & \text { Document d'archéologie française. } \\ G . C . & \text { In Gloria Confessorum. } \\ H . F . & \text { Historia Francorum. } \\ H . N . & \text { Histoire naturelle. } \\ \text { INRAP } & \text { Institut national de recherches archéologiques préventives. } \\ R A C F & \text { Revue archéologique du Centre de la France. } \\ R A N & \text { Revue archéologique de Narbonnaise. } \\ \text { SFECAG } & \text { Société française de la céramique antique en Gaule. } \\ \text { SRA } & \text { Service régional de l'archéologie. }\end{array}$

\section{SOURCES ANTIQUES}

\section{ACTES DES CONCILES}

Acta Conciliorum, Concilia Galliae (a.d. 314-a.d. 506), éd. C. Munier, dans Corpus Christianorum, Series Latina, 148, Turnhout, 1963.

\section{CÉSAR}

Guerre des Gaules, I et II, éd. et trad. L.-A. Constans, Paris, Les Belles Lettres (coll. CUF, G. Budé), $1^{\text {re }}$ éd. 1926, $11^{\mathrm{e}}$ éd. 1981.

\section{CIL}

Corpus Inscriptionum Latinarum -XIII- Inscriptiones trium Galliarum et Germaniarum Latinae, 4 vol., Berlin, 1899-1916 (rééd. 1967-1968).

\section{GRÉGOIRE DE TOURS}

Historia Francorum, éd. B. Krusch et W. Levison, dans Monumenta
Germaniae Historiae, Scripta Rerum Merovingicarum, I, Hanovre, 1884-1885 (rééd. 1937-1951).

\section{PLINE L'ANCIEN}

Histoire naturelle, XI, texte établi, traduit et commenté par A. Ernout et R. Pépin, Paris, Les Belles Lettres (coll. CUF, G. Budé), 1947.

\section{PTOLÉmÉE}

Géographie, I-V, éd. et trad. latine C. Müller et K. Th. Fischer, Paris, Firmin Didot, 1883-1901.

\section{SIDOINE APOLLINAIRE}

Carmina-I-Poèmes, éd. et trad. A. Loyen, Paris, Les Belles Lettres (coll. CUF, G. Budé), 1960.

\section{BIBLIOGRAPHIE}

Les références précédées d'un astérisque sont inédites, mais consultables au Service régional de l'archéologie du Languedoc-Roussillon ; celles qui sont précédées de deux astérisques sont consultables au dépôt de fouilles de Javols.

\section{AGUSTA-BOUlarot S.}

2008 : « Le lacus de la rue romaine : un exemple de "mobilier urbain" antique? ", in BAllet P., Dieudonné-Glad N., SALIOU C. (DIR.), La Rue dans l'Antiquité : définition, aménagement et devenir, Actes du colloque international, Poitiers, 7-9 sept. 2006, Rennes, Presses Universitaires de Rennes, p. 93-100.

\section{Alla R.}

1972-1973 : « La voie d'Agrippa en Gévaudan : section des monts d'Aubrac à Javols ", in " Cévennes et Gévaudan, Actes du $\mathrm{XLVI}^{\mathrm{e}}$ congrès de la Fédération historique du Languedoc méditerranéen et du Roussillon, Mende-Florac, 16-17 juin 1973 ", Bulletin de la Société des lettres, sciences et arts de Lozère, nouvelle série, 18-19, p. 35-40.

\section{ANDRÉ F.}

1885 : "Le Pagus Gabalicus ou Gévaudan», Bulletin de la Société d'agriculture, industrie, sciences et arts du département de la Lozère, I, p. 379-401.

1986 : « Notes sur les divisions territoriales du Gévaudan à l'époque franque ", Bulletin de géographie historique et descriptive du Comité des travaux historiques et scientifiques, p. 120-126. 


\section{BALMELLE M.}

1937 : Répertoire archéologique du département de la Lozère: périodegallo-romaine, Montpellier, Fédération historique du Languedoc méditerranéen et du Roussillon, 57 p.

BARRUOL G.

1971 : «Informations archéologiques : circonscription de Languedoc-Roussillon ", Gallia, 29, 2, p. 369-405.

1978 : " Informations archéologiques : circonscription de Languedoc-Roussillon ", Gallia, 36, 2, p. 431-459.

BAYARD D., MASSY J.-L.

1983 : Amiens romain, Amiens (coll. Revue archéologique de Picardie, $\mathrm{n}^{\circ}$ spécial).

BÉAL J.-C.

1981 : " Fouilles de Javols 1969-1978 : catalogue des objets en os (II) ", Revue $d u$ Gévaudan, des Causses et des Cévennes, 27, 1, p. 5-25, 6 pl.

1986 : « Javols, l'Espagne et le Portugal : les estampilles sur amphores du site de Javols ", Revue du Gévaudan, des Causses et des Cévennes, 32, 2, p. 12-17.

1999 : «Statue de Silvain-Sucellus de Javols", in $\grave{A}$ la rencontre des dieux gaulois : un défi à César, Catalogue d'exposition, Lattes, Musée archéologique Henri-Prades, MAN, p. 131

BÉAL J.-C., HAMM L.

1976 : « Fouilles de Javols : étude des objets en os ", Revue du Gévaudan, des Causses et des Cévennes, 22, p. 79-88.

BÉAL J.-C., PEYRe P.

1987 : «Une statue antique de SilvainSucellus à Javols (Lozère) ", RAN, 20 p. $349-368$

\section{BEDON R.}

1999 : Les Villes des Trois Gaules de César à Néron dans leur contexte historique, territorial et politique, Paris, Picard, 396 p.

2001 : Atlas des villes, bourgs, villages de France au passé romain, Paris, éd. Union latine et Picard, $351 \mathrm{p}$.

\section{BEDON R. (DIR.)}

1998 : Suburbia : les faubourgs en Gaule romaine et dans les régions voisines, Actes du colloque de l'École nomale supérieure, Paris, 1997, Limoges, PULIM (coll. Caesarodunum, XXXII).

\section{BELINGARD C.}

**2007 : Détermination taxonomique des bois de Javols-Anderitum (JSF.05), Rapport inédit, $1 \mathrm{p}$.

\section{BERGER J.-F.}

2001 : « Evolution des agro- et des hydrosystèmes dans la région médio-rhodanienne " in Ouzoulias P., Pellecuer C., RAYNAUD C., VAN OSSEL P., GARMY P. (DIR.), Les Campagnes de la Gaule à la fin de l'Antiquité, Actes du IV colloque AGER, Montpellier, 11-14 mars 1998, Antibes, APDCA, p. 369-403.

BERNARD R. J.

1982 : « Lozère ", in BARDET J.-P. (DIR.), Paroisses et communes de France, Dictionnaire d'histoire administrative et démographique : Lozère, Paris, CNRS Éditions.

\section{BERNARD-AlléE P., VAladas B.}

1993 : " Archéologie agraire en Limousin : l'apport des remblaiements des fonds de vallons et des banquettes de culture ", Travaux d'archéologie limousine, 13 , p. 7-18.

\section{BOËMARE A}

*1998 : " Recherches archéologiques sur le site de Javols. Photographie aérienne oblique. Vols de reconnaissance 1998 ", in FERDIÈRE A. (DIR.), Programme collectif de recherches, Rapport d'activité 1998, vol. II, annexe 2, 6 p., 5 photos.

BOUDE C.

1984 : «Petit fanum gallo-romain du MontBuisson ", Lozère archéologie, 1, p. 14-15.

\section{Bouet A.}

2003 : Les Thermes privés et publics en Gaule Narbonnaise, Rome (coll. École française de Rome, 320), 2 vol., 416 p. et 381 p.

\section{BOULLIER DE BRANCHE H.}

1938a : Feuda Gaballorum -I-Département Lozère, Nîmes, 188 p.

1938b : Feuda Gaballorum -II- Département Lozère, $2^{\mathrm{e}}$ partie, Nîmes, $290 \mathrm{p}$.

BRUNEL C.

1916 : " Documents linguistiques du Gévaudan ", extrait de la Bibliothèque de l'École des Chartes, LXXVII, 102 p.

\section{BUFFIÈRE $\mathbf{F}$.}

1985 : " Ce tant rude " Gévaudan, Mende, Société des lettres, sciences et arts de Lozère, $956 \mathrm{p}$

Calzone A. et al.

1997 : « Anderitum (Javols, France) : la céramique commune, $\mathrm{I}^{\mathrm{er}}-\mathrm{VI}^{\mathrm{e}}$ siècles après J.-C. ", in Rei Cretariae Romanae Fautorum Acta 35 (1996), Abingdon, p. $73-83$.
Calzone A., Febbraro S., Monaco M., STORTI D.

*2001 : « Le mobilier céramique gallo-romain d'Anderitum-Javols (Lozère) : fouilles Peyre 1969-1978 ", in FERDIÈRE A., ODE B. (DIR.), Programme collectif de recherches sur Javols 1996-2002, Rapport d'activité pour 2001, Tours, UMR Archéologie et Territoires, vol. 2, ann. 6 .

\section{CaUmonT A. DE}

1856 : «Rapport verbal fait à la société française d'archéologie, dans les séances des 20 nov. 1855 et 8 sept. 1856, sur divers monuments et plusieurs excursions archéologiques », Bulletin monumental, $3^{\text {e }}$ série, t. II, vol. 22, p. 447-504.

\section{CAYX J.-A.}

1826 : « Nouvelles recherches sur l'étendue du pays des Gabali et sur la position de leurs villes antiques ", Mémoires de la Société royale des Antiquaires de France, 7 , p. 80-113.

\section{Chambrun J. DE}

1981 : LeOs Habitats ruraux de la civitas des Gabales, mémoire de Maîtrise d'archéologie, Université Paris-I, inédit (consultable aux Archives départementales de la Lozère), 72 p.

\section{Chardonnet C.}

*1995 : Javols "Le Regimbal ", Document final de synthèse de sauvetage urgent, Montpellier, SRA Languedoc-Roussillon, dactylographié, inédit, 15 p., 15 fig.

Chardonnet C., Fages G.

2002 : «Banassac et La Canourgue (Lozère) », in FICHES J.-L. (DIR.), Les Agglomérations gallo-romaines en Languedoc-Roussillon, Lattes (coll. Monographies d'archéologie méditerranéenne, 13-14), vol. 2 , p. $923-929$

\section{Chardonnet C., Ferdière A.}

2002 : " Ad Silanum et Mons Helarius, Nasbinals et Marchastel : deux établissements, une agglomération secondaire?" in FICHES J.-L. (DIR.), Les Agglomérations gallo-romaines en Languedoc-Roussillon, Lattes (coll. Monographies d'archéologie méditerranéenne, 13-14), vol. 2, p. $945-949$.

Chassaing M.

1962 : « Deux statues de tradition archaïque de la Lozère ", Bulletin de la Société préhistorique française, LIX, p. 707-716.

1986 : Une Passion : l'archéologie. Le Dieu au maillet, Rozé, Orbec, 294 p. 


\section{Chazottes M.}

s. d. (1947) : La Commune de Javols : essai d'une monographie communale, manuscrit dactylographié, non paginé (consultable aux Archives départementales de Lozère, cote $8^{\circ} \mathrm{H} 325$ ).

\section{CORD E., CORD G.}

1900 : La Lozère : guide du touriste, du naturaliste et de l'archéologue, Paris.

\section{DALLE J.-A.}

1968 : Javols, capitale des Gabales (rééd. de 1912), Lou Pais, $17^{\mathrm{e}}$ année, $\mathrm{n}^{\circ} 150$ bis et Cahiers $d u$ Gévaudan, 10, 25 p. non paginées.

\section{DALLE R.}

1977 : « Javols, capitale des Gabales », Bulletin de l'académie du Var, p. 355-363.

\section{DARDAINE S., WATON M.-D.}

1986 : «Un four à tuiles du I ${ }^{\text {er }}$ siècle après J.-C. à Saint-Maurice-de-Ventalon (Lozère) », $R A N, 19$, p. 337-350.

\section{DARNAS I., DUTHU H.}

2002 : « Le Moyen Âge : l'affirmation du Gévaudan » in CHABROL J.-P. (DIR.), La Lozère de la Préhistoire à nos jours, Saint-Jean-d'Angély, éd. Bordessoules, p. 92-123.

\section{DaUSSE L., SCHAAd D.}

À paraître : " Segodunum, chef-lieu des Rutènes gallo-romains ", in GRUAT P., PAIller J.-M., SCHAAD D. (DIR.), Les Rutènes: du peuple à la cité, Actes du colloque de Rodez-Millau, 15-17 nov. 2007.

\section{DEGBOMONT J.-M.}

1984 ( $2^{\mathrm{e}}$ éd.) : Le Chauffage par hypocauste dans l'habitat privé, Liège (coll. Études et recherches archéologiques de l'université de Liège, 17), 240 p.

DELAPIERRE G.

1864 : «Fouilles de Javols : compte rendu ", Bulletin de la Société d'agriculture, lettres, sciences et arts du département de la Lozère, p. $337-348$

De Rose Evans J., Ferdière A., Marot E.

2009 : "Anderitum : excavations in a roman town in Gallia Aquitania", American Journal of Archaeology, 113, p. 255-272.

\section{DESJARDINS E.}

1884 : La Table de Peutinger, d'après l'original conservé à Vienne, Paris, Hachette, 2 vol.

DEYTS S.

2003 : «Un cheval harnaché à Javols ", Revue du Gévaudan, des Causses et des Cévennes, 15 , p. $151-155$.

\section{NAPOLI F.}

*2003 : « Les amphores de Javols : a, les amphores des sondages 1996-2002 ; b, amphores des fouilles Peyre : étude préliminaire ", in FERDIÈRE A. (DIR.), Rapport final de synthèse, Programme pluriannuel d'évaluation du site archéologique de Javols (1996-2003), Tours, vol. 1, p. 106-112.

**2004: «Les amphores de Javols / Anderitum », in Les Denrées en Gaule romaine: production, consommation, échanges, Communication à la table ronde de Nanterre, 18-19 nov. 2004, manuscrit inédit, $6 \mathrm{p}$

\section{DOCUMENTS...}

1886 : Documents antérieurs à 1790, Mende, Société d'agriculture, industrie, sciences et arts du département de la Lozère, vol. II.

\section{DUFORT P.}

1966 : Dictionnaire topographique du département de la Lozère, manuscrit dactylographié (consultable aux Archives départementales de la Lozère, cote $\Delta 4623$ ), 468 p.

\section{DURAND A., LEVEAU P.}

2004 : "Farming in Mediterranean France and rural settlement in the Late Roman and Early Medieval periods : the contribution from archaeology and environmental sciences in the last twenty years (1980-2000)", in BARCELO M., SIGAUT F. (DIR.), The Transformation of the Roman World. from Roman Possessors to Feudal Lords : the Making of Feudal Agriculture ( $V^{\text {th }}-X^{\text {th }}$ centuries), Boston/Leiden, Brill, p. 177-253.

\section{EBNÖTHER C}

2008 : "Auf den Spuren von Handwerkergemainschaften in römischen Westen : ein Beitrag zum antiken Vereinswesen aus archäologischer Prspective”, in «Artisanat et société dans les provinces romaines/Handwerk und Gesellschaft in den römischen Provinzen, Actes du colloque international CRAFTS, Zürich, 1-3 mars 2007 ", Zeitschrift für Schweizerische Archäologie und Kunstgeschichte, 65, 1-2, p. 27-32.

\section{ESMONDE CLEARY S.}

1987 : Extra-Mural Areas of Romano-British Towns, Oxford, Archaeopress (coll. BAR, British Series, 169).

\section{ÉTIENNE M.}

1996 : « Les banquettes agricoles, archives sédimentaires du parcellaire limousin : exemples en pays d'Uzerche (Corrèze) ", Travaux d'archéologie limousine, 16, p. 7-14.

\section{ÉTIÉVANT E.}

1869 : «Voies romaines de la Lozère », Bulletin de la Société d'agriculture, industrie, sciences et arts du département de la Lozère, p. 15-22.

\section{FABRE L.}

*2006 : « Rapport provisoire de l'étude anthracologique... ", in TRINTIGNAC A. (DIR.), Programme de recherches archéologiques 2005-2007 sur le site de JavolsAnderitum (Lozère, 48), Rapport de recherche 2006, manuscrit non paginé, vol. II/2, annexe 34,1 tabl.

\section{FABRIÉ D.}

1985 : « Lieux de culte et divinités galloromaines en Lozère ", in Études languedociennes, Actes du $110^{e}$ congrès national des sociétés savantes, Montpellier, p. 255-270.

1989 : La Lozère, Paris, Académie des inscriptions et belles-lettres (coll. CAG, 48), $144 \mathrm{p}$

FAGES G.

*1991 : Javols : surveillance assainissement du bourg, manuscrit inédit, 4 p., 19 pl.

*1992 : Javols : terrain de sport, mise au jour de vestiges gallo-romains, manuscrit inédit, 6 p., 4 pl.

*1999 : Javols, Lozère : complément assainissement collectif (extension du réseau égouts quartier «Lou Mounnet »), manuscrit inédit, 6 p., 3 fig.

\section{FERDIÈRE A.}

*1997 : "Corpus des textes littéraires et épigraphiques sur la cité des Gabales : révision critique ", in FERDIÈRE A. (DIR.), Programme de recherches sur Javols, Rapport intermédiaire (1 ${ }^{\text {re }}$ année) 1997, vol. 2 : ann. $\mathrm{n}^{\circ} 12,73 \mathrm{p}$.

2000a : «L'église primitive du Gévaudan découverte d'un lieu de culte à Javols ? ", Antiquité tardive, 8, p. 343-347.

2000b : " Mais où était le chef-lieu des Gabales avant la conquête romaine ? ", in Aspects de l'âge du Fer dans le sud du Massif central (thème régional), Actes du XXIe colloque de l'AFEAF, Conques-Montrozier, 8-11 mai 1997, Lattes (coll. Monographies d'archéologie méditerranéenne, 6), p. 19-26.

2001a : "Histoires de noms de lieux : notes de toponymie antique du Gévaudan ", Bulletin du Centre d'études et de recherches de Mende, 19, p. 18-22.

2001b : «La "distance critique" : artisans et artisanat dans l'Antiquité romaine et en 
particulier en Gaule ", Les Petits Cahiers d'Anatole, Publication en ligne : http:// www.univ-tours.fr/lat/F2-1.html

2002a : "Castrum Gredonensis, Grèzes ", in FICHES J.-L. (DIR.), Les Agglomérations gallo-romaines en Languedoc-Roussillon, Lattes (coll. Monographies d'archéologie méditerranéenne, 13-14), vol. 2, p. 915-917.

2002b : « Le Truc ou Le Puech, Saint-Bonnetde-Chirac ", in FICHES J.-L. (DIR.), Les Agglomérations gallo-romaines en LanguedocRoussillon, Lattes (coll. Monographies d'archéologie méditerranéenne, 13-14), vol. 2, p. 918-922.

2002c : Anderitum-Javols, in FICHES J.-L. (DIR.), Les Agglomérations gallo-romaines en Languedoc-Roussillon, Lattes (coll. Monographies d'archéologie méditerranéenne, 13-14), vol. 2, p. 933-940.

2002d : "Condate (Chapeauroux), SaintBonnet-de-Montauroux », in FICHES J.-L. (DIR.), Les Agglomérations gallo-romaines en Languedoc-Roussillon, Lattes (coll. Monographies d'archéologie méditerranéenne, 13-14), vol. 2, p. 941-944.

*2003a : Programme pluriannuel d'évaluation du site archéologique de Javols (1996-2003), Rapport final de synthèse, Tours, vol. 2, ann. 7, 63 p.

2003b : "Le territoire gabale, poste avancé de la Gaule intérieure aux confins de la Narbonnaise ", in Peuples et territoires en Gaule méditerranéenne, Hommage à Guy Barruol, (Suppl. à la RAN, 35), p. 215-222.

2005 : Les Gaules, II ${ }^{e}$ s. av. J.-C.-Ve s. apr. J.-C., Paris, Armand Colin (coll. U-Histoire), $447 \mathrm{p}$.

À paraître a : «L'artisanat en Gaule romaine : organisation et place ", in L'Artisanat grec : approches méthodologiques et perspectives, Actes de la table ronde de l'École française d'Athènes, Athènes, 5-6 oct. 2007.

À paraître b : "Évaluation archéologique urbaine : le cas de Javols-Anderitum (Lozère) ", in Hommages à Gilbert Fages.

FERDIÈRE A. (DIR.)

*1997 : Programme de recherches sur Javols, Rapport intermédiaire (1re année) 1997, 2 vol. multicopiés, 45 p., fig., ann.

*1998 : Programme collectif de recherches, Rapport d'activité 1998, 2 vol., 35 p., fig., ann.

*1999 : Evaluation du site de Javols, Programme collectif de recherches, Rapport d'activité 1999 et rapport de synthèse 1996-1999, 3 vol. multicopiés, 48 p. et 58 p., fig., ann.

*2003 : Programme pluriannuel d'évaluation du site archéologique de Javols (1996-2003), Rapport final de synthèse, Tours, 2 vol., 192 p. et ann.
2004 : Capitales éphémères : des capitales de cités perdent leur statut dans l'Antiquité tardive, Actes du colloque LAT, Tours, 6-8 mars 2003, Tours (coll. Suppl. à la RACF, 25), 508 p.

Ferdière A., Fages G., Guibert P., GRICI S., BECHTEL F.

2006 : "Une fosse du Néolithique final ou du Chalcolithique à Javols (Lozère) et sa datation par thermoluminescence ", Préhistoire du Sud-Ouest, 13, 1, p. 99-110.

\section{Ferdière A., Marot E., TrintignaC A.} (DIR.)

À paraître: Javols-Anderitum (Lozère), chef-lieu de cité des Gabales : une ville romaine de moyenne montagne. Bilan de 13 ans d'évaluation et de recherche (1996-2008), Montagnac, Monique Mergoil.

\section{FERDIÈRE A., OdE B.}

1998 : « Le nouveau programme de recherches sur Javols (Lozère) et la question du siège de la première communauté chrétienne en Gévaudan ", Archéologie en Languedoc, 20-2, p. 67-72, 3 fig.

1999 : Javols-Anderitum et le Gévaudan antique, Mende, Conseil général de la Lozère, $26 \mathrm{p}$.

2001a : "Recherches archéologiques à JavolsAnderitum : campagne 2000 ", Revue du Gévaudan, des Causses et des Cévennes, 11, p. 51-64.

2001b : " Aménagement de berges à Javols (Lozère) ", in BEDON R., MALISSARD A. (DIR.) La Loire et les fleuves de la Gaule romaineet desrégionsvoisines, Actes du colloque d'Orléans, 1997, Limoges, Université de Limoges/Centre de recherches AndréPiganiol, PULIM (coll. Caesarodunum, XXXIII-XXXIV), p. 87-99.

2002 : « Recherches archéologiques à JavolsAnderitum : campagne 2001 ", Revue du Gévaudan, des Causses et des Cévennes, 13, p. 125-140.

2003 : « Recherches archéologiques à JavolsAnderitum : campagne 2002 ", Revue du Gévaudan, des Causses et des Cévennes, 15, p. $134-150$.

2004 : "Genèse, transformation et effacement de Javols-Anderitum ", in FERDIÈRE A. (DIR.), Capitales éphémères : des capitales de cités perdent leur statut dans l'Antiquité tardive, Actes du colloque LAT, Tours, 6-8 mars 2003, Tours (coll. Suppl. à la RACF, 25), p. 207-217.

\section{FERDIÈRE A., ODE B. (DIR.)}

*2000 : Programme collectif de recherches sur Javols 1996-2002, Rapport d'activité pour 2000, Tours, UMR Archéologie et Territoires, 2 vol., 38 p., fig., ann.
*2001 : Programme collectif de recherches sur Javols 1996-2002, Rapport d'activité pour 2001, Tours, UMR Archéologie et Territoires, 2 vol., 56 p., fig., ann.

*2002 : Programme collectif de recherches sur Javols 1996-2002, Rapport d'activité pour 2002, Tours, UMR Archéologie et Territoires, 2 vol., 43 p., fig., ann.

FERdière A. avec la collab. de OdE B., Bideau C., Pierobon R., Poitevin G.

2000 : «Recherches archéologiques à JavolsAnderitum : campagne 1999 ", Revue du Gévaudan, des Causses et des Cévennes, 9, p. $94-109$.

Ferdière A., Ode B., Pierobon R.

*1996 : Programme de recherches sur le site de Javols : évaluation et état des connaissances. Bilan d'activités pour 1996, 1 vol. multicopié, 52 p., fig., ann.

1997 : « Nouvelles recherches à JavolsAnderitum ", Revue du Gévaudan, des Causses et des Cévennes, nouvelle série 3, p. 73-90.

1998 : «Nouvelles recherches à JavolsAnderitum : campagne 1997 ", Revue du Gévaudan, des Causses et des Cévennes, nouvelle formule 5, p. 68-80.

1999 : « Recherches archéologiques à JavolsAnderitum : campagne 1998 ", Revue du Gévaudan, des Causses et des Cévennes, nouvelle formule 7, p. 128-139.

\section{FERdière A., POUPET P.}

2005 : «Une ville romaine de moyenne montagne : évolution du paysage et de l'environnement à Javols-Anderitum (Lozère) ", in BOUET A., VERDIN F. (DIR.), Territoires et paysages de l'âge du Fer au Moyen Âge, Mélanges offerts à Philippe Leveau, Bordeaux, Ausonius et De Boccard, p. 155-169.

\section{FERdière A., PRÉVot F.}

1998 : « Javols-Anderitum, capitale galloromaine des Gabales, premier siège épiscopal du Gévaudan ? ", Bulletin du Centre d'études et de recherches littéraires et scientifiques de Mende, 17, p. 15-24.

FICHES J.-L. (DIR.)

2002 : Les Agglomérations gallo-romaines en Languedoc-Roussillon, Lattes (coll. Monographies d'archéologie méditerranéenne, 13-14), 2 vol.

\section{FONDRILLON M.}

2007 : La Formation du sol urbain : étude archéologique des terres noires à Tours (IV $-X I I^{e}$ siècle), thèse de Doctorat, Université de Tours, 3 vol., 856 p. (consultable au LAT Tours). 


\section{FONT-RÉAULX J. DE}

1961-1962 : «Pouillés de la province de Bourges ", Recherche commencée par Prou M., publiée sous la dir. de Perrin C.-E., Recueil des historiens de la France, Paris, Imprimerie nationale, 2 vol., 876 p. et CLXXV p.

\section{FOULQUIER A.}

1913 : Notes biographiques sur le clergé desservant les paroisses comprises dans les trois anciens archiprêtrés de Barjac, Javols et Saugues depuis les temps anciens jusqu'à nos jours -IIArchiprêtré de Javols, $704 \mathrm{p}$.

\section{Galinié H.}

2000 : Terres noires 1, Tours, CNRS/Université de Tours (coll. Documents scientifiques de la ville, 6), $119 \mathrm{p}$.

2004 : " L'expression "terres noires", un concept d'attente ", in VERSLYPE L., BRULET R. (DIR.), Terres noires, Dark Earth. Actes de la table ronde internationale, Louvain-la-Neuve, 9-10 nov. 2001, Louvain-la-Neuve, Université catholique de Louvain, p. 1-11.

2007 : Tours antique et médiévale, lieux de vie, temps de la ville : 40 ans d'archéologie urbaine, Tours (coll. Suppl. à la RACF, 30), $440 \mathrm{p}$

\section{GERMER-DURAND F.}

1888 : «Les fouilles de Javols : avril 1882 », Bulletin de la Société d'agriculture, industrie, sciences et arts de Lozère, p. 143-146.

\section{GINOUVÈS R.}

1992 : Dictionnaire méthodique de l'architecture grecque et romaine -II- Éléments constructifs : supports, couvertures, aménagements intérieurs, Rome (coll. École française de Rome, 84).

\section{GIRARDCLOS O.}

*2006 : « Études xylologique et dendrologique de bois de l'US 5072, sondage JTS.98, agglomération romaine d'Anderitum à Javols (Lozère) ", in TRINTIGNAC A. (DIR.), Programme de recherches archéologiques 2005-2007 sur le site de JavolsAnderitum (Lozère, 48), Rapport de recherche 2006, manuscrit multicopié, vol. 2, 2, ann. $33,33 \mathrm{p}$.

\section{GODIGNON D.}

**2004 : Pratiques funéraires du Haut-Empire à Javols-Anderitum d'après l'étude de cinq sépultures, mémoire de Maîtrise d'archéologie, Université de Tours, 2 vol., vol. 1 : texte, 66 p., 30 fig., vol. 2 : annexes, $67 \mathrm{p}$.

**2005 : Les Ensembles funéraires de Javols à l'époque gallo-romaine, mémoire de Master 2 d'archéologie, Université de Tours, 2 vol., 112 p. et ann. 196 p.

\section{GOODMAN P.}

2006 : The Roman City and its Periphery : from Rome to Gaul, Abingdon, Routledge, $328 \mathrm{p}$.

\section{GOUMY S.}

2001 : Étude de l'évolution géomorphologique d'un vallon en milieu cristallin dans le Massif central français par une approche archéologique, d'Anderitum à Javols, mémoire de Maîtrise d'archéologie, Université de Tours, 2 vol., 127 p. et annexes.

\section{GRENIER A.}

1958 : Manuel d'archéologie gallo-romaine -IIIArchitecture, Paris, Picard, 2 vol., 1026 p.

\section{Grimaud A., Balmelle M.}

1925 : Précis d'histoire du Gévaudan, rattachée à l'histoire de France, Paris/Mende, Champion-Bonnefoy, 368 p. (rééd. Société des lettres, sciences et arts de la Lozère, 1996).

\section{GUIBERT P. ET AL.}

2006 : «Datation par thermoluminescence d'une structure de combustion granitique à Javols (Lozère) : quelques considérations sur la microdosimétrie des irradiations naturelles ", Archéosciences, Revue d'archéométrie, 30, p. 119-128.

\section{HATT J.-J.}

1991 : «Le Sucellus-Silvain-Liber Pater de Javols (Lozère) : signification d'une œuvre de sculpture gallo-romaine ", $R A N, 24$, p. 133-140.

2005 : Mythes et dieux de la Gaule, 2, en ligne : http://jeanjacqueshatt.free.fr/mythes-etdieux-jjhatt.htm

\section{HOFMANN B.}

1986 : «Banassac », in BÉMONT C., JACOB J.-P. (DIR.) La Terre sigillée gallo-romaine, lieux de production du Haut-Empire : implantations, produits, relations, Paris, éd. de la Maison des sciences de l'homme (coll. DAF, 6), p. 103-110.

1988 : «L'atelier de Banassac », Revue archéologique Sites, hors-série 33, 160 p.

\section{IGNON J.-J.-M.}

1840-1841 : « Notice sur les monuments antiques et du Moyen Âge dans le département de la Lozère, $2^{\mathrm{e}}$ partie (I) ", Bulletin de la Société d'agriculture, industrie, sciences et arts du département de la Lozère, p. 129-175.
JOULIA J.-C.

1974 : « Historiographie du monument de Lucius Pomponius Bassulus et de L. Pomponius Balbinus ", Revue $d u$ Gévaudan, des Causses et des Cévennes, 20, p. 17-39.

1975 : «Le monument de Lanuéjols », RAN, VIII, p. 275-294.

JULLIAN C.

1920-1926 (rééd. 1993) : Histoire de la Gaule, VIII livres, Paris, Hachette, 2 vol.

\section{LABROUSSE M.}

1980 : «Un milliaire de Philippe l'Arabe à la frontière des Rutènes et des Gabales ", Gallia, 38, p. 247-251.

\section{LAFAURIE J.}

1973 : « Monnaies mérovingiennes du Gévaudan », Bulletin du Club français de la médaille, 41, p. 126-133.

\section{LATOUR-Argant C., ARgant J.}

*2005 : «Analyses polliniques : sédiments prélevés ", in TRINTIGNAC A. (DIR.), Programme de recherches archéologiques sur le site de Javols-Anderitum (Lozère, 48), Rapport de recherche 2005, manuscrit multicopié, 2 vol., vol. 1 : texte et fig., 187 p. ; vol. 2 : 29 ann., p. 8-10.

\section{LEVEAU P.}

1983 : « La ville antique, "ville de consommation" ? : parasitisme social et économie antique ", Études rurales, 89-90-91, p. 275-289.

\section{LEVEAU P. ET $A L$.}

2002 : «La crise environnementale de la fin de l'Antiquité et du haut Moyen Âge : définition d'un modèle et retour aux milieux réels ", in RICHARD H., VIGNOT A. (DIR.), Équilibres et ruptures durant les 20 derniers millénaires en Europe de l'Ouest, actes du colloque international (Besançon, sept. 2000), Besançon, Presses universitaires franccomtoises (coll. Annales littéraires de l'université de Franche-Comté, 730, série Environement, Société et Archéologie, 3), p. 291-303.

\section{LONGNON A.}

1878 : Géographie de la Gaule au VI $I^{e}$ siècle, Paris, Hachette, $\mathrm{X}+653$ p. et 11 cartes h. t.

1887 (rééd. 1907) : Atlas historique de la France, Paris.

L'OUVRELEUL R. P.

1724-1726 (rééd. 1825) : Mémoire historique sur le pays du Gévaudan et sur la ville de Mende, Mende, $77 \mathrm{p}$. 


\section{MAGNY M.}

2001 : « Les variations du niveau des lacs du Jura et des Alpes du Nord et leur signification pour une histoire du climat aux $\mathrm{IV}^{\mathrm{e}}$ et $\mathrm{V}^{\mathrm{e}}$ siècles de notre ère ", in OUZOULIAS P., Pellecuer C., Raynaud C., VAN OSSEL P., GARMY P. (DIR.), Les Campagnes de la Gaule à la fin de l'Antiquité, Actes du colloque de Montpellier, 11-14 mars 1998, Antibes, APDCA, p. 357-368.

\section{MAISON URBAINE...}

1996a : La Maison urbaine d'époque romaine en Gaule Narbonnaise et dans les provinces voisines, Actes du colloque d'Avignon, 1994, Avignon, APRAV (coll. Document d'archéologie du Vaucluse, 6), $261 \mathrm{p}$.

1996b : La Maison urbaine d'époque romaine, Atlas des maisons de Gaule Narbonnaise, Avignon, APRAV (coll. Document d'archéologie du Vaucluse, 6), 420 p.

\section{MALJEAN D.}

*2006 : L'Approvisionnement en matériaux de construction lithiques de la ville romaine de Javols (Lozère), mémoire de Master 2 archéologie, université de Tours, 2 vol., 88 p. et ann. 159 p.

\section{MARINVAL P.}

*2002 : «Offrandes végétales de la sépulture gallo-romaine à incinération (S.04) de Javols (Lozère) », in FERDIÈRE A., ODE B. (DIR.), Programme collectif de recherches sur Javols 1996-2002, Rapport d'activité pour 2002, Tours, UMR Archéologie et Territoires, vol. 2 : ann. 26, 4 p.

MARNhaC M. DE, Chambrun G. DE

1970 : « Le fanum du Vidalès », Bulletin de la Société des lettres, sciences et arts du département de la Lozère, p. 18-22.

\section{MAROT E.}

2006 : «Éléments de réflexion sur le faciès céramique ruténo-gabale, de la période augustéenne au $\mathrm{III}^{\mathrm{e}}$ siècle après J.-C. ", Vivre en Rouergue, Cahiers d'archéologie aveyronnaise, 18 , p. 97-122.

2007 : L'Approvisionnement céramique de JavolsAnderitum de la fin du $I^{e r}$ s. av. J.-C. au III ${ }^{e}$ s. apr. J.-C. dans son contexte chronotypologique, économique et culturel pour le sudest du Massif central, thèse de Doctorat, Université de Tours, 3 vol., 842 p. (consultable au LAT, Tours).

\section{MAROT E. (DIR.)}

2007 : «Une resserre incendiée au début du II $^{\mathrm{e}}$ siècle après J.-C. découverte à Javols-Anderitum (Lozère) ", RAN, 40, p. $325-413$
MASSY J.-L. ET AL.

1992 : « Languedoc-Roussillon », Gallia Informations, 1, p. 87-200.

\section{MATTERNE V.}

2003 : Restes végétaux associés aux sépultures à incinération 1, 2, 5 et 7 du site de Javols (Lozère), Compiègne, Cravo/Inrap, 4 p., manuscrit inédit.

\section{MICHOU J., DUFORT P.}

1974 : " Contribution à l'étude des voies romaines de la Lozère ", Bulletin du Cercle d'études et de recherches de Mende, 3, p. 1-14.

\section{MORÉ É. DE}

1856a : « Nouvelles fouilles de Javols », Bulletin de la Société d'agriculture, industrie, sciences et arts de Lozère, p. 247-248.

1856b : "Mémoire sur les fouilles exécutées à Javols (Lozère) ", Bulletin monumental, $3^{\mathrm{e}}$ série, t. II, $22^{\mathrm{e}}$ vol., p. 92-94.

1858a : «Rapport sur les Antiquités galloromaines de l'ancienne province de Gévaudan ", in Actes du congrès archéologique de France, XXIV session, Mende, 1857, Paris, p. 86-110.

1858b : «Notice sur les fouilles exécutées à Javols en 1857 ", in Actes du congrès archéologique de France, XXIV session, Mende, 1857, Paris, p. 209-214, plan h. t. p. 230.

1859 : « Notice sur les fouilles exécutées à Javols en 1857 ", Bulletin de la Société d'agriculture, industrie, sciences et arts de Lozère, p. 48-53.

\section{MOREL C.}

1962 : "Compte rendu des fouilles faites à Javols en 1937 et 1950 ", in Actes du $86^{e}$ congrès national des sociétés savantes, Montpellier, 1961, section d'archéologie, Paris, Imprimerie nationale, p. 95-116 et 1 plan h. t.

\section{MOREL C., BARDY B.}

1959 : « Fouilles et recherches en Lozère : campagne 1959 », Revue du Gévaudan, des Causses et des Cévennes, 5, p. 6-24.

\section{NAVEAU J. (DIR.)}

1997 : Recherches sur Jublains (Mayenne) et sur la cité des Diablintes, Rennes, Pôle éditorial archéologique de l'Ouest (coll. Documents archéologiques de l'Ouest), $352 \mathrm{p}$

\section{NOËL M.}

**2002: Inventaire et étude des blocs architecturaux de Javols-Anderitum (Lozère), mémoire de Maîtrise d'archéologie, Université de Tours, 2 vol. (texte et annexes), 145 p., 51 fig., 1 cédérom.
NOTICE...

1865 : « Notice sur le Gévaudan [écrite sous l'épiscopat de Charles de Rousseau, 1609-1623] (présentation André F.) ", Bulletin trimestriel de la Société d'agriculture, d'industrie, sciences et arts du département de la Lozère, 16, p. 468-490.

ODE B. (DIR.)

*2004 : Programme collectif de recherches : évaluation du site de Javols-Anderitum (Lozère), Rapport 2004, manuscrit inédit, 233 p.

PAiller J.-M.

1989 : « À propos du dieu de Javols ", RAN, 22, p. 395-402.

\section{PAUC R.}

1987 : « Notes d'archéologie gauloise lozérienne ", $R A N, 20$, p. 403-414.

\section{PEYRE P.}

1968 : « L'ensemble gallo-romain de Ron de Gleiso-Cadoule (commune de La Canourgue) ", Revue du Gévaudan, des Causses et des Cévennes, 14, p. 99-135.

*1969a : Chantier de fouille de Javols : campagne 1969, Compte rendu provisoire des travaux, manuscrit inédit, 11 p., 15 pl.

1969b : " Les fouilles de Javols », Revue du Gévaudan, des Causses et des Cévennes, 15, p. 33-62.

*1970a : Javols 1970, Rapport de fouilles, manuscrit inédit, 29 p., $68 \mathrm{pl}$.

1970b : «Javols », Revue du Gévaudan, des Causses et des Cévennes, 16, p. 23-42.

1970c : " Un établissement gallo-romain à Rouffiac ", Revue du Gévaudan, des Causses et des Cévennes, 16, p. 43-46.

1971a : "Javols ", Revue du Gévaudan, des Causses et des Cévennes, 17, p. 41-65.

*1971b : Javols 1971, Rapport de fouilles, manuscrit inédit, 2 vol. : 31 p. et $77 \mathrm{pl}$.

*1972 : Javols 1972 : illot central, Rapport de fouilles, manuscrit inédit, 2 vol. : $45 \mathrm{p}$. et $32 \mathrm{pl}$

*1973 : Javols 1973 : îlot central, Rapport de fouilles, manuscrit inédit, 2 vol. : 36 p. et 51 pl.

*1974 : Javols 1974, Rapport de fouilles, manuscrit inédit, 3 vol., vol. 1 : 30 p.; vol. 2 : 38 pl. ; vol. $3: 57$ p. et 2 fig.

1975a : " Les travaux de fouilles archéologiques ", Cahiers de Javols, 1, p. 5-9.

*1975b : Javols 1975, Rapport de fouilles, manuscrit inédit, $19 \mathrm{p}$.

1976a : "Monnaies de Javols », Revue du Gévaudan, des Causses et des Cévennes, 22, p. 135-168.

1976b : Sans titre [Fouilles de Javols], Cahiers de Javols, 2, p. 13-30.

*1976c : Javols 1976, Rapport de fouilles, manuscrit inédit, 37 p., 8 pl. 
*1977 : Javols 1977, Rapport de fouilles, manuscrit inédit, 2 vol., 30 p. et $45 \mathrm{pl}$.

1978a : "Comment pouvait être une maison dans la cité de Javols au II $^{\mathrm{e}}$ siècle », Cahiers de Javols, 4, p. 19-33.

*1978b : Javols 1978 : îlot central, Rapport de fouilles, manuscrit inédit, 3 vol., vol. 1 : 47 p. ; vol. 2 : 38 pl. ; vol. 3 : 28 pl. mobilier.

1979 : "La céramique sigillée de Javols », Revue du Gévaudan, des Causses et des Cévennes, 25, p. 89-124.

1981a : "Outillage gallo-romain de Javols ", Revue du Gévaudan, des Causses et des Cévennes, nouvelle série 27, 2, p. 5-24, 12 pl. h. t.

1981b : "La céramique métallescente de Javols ", Revue du Gévaudan des Causses et des Cévennes, nouvelle série 27, 2, p. 25-64.

1981c : Les Objets de bronze de Javols, Catalogue ( $1^{\text {re }}$ partie), Mende, Musée Ignon-Fabre, 33 p. et LXI pl.

1982 : « L'eau et son utilisation sur le site archéologique de Javols ", Revue du Gévaudan, des Causses et des Cévennes, nouvelle série 28, 4, p. 23-39.

\section{PEYRe P. BÉAL J.-C.}

1979 : «Fouilles de Javols : découverte d'une petite boîte en bronze ", Revue du Gévaudan, des Causses et des Cévennes, nouvelle série 25, p. 9-13.

PEYRe P., BÉAL J.-C., SIRVIN J.

1979 : Javols (fouilles 1969-1979) : les objets de fer, Mende (coll. Bulletin de la Société des lettres, sciences et arts de la Lozère, $\mathrm{n}^{\circ}$ spécial), 2 vol. multicopiés, 214 p. et LXXXV pl.

\section{Peytavin J.}

*1996 : « Notes sur des pierres déposées à proximité de la place ", in FERDIÈRE A., OdE B., PIEROBON R. (DIR.), Programme de recherches sur le site de Javols : évaluation et état des connaissances, bilan d'activités pour 1996, 1 vol. multicopié, 52 p., fig., ann. $\mathrm{n}^{\circ} 15,6 \mathrm{p}$.

1998 : « Chemins de crête autour de Javols », Bulletin du Centre d'études et de recherches littéraires et scientifiques de Mende, 17, p. 7-14.

\section{PIEROBON R.}

*1987: Javols 1987, Rapport de fouilles, manuscrit inédit, 8 p., 21 photos, 1 plan, ann.

*1988 : Javols (Lozère) 1988, Rapport de fouilles, manuscrit inédit, 77 p., fig., 3 plans h. t.

1989a : «Javols : campagne de fouilles 1989 », Lozère Archéologie, 6 (1990), p. 34-37.

*1989b : Javols (Lozère) 1989, Rapport de fouilles, manuscrit inédit, 22 p., 22 fig., 13 plans h. t.
*1990: Javols 1990, Rapport de fouilles, manuscrit inédit, 11 p., 25 fig., 14 plans h. t.

*1991a: Javols 1991, Rapport defouilles, manuscrit inédit, 13 p., 10 fig., 13 plans h. t.

1991b: «Javols, las Pessos », Bilan scientifique, SRA Languedoc-Roussillon, p. 84.

*1992 : Javols, Bilan des recherches et programme 1992, manuscrit inédit, 8 p., 1 fig., ann.

*1997 : «Fouilles du terrain de l'État » [en italien], in FERDIÈRE A. (DIR.), Programme de recherches sur Javols, Rapport intermédiaire (1 ${ }^{\text {re }}$ année) 1997, manuscrit inédit, p. 15-22.

*1999 : « Poursuite des fouilles du terrain de l'État (bâtiment public) ", in FERDIÈRE A. (DIR.), Programme collectif de recherches: "Évaluation du site de Javols ", Rapport de synthèse 1996-1999, manuscrit inédit, p. 9-19.

\section{PIEROBON-BENOÎT R.}

1992 : " Javols-Anderitum (Lozère) ", in Villes et agglomérations urbaines antiques $d u$ Sud-Ouest de la Gaule, histoire et archéologie, Actes du $2^{e}$ colloque Aquitania, Bordeaux, 13-15 sept. 1990, Bordeaux (coll. Suppl. à Aquitania, 6), p. 97-99.

*1993a : «Javols », Bilan scientifique de la région Languedoc-Roussillon 1993, p. 123-124.

*1993b : Anderitum, Rapport de fouilles 1993, manuscrit inédit, 39 p., 37 fig.

\section{Pierobon-benoît R., Febbraro S.,} BARBARINO P.

1994: «Anderitum (Javols, Lozère) 1987-1993: notes préliminaires sur la céramique ", in Actes du congrès de la SFECAG, Millau, 12-15 mai 1994, Marseille, SFECAG, p. $233-254$

\section{PISKORZ M.}

*2003 : Javols, le bourg : terrain Tichit à Javols (Lozère), Document final de synthèse, diagnostic archéologique, Montpellier, Inrap, $29 \mathrm{p}$.

\section{PORÉE C.}

1919 : Études d'histoire et d'archéologie sur le Gévaudan, archives gévaudanaises, vol. IV, Mende, Société d'agriculture, industrie, sciences et arts du département de la Lozère.

PORTAL J.-B.

1890 : Notice historique et statistique sur l'ancienne paroissedeJavolsavantla Révolution française, Mende, $132 \mathrm{p}$.

Poupet P., Ferdière A., Harfouche R., ODE B.

2006 : «Granite, Gabales et climat : l'histoire du bassin versant du Triboulin à
Javols/Anderitum en Margeride (Lozère, France) », in ALLÉE P., LESPEZ L. (DIR.), L'Érosion entre société, climat et paléoenvironnement, Actes de la table ronde en l'honneur $d u$ professeur R. Neboit-Guilhot, ClermontFerrand, GEOLAB/UMR 6012, 25-27 mars 2004, Clermont-Ferrand, Presses de l'université Blaise-Pascal (coll. Nature et Société, 3), p. 311-318.

\section{PRÉVOT F.}

1989 : «Javols-Mende », in PrÉVOT F., BARRAL I Altet X. (DIR.), Province ecclésiastique de Bourges (Aquitaine Prima) : topographie chrétienne des cités de la Gaule des origines au milieu du VIII ${ }^{e}$ siècle, vol. VI, Paris, De Boccard, p. 79-85.

\section{Provost M.}

2006 : « Les relations entre Arvernes et Arécomiques dans l'Antiquité ", in FRÈRE D. (DIR.), De la Méditerranée à l'Atlantique : aspects des relations entre la Méditerranée et la Gaule centrale et occidentale (VIII'-II siècle av. J.-C.), Actes du colloque de Rennes, Rennes, Presses universitaires de Rennes, p. 93-114.

\section{PRUNIÈres B.}

1866 : «L'ancienne baronnie de Peyre d'après des documents originaux et inédits ", Bulletin de la Société d'agriculture, industrie, sciences et arts du département de la Lozère, XVII, 2, p. 159-361.

\section{REISSER E.}

1901 : "Pline l'Ancien et le "caseus Lesurae Gabalicique pagi musteus" ", Bulletin trimestriel de Société d'agriculture, industrie, sciences et arts du département de la Lozère, p. 52-68.

\section{REMIZE F.}

1921 : Allenc, sa baronnie, sa paroisse et sa communauté. Archives gévaudanaises, V, Mende, Société d'agriculture, industrie, sciences et arts du département de la Lozère.

\section{RÉMY B.}

1995 : Inscriptions latines d'Aquitaine (ILA): Vellaves, Bordeaux, Centre Pierre-Paris, $157 \mathrm{p}$

1996 : Inscriptions latines d'Aquitaine (ILA) : Arvernes, Bordeaux, IRAM, $214 \mathrm{p}$.

\section{RICHARD H.}

*2002 : " Javols (48), JPN.00 : analyse pollinique ", in FERDIÈRE A., ODE B. (DIR.), Programme collectif de recherches sur Javols 1996-2002, Rapport d'activité pour 2002, Tours, UMR 6565 Archéologie et Territoires, vol. 2 : ann. 19, 1 p. 
*2003 : « Analyse pollinique », in FERDIÈRE A. (DIR.), Programme pluriannuel d'évaluation du site archéologique de Javols (1996-2003), Rapport final de synthèse, Tours, vol. 2, ann. 10.

RICHARD J.-C., FABRIÉ D.

1984 : « Trésors et découvertes monétaires en Lozère (Languedoc-Roussillon) », Cahiers numismatiques, 79, p. 3-20.

\section{ROGER K.}

1993 : « Lozère ", in Formes de l'habitat rural en Gaule Narbonnaise, vol. 1, Juan-les-Pins, APDCA, 10 notices.

\section{ROUCHE M.}

1969 : « Le changement des noms de chefslieux de cités en Gaule au Bas-Empire », Mémoires de la Société nationale des Antiquaires de France, $9^{\mathrm{e}}$ série, IV, p. 47-64.

\section{SAINT-DIDIER G.}

**2006 : L’Artisanat des métaux à JavolsAnderitum (Lozère) à l'époque romaine : structures et déchets de production, mémoire de Master 1, Université de Tours, 2 vol., texte et ann., $128 \mathrm{p}$.

**2007 : Le Travail des métaux à JavolsAnderitum (Lozère) à l'époque romaine : structures et déchets de production, mémoire de Master 2, Université de Tours, 2 vol., texte et ann., $466 \mathrm{p}$

\section{SILLIÈRES P.}

1992 : «Voies de communication et réseau urbain en Aquitaine romaine », in Villes et agglomérations urbaines antiques $d u$ sud-ouest de la Gaule : histoire et archéologie, Actes du $2^{e}$ colloque Aquitania, Bordeaux, 13-15 sept. 1990, Bordeaux (coll. Suppl. à Aquitania, 6), p. $431-438$

SLATER T. R. (DIR.)

2000 : Towns in Decline, AD 100-1600, Ashgate, Adelshot.

\section{Soutou A.}

1988: «Tracé probable de la voie romaine Millau-Javols par Banassac ", in Actes du LXIX ${ }^{e}$ congrès de la Fédération d'histoire du Languedoc Méditerranée et Roussillon, Millau, 1987, Montpellier, Fédération d'histoire du Languedoc Méditerranée et Roussillon, p. 7-14.

\section{STORTI D.}

1998 : «Anderitum (Javols, France) : la circolazione delle anfore tra circuiti regionali e commercio a lunga distanza, studio preliminare ", in Importations d'amphores en Gaule du Sud, du règne d'Auguste à l'Anti- quité tardive, Actes du congrès de la SFECAG, Istres, 21-24 mai 1998, Marseille, SFECAG, p. 61-68.

\section{Thuault M., Vernhet A.}

1986 : « Le Rozier ", in BÉMONT C., JACOB J.-P. (DIR.), La Terre sigillée galloromaine : lieux de production du HautEmpire, implantations, produits, relations, Paris, Maison des sciences de l'homme (coll. DAF, 6), p. 110-113.

Trément F., Ballut C., MennessierJouannet C., ARgant J.

2002 : «Mutations environnementales et systèmes socio-économiques en Grande Limagne (Massif central) de l'âge du Fer au Moyen Âge ", in RICHARD H., VIGNOT A. (DIR.), Équilibres et ruptures dans les écosystèmes depuis 20000 ans en Europe de l'Ouest, Actes du colloque international de Besançon, 18-22 sept. 2000, Besançon, Presses universitaires franccomtoises (coll. Annales littéraires de l'université de Franche-Comté, 730, Série Environnement, Société et Archéologie, 3), p. 269-279.

Trément F., Chambon J.-P., Guichard V., LALLEMAND D.

2007 : « Le territoire des Arvernes : limites de cité, tropismes et centralité ", in MENNESSIER-JOUANNET C., DEbERGE Y. (DIR.), L'Archéologie de l'âge du Fer en Auvergne, Actes du XXVII colloque international de l'AFEAF, Clermont-Ferrand, 29 mai- $^{\text {er }}$ juin 2003, Lattes, éd. ADALR (coll. Monographies d'archéologie méditerranéenne), p. 99-110.

\section{TRÉMOLlET DE VILLERS A.}

1998 : Églises romanes oubliées du Gévaudan, Montpellier, Presses du Languedoc, $462 \mathrm{p}$.

\section{TrintignaC A.}

**2001a : L'Économie des cités du sud du Massif central à l'époque gallo-romaine : l'exemple de la civitas des Gabales (Lozère), mémoire de DEA, Université de Montpellier, 2 vol., 238 p. et 157 p., 146 fig.

2001b : «Évolution de l'artisanat dans la cité des Gabales (Lozère) du Haut-Empire à l'Antiquité tardive ", in POLFER M. (DIR.), L'Artisanat romain : évolutions, continuités et ruptures (Italie et provinces occidentales), Actes du $2^{e}$ colloque Erpeldange, 26-28 oct. 2001, Montagnac, Monique Mergoil (coll. Monographies Instrumentum, 20), p. 221-242.

2002 : «État des connaissances sur l'artisanat à Javols/Anderitum, capitale de la cité des
Gabales (département de la Lozère), à l'époque gallo-romaine ", in BÉAL J.-C., GOYON J.-C. (DIR.), Les Artisans dans la ville antique, Actes du colloque de Lyon, 2000, Lyon, Université Lumière-Lyon II et Paris, De Boccard (coll. Archéologie et histoire de l'Antiquité, 6), p. 221-234, 8 pl.

2003 : " La production de poix dans la cité des Gabales (Lozère) à l'époque galloromaine ", in LEPETZ S., MATTERNE V. (DIR.), Cultivateurs, éleveurs et artisans dans les campagnes de la Gaule romaine, Actes du VI ${ }^{e}$ colloque AGER, Compiègne, 5-7 juin 2002 (coll. Suppl. à la Revue archéologique de Picardie, 1-2), p. 239-248.

2005a : "La production de poix dans la cité des Gabales (Lozère) à l'époque galloromaine », Bulletin du Centre d'études et de recherches littéraires et scientifiques de Mende, 24, p. 20-27.

2005b : « L'artisanat à Javols-Anderitum, chef-lieu de la cité des Gabales, à l'époque gallo-romaine ", Revue du Gévaudan, des Causses et des Cévennes, 19, p. 140-156.

2006 : «Recherches archéologiques à JavolsAnderitum : campagne 2005 ", Revue du Gévaudan, des Causses et des Cévennes, 22, p. 116-131.

**2007a: Rapport d'étude archéologique préalable à la restauration et à la mise en valeur des vestiges des fouilles Peyre (1969-1978) dans le "Terrain de l'État" (parcelle A 1111/ Las Pessos), Conseil général de Lozère, 64 p., fig.

2007b : «Recherches archéologiques à JavolsAnderitum : campagne 2006 ", Revue du Gévaudan, des Causses et des Cévennes, 24 (2e sem.), p. 144-159.

À paraître : « L'exploitation forestière dans les cités gallo-romaines du sud du Massif central : le bois et ses produits dérivés (charbons de bois, poix) dans les activités artisanales et l'économie des cités des Arvernes, des Gabales, des Rutènes et des Vellaves ", in Silva et Saltus en Gaule romaine, Actes du VII e colloque AGER, Rennes, 27-28 oct. 2004, Presses universitaires franc-comtoises.

\section{TRINTIGNAC A. (DIR.)}

*2005 : Programme de recherches archéologiques sur le site de Javols-Anderitum (Lozère, 48), Rapport de recherche 2005, manuscrit inédit, 2 vol., vol. 1 : texte et fig., 187 p. ; vol. 2 : 29 ann.

*2006 : Programme de recherches archéologiques 2005-2007 sur le site de Javols-Anderitum (Lozère, 48), Rapport de recherche 2006, manuscrit inédit, vol. 1 : texte et fig., 65 p., fig. ; vol. 2 et $3: 39$ ann.

*2007 : Programme de recherches archéologiques sur le site de Javols-Anderitum (Lozère, 
48), Rapport de recherche 2007, manuscrit inédit, 2 vol., vol. 1 : 109 p., fig. ; vol. 2 : 36 ann. non paginées.

Trintignac A., Courtois J., Ferdière A., GUILlEMARD T., MAROT E.

2009 : «Recherches archéologiques à JavolsAnderitum: campagnes 2007-2008 ", Revue du Gévaudan, des Causses et des Cévennes, 27 ( $\mathrm{er}^{\mathrm{er}}$ sem.), p. 148-160.

Trintignac A., Courtois J., Ferdière A. MAROT E., ODE B., POITEVIN G.

2008 : «Le réseau de voirie de la ville d'Anderitum (Javols, Lozère) : état des connaissances à la lumière du récent programme d'évaluation ", in BALLET P., DIEUdONNÉ-GLAD N., SALIOU C. (DIR.), La Rue dans l'Antiquité : définition, aménagement et devenir, Actes du colloque international, Poitiers, 7-9 sept. 2006, Rennes, Presses universitaires de Rennes.

Trintignac A., Marot E., Ferdière A., GUILlEMARD T., ODE B.

2005 : «Recherches archéologiques à JavolsAnderitum : campagne 2004 ", Revue du
Gévaudan, des Causses et des Cévennes, 20, p. $141-158$.

\section{VALADAS B.}

1987 : « Morphodynamiques récentes dans le Massif central français : étude comparée des massifs granitiques du Limousin, de Margeride et du mont Lozère ", in BREMER H., GODARD A. (DIR.), Géomorphologie des massifs européens, Berlin (coll. Suppl. aux Annales de géomorphologie, 65), p. 85-99.

VALAISON M.-O.

2002 : " Bagnols-les-Bains (Lozère) ", in FICHES J.-L. (DIR.), Les Agglomérations galloromaines en Languedoc-Roussillon, Lattes (coll. Monographies d'archéologie méditerranéenne, 13-14), vol. 2, p. 910-914

VALETTE P., GUICHARD V.

1991 : « Le forum gallo-romain de Feurs (Loire) ", Gallia, 48, p. 109-164.

\section{VERNHET A.}

1967 : « Oppidum de Saint-Bonnet-deChirac : première campagne de fouilles (mai-juin 1967) ", Revue du Gévaudan, des Causses et des Cévennes, 13, p. 24-42.

1981 : "Un four de la Graufesenque (Aveyron) : la cuisson des vases sigillés ", Gallia, 39, 1, p. 25-43.

VIDIMUS...

1863 : «Vidimus d'une charte de Charles V, roi de France ", Bulletin de la Société d'agriculture, industrie, sciences et arts du département de la Lozère, p. 106-117.

VISITE...

1959 : «Visite à Javols, séance du 13 août 1959 ", Revue du Gévaudan, des Causses et des Cévennes, 5 (1960), p. 188.

WEBER E.

1976 : Tabula Peutingeriana. Codex Vidobonensis 324, Vollst. Faksimile, Graz, Akademie Druck- und Verlagsanstalt Graz, XI segments.

\section{WOOLF G.}

1998 : Becoming Roman : the Origins of Provincial Civilization in Gaul, Cambridge, Cambridge University Press, 296 p. 